\title{
AN ASSESSMENT OF STEADY-STATE PROPANE-GAS TRACER METHOD FOR REAERATION COEFFICIENTS- COWASELON CREEK, NEW YORK
}

by N. Yotsukura, D.A. Stedfast, R.E. Draper, and W.H. Brutsaert 
UNITED STATES DEPARTMENT OF THE INTERIOR

JAMES G. WATT, Secretary

GEOLOGICAL SURVEY

Dallas L. Peck, Director

For additional information write to:

Office of the Regional Research Hydrologist

U.S. Geological Survey

430 National Center

Reston, Virginia 22092

(Telephone (703) 869-6947)
Copies of this report can be purchased from:

Open-File Services Section Western Distribution Branch U.S. Geological Survey Box 25425, Federal Center Denver, Colorado 80225 (Telephone (303) 234-5888) 
Page

Abstract ...................... I

Introduction $\ldots \ldots \ldots \ldots \ldots$

Purpose and scope $\cdots \cdots \cdots \cdots$

Acknowledgments $\cdots \cdots \cdots \cdots$

Equations for dissolved gas concentration . . . . . . 5

Basic equation for steady channel flow $\cdots \cdots$

Equation for straight prismatic channel $\ldots . \cdots 12$

Description of field tests . . . . . . . . 14

June 30,1981 , test $\cdots \cdots \cdots \cdots$

July 1,1981 , test $\cdots \cdots \cdots$

October 20-21, 1981, test $\cdots \cdots 20$

Presentation of data $\ldots \ldots \ldots 23$

June 30,1981 , test $\ldots \ldots \ldots 23$

July 1,1981 , test $\cdots \cdots \cdots \cdots \cdots \cdots \cdots$

October $20-21,1981$, test $\cdots \cdots 43$

Analysis of data ............ 57

Calculations from dye data . • • . . . . . 57

Calculations of gas desorption coefficients . . . . . 60

June 30 test .......................... 61

July 1 test $\ldots \ldots \cdot \ldots \cdot \ldots$

October $20-21$ test $\ldots \ldots \ldots$. . . . . . . 70

Discussion ......................... 76

Field procedure $\cdots \cdots \cdot \cdots \cdot \cdots$

Desorption coefficient............ 81

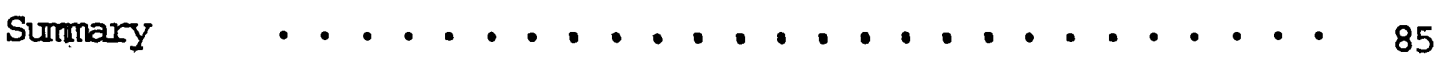

References .............. 87 


\section{ILLUSTRATIONS}

Figure 1. Sketch of the Cowaselon Creek study reach near Canastota, New York . . . . . . . . . . . . . . . 4

Figure 2. The principle of linear superposition by equation 10 . . . . . . 11

Figure 3. Sketch of wind instrument arrangement . . . . . . . . . . . 18

Figure 4. Temporal variation of dye concentration at section 1, June 30,1981 . . . . . . . . . . . . . . . . 24

Figure 5. Temporal variation of dye concentration at section 2, June 30,1981 . . . . . . . . . . . . . . . . 25

Figure 6. Temporal variation of dye concentration at section 3, June 30,1981 . . . . . . . . . . . . . . . 26

Figure 7. Temporal variation of propane-gas concentration at section 1 , June 30,1981 . . . . . . . . . . . . . . . . . 27

Figure 8. Temporal variation of propane-gas concentration at section 2, June 30,1981 . . . . . . . . . . . . . . . . . 28

Figure 9. Temporal variation of propane-gas concentration at section 3 , June 30,1981 . . . . . . . . . . . . . . . . . . 29

Figure 10. Temporal variation of wind speed at Position 1, June 30 and July 1, 1981. . . . . . . . . . . . . . . . . 34

Figure 11. Temporal variation of wind speed at Position 3, June 30

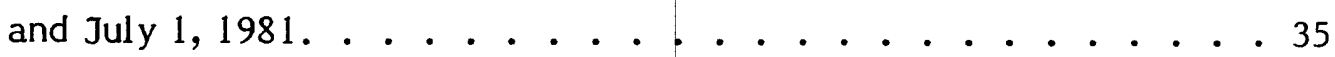

Figure 12. Temporal variation of dye concentration at section 1 , July 1,1981 . . . . . . . . . . . . . . . . 36

Figure 13. Temporal variation of dye concentration at section 2 , July $1,1981 \ldots . . . . . .$. 
Figure 14. Temporal variation of dye concentration at section 3, July $1,1981 \ldots \ldots 38$

Figure 15. Temporal variation of propane-gas concentration at section 1 , July 1,1981 . . . . . . . . . . . . . . . 40 40

Figure 16. Temporal variation of propane-gas concentration at section 2 , July $1,1981 \ldots \ldots 41$

Figure 17. Temporal variation of propane-gas concentration at section 3, July $1,1981 \ldots \ldots 42$

Figure 18. Temporal variation of wind speed at Position 4, July $1,1981 \ldots \ldots 45$

Figure 19. Temporal variation of dye concentration at section 1 ,

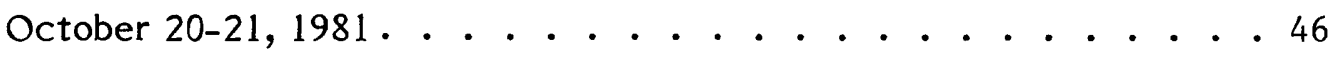

Figure 20. Temporal variation of dye concentration at section 2, October $20-21,1981 \ldots \ldots 47$

Figure 21. Temporal variation of dye concentration at section 3

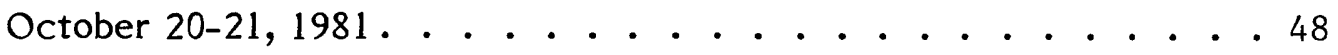

Figure 22. Temporal variations of propane concentration, discharge, and propane mass flow at section 1, October 20-21, 1981 . . . . 49

Figure 23. Temporal variations of propane concentration, discharge, and propane mass flow at section 2, October 20-21, 1981 . . . . . 50

Figure 24. Temporal variations of propane concentration, discharge, and propane mass flow at section 3, October 20-21, 1981 . . . . . . 51

Figure 25. Temporal variation of wind speed at Positions 2 and 5 , October 20-21, 1981. . . . . . . . . . . . . . 56

Figure 26. Relation between the variance and the mean time of dye clouds, June 30 and July $1,1981 \ldots 68$ 
Figure 27. Temporal variations of wind speed and propane desorption coefficient, October $20-21,1981 \ldots . . . . . . .77$

\section{TABLES}

Table 1. Discharge, channel geometries, and water temperature at three cross sections, June 30 and July $1,1981 \ldots 32$

Table 2. Temporal variations of wind speed and direction, June $30,1981 \ldots \ldots 33$

Table 3. Temporal variations of wind speed and direction, July $1,1981 \ldots \ldots 44$

Table 4. Discharge, channel geometries, and water temperature at three cross sections, October 20-21, 1981 ......... 53

Table 5. Temporal variations of wind speed and direction, October $20-21,1981 \ldots \ldots 55$

Table 6. Moment-related properties of dye cloud, June 30,1981 . . . . 62

Table 7. Desorption coefficient of propane, June 30, 1981 . . . . . . . 64

Table 8. Moment-related properties of dye cloud, July 1, 1981 . . . . . 66

Table 9. Desorption coefficient of propane, July 1, 1981. . . . . . . . 69

Table 10. Moment-related properties of dye cloud, October 20-21, 1981 . . . 71

Table 11. Desorption coefficient of propane averaged over 16.8-hour period, October 20-21, 1981.............. . 74 


\section{CONVERSION FACTORS}

For the convenience of readers who may want to use Inch-Pound Units, the data may be converted by using the following factors:

Multiply SI units

millimeter $(\mathrm{mm})$

meter $(m)$

kilometer $(\mathrm{km})$

square meter $\left(\mathrm{m}^{2}\right)$

cubic meter $\left(\mathrm{m}^{3}\right)$

kilogram (kg)

meter per second $\left(\mathrm{m} \mathrm{s}^{-1}\right)$ by

0.03937

3.281

0.6214

10.76

35.31

2.205

2.237
To obtain inch-pound units inch (in) foot $(f t)$ mile (mi) square foot $\left(\mathrm{ft}^{2}\right)$ cubic foot $\left(\mathrm{ft}^{3}\right)$ pound (lb) mile per hour (mph)

Temperature in degrees Celsius $\left({ }^{\circ} \mathrm{C}\right)$ can be converted to degrees Fahrenheit $\left({ }^{\circ} \mathrm{F}\right)$ as follows:

$$
{ }^{\circ} \mathrm{F}=32+\frac{9}{5}{ }^{\circ} \mathrm{C}
$$




\section{AN ASSESSMENT OF STEADY-STATE PROPANE-GAS TRACER METHOD}

FOR REAERATION COEFFICIENTS--COW ASELON CREEK, NEW YORK

by N. Yotsukura, D. A. Stedfast, R. E. Draper $\frac{1 /}{\text {, }}$, and W. H. Brutsaert $\underline{2 I}$

\section{ABSTRACT}

Three tests were conducted in a straight $5.2-\mathrm{km}$ reach of the Cowaselon

Creek, Canastota, New York, in order to assess the feasibility of the steady-state propane-gas tracer method as a means of estimating in situ reaeration coefficients. In the summer of 1981 , two replicate tests were conducted on two consecutive days, during which channel flow was steady and wind speed was low. The purpose of the tests was to examine reproducibilities of tracer data and of the propane desorption coefficient, which is proportional to the reaeration coefficient. In the fall of 1981, the third test was conducted employing a 24-hour continuous injection of propane tracer, during which channel flow was slightly unsteady and wind speed was variable. A major purpose of the test was to evaluate the effect of wind shear on the desorption coefficient.

It is concluded that the steady-state method, which combines an instantaneous injection of dye tracer with a long duration injection of propane tracer, is an operationally feasible field technique and provides a very reliable means of determining the propane desorption coefficient in a steady channel flow. The effect of wind shear on propane desorption coefficients was not detected in any tests, apparently because of the sheltering effect of high banks.

1 Sanitary Engineer, New York Department of Environmental Conservation, Albany, New York.

21 Professor, School of Civil and Environmental Engineering, Cornell University, Ithaca, New York. 


\section{INTRODUCTION}

Accurate estimation of reaeration coefficients in a natural stream is one of the basic factors in the modeling of dissolved oxygen concentration for the purpose of waste load allocation and water pollution abatement. Since its advent by Tsivoglou and others (1965), the gas tracer method has been considered as the most promising technique for estimating in situ reaeration coefficients in natural streams, because the method determines the desorption rate of dissolved gases at the air-water interface and is free of the interference by biological and chemical reactions. Recently, the method has gained further acceptance by the discipline as Rathbun and others (1978) introduced hydrocarbon gases as alternative tracers. These tracers eliminate the need for special training and licensing necessary for use of the radioactive krypton tracer, which is exclusively used in Tsivoglou's method.

Despite increasing popularity and usage of gas tracer method, some questions still remain concerning the accuracy and reproducibility of field data and the soundness of field procedures (G. H. Jirka, 1978, Cornell University, written commun.: E. R. Holley, 1979, University of Texas, written commun.). An independent assessment of the gas tracer method is desirable based on the mechanics of turbulent mass transport and transfer so that this potentially useful method can be utilized with confidence for a wide range of environmental conditions.

This report is the first of a series of reports to be published on field assessments of the hydrocarbon gas tracer method, which are jointly undertaken by the School of Civil and Environmental Engineering, Cornell University, the New York Department of Environmental Conservation, and the U.S. Geological Survey. The first conference of the three groups in Albany, New York, April 8, 1981, concluded that the first field assessment should be conducted in a steady uniform channel flow, in 
which bulk hydraulic paramenters are relatively constant and accurately measurable. The preliminary survey indicated that a straight $5.2-\mathrm{km}$ reach of the Cowaselon Creek near Canastota, New York, was a suitable site because of its size, alignment, and accessibility shown in figure 1 .

The conference also concluded that only the steady-state method should be employed in the test--namely, that the gas tracer should be injected continuously at a uniform rate for a long period to produce a steädy-state gas-tracer concentration in a plume that would be mixed uniformly in a cross section. This is a deviation from the currently used procedures of Tsivoglou and Rathbun, which employ shortduration injections and measure transient gas concentrations. The expectation was that, because the gas concentration obtained under steady-state uniformlymixed conditions will not require correction for dispersion effects, it represents a more direct measure of gas desorption than under transient conditions.

Even though the gas tracer method is sometimes called a "direct method" of reaeration estimation, its field procedure involves neither the measurement of dissolved oxygen concentration nor the calculation of reaeration coefficient directly. The entire procedures is concerned with determination of the desorption coefficient of a dissolved gas tracer along a test reach. The reaeration coefficient is estimated by applying a conversion factor determined from laboratory experiments to the gas desorption coefficient. The assessment of this conversion factor, which is currently conducted at the University of Texas at Austin (Rainwater and Holley, 1983), is outside the scope of the present report.

\section{Purpose and Scope}

The purpose of this report is to develop and test steady-state method for the measurement of propane-gas desorption coefficients in a natural channel flow as the first phase of the field assessments of hydrocarbon gas tracer method 


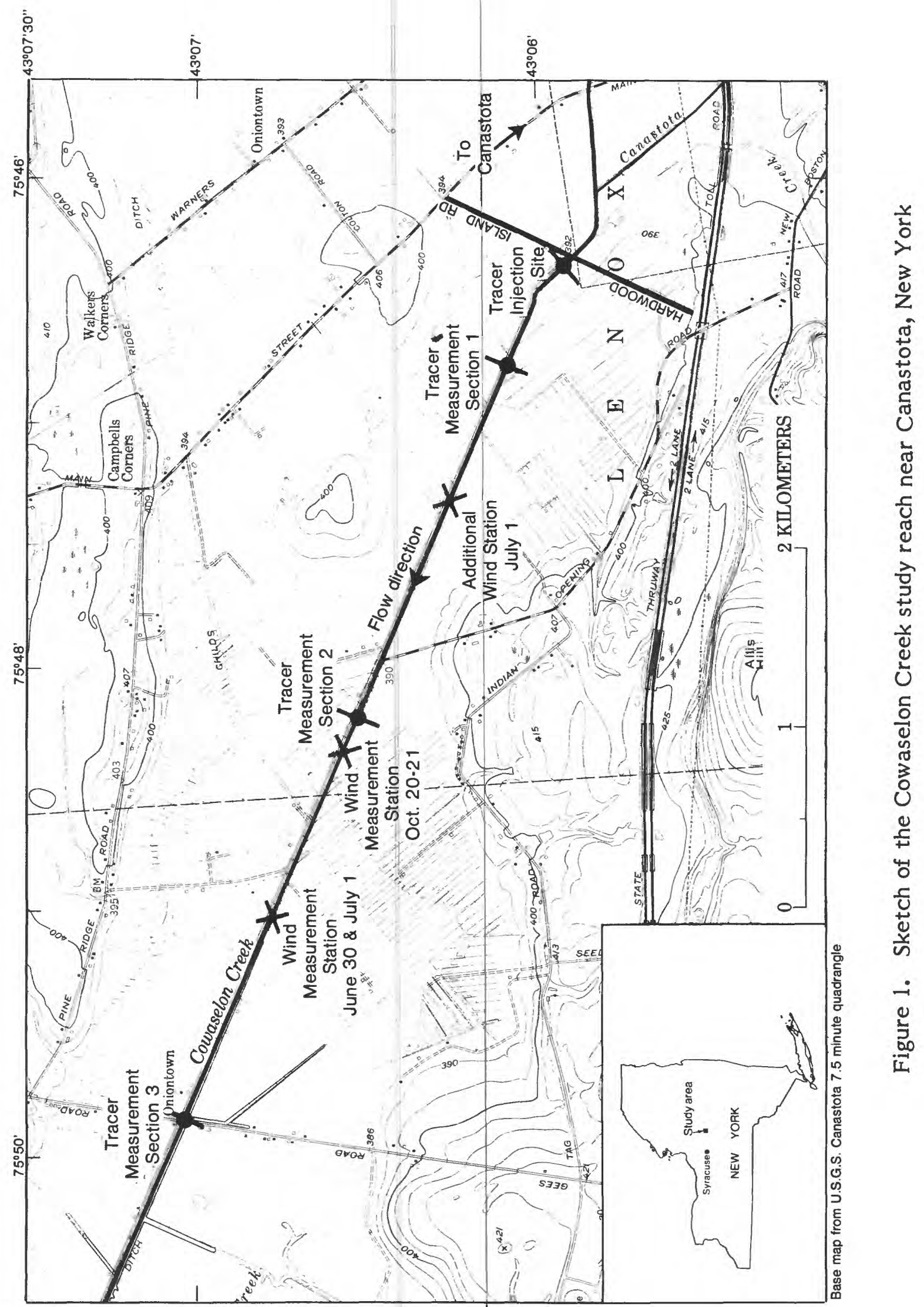


for reaeration coefficients. Three field tests were conducted in a straight 5.2 $\mathrm{km}$ reach of the Cowaselon Creek near Canastota, New York in June, July, and October, 1981.

\section{Acknowledgments}

The authors would like to acknowledge E. R. Holley, G. H. Jirka, and R. E. Rathbun for their technical advice and consultation. The credit for successful completion of the field work is due to the personnel from the New York Department of Environmental Conservation, the U.S. Geological Survey, and the Cornell University.

\section{EQUATIONS FOR DISSOLVED GAS CONCENTRATION}

The desorption or volatilization coefficient of dissolved gases is a defined parameter not directly measurable in a natural stream. It is thus desirable to define the desorption coefficient starting with a model equation which employs the smallest number of assumptions. In the following section, the first model equation will be derived from two major assumptions--namely, the first-order decay of dissolved gas concentration with time and the linear superposition principle for solute transport in a steady channel flow. However, because the first equation is not convenient for field applications, the second model equation will be derived in the following section by adding the assumption of a straight prismatic channel geometry. The second equation is the most commonly used equation which enables a direct calculation of the desorption coefficient. Use of these two equations in the present study is not only for theoretical interest but also for establishing the second equation as the feasible equation for nonstraight and nonprismatic conditions of a natural stream flow.

\section{Basic Equation for Steady Channel Flow}

Based on a number of mixing tank experiments, the desorption or volatilization of a certain class of dissolved gases through the air-water interface can be considered as a first-order transfer mechanism. In a typical tank experiment, the concentration 
of dissolved gas is maintained uniform within the water depth by means of mechanical stirring so that the time rate of change of the gas concentration in the tank can be described (Tsivoglou and others, 1965; Rathbun and others, 1978) by

$$
\frac{\mathrm{dC}}{\mathrm{dt}}=-\mathrm{KC}
$$

where $\mathrm{C}$ is the dissolved gas concentration, $\mathrm{t}$ is time, and $\mathrm{K}$ designates the desorption coefficient expressed by

$$
\mathrm{K}=\frac{\mathrm{K}_{\mathrm{L}}}{\mathrm{H}}
$$

Notation $\mathrm{K}_{\mathrm{L}}$ is the surface film coefficient of mass transfer and $\mathrm{H}$ is the water depth of a mixing tank (Holley, 1973). Note that the formulation of eq. 1 is to treat gas desorption, which takes place only at the water surface, as if it were equivalent to a first-order decay that occurs uniformly within the total depth of water.

As for gas desorption in natural streams, one may expect that a similar first-order transfer equation could be employed because most flowing streams maintain adequate intensity of turbulence within the flow. This turbulence, created by friction at the channel bottom and by the wind shear at the water surface, is essential in mixing dissolved gases in a stream just as the mechanical stirring is in a mixing tank.

Assume that a neutrally buoyant mixture of a dissolved gas tracer and a hypothetical conservative tracer is injected instantaneously into a natural stream. From well-estalished hydraulic experience (Yotsukura and Sayre, 1976), the reach downstream from the injection site may be divided into three zones, each corresponding to a different stage of the mixing process. In the first zone immediately downstream of the injection site, the mixing is three-dimensional and, while the conservative tracer is advected and mixed in an identical manner with the neighboring water, mixing of the gas tracer is not quite identical to that of the conservative tracer, 
primarily in the vertical direction, due to the desorption of gas through the water surface. However, the length of this zone is fairly short, being on the order of only 50 to 100 times the stream depth, and the concentration distributions of both tracers become vertically uniform at the end of the first zone.

When both tracers are in the second zone, the mixing proceeds in the longitudinal and transverse directions. Assuming that the surface desorption of gas tracer can now be treated as a first-order decay occurring uniformly within the total depth and also that the advection and mixing of both tracers become more identical with time, thereby eliminating small discrepancies of mixing in the first zone, one may relate the concentration of gas tracer to that of conservative tracer by the equation

$$
C(x, z, t)=\frac{M}{M_{C}} C_{c}(x, z, t) \exp (-K t)
$$

where $\mathrm{C}$ and $\mathrm{C}_{\mathrm{C}}$ designate the concentration of dissolved gas tracer and conservative tracer, and $M$ and $M_{C}$ denote the initial masses of gas and conservative tracers, respectively. The longitudinal coordinate, $x$, is measured downstream from the injection site, the time, $t$, is measured from the instant of injection, and $z$ designates the transverse coordinate. Note that eq. 3 assumes a linear relation between the total mass and concentration of a tracer. Also, eq. 3 utilizes the integrated form of eq. 1 so that $K$ is assumed to be constant over a finite time, $t$.

Even though the length of the second zone is much longer than that of the first zone, the turbulent mixing eventually will produce an essentially uniform 
distribution of tracer concentration in the transverse direction downstream of a certain cross section. This marks the beginning of the third zone or the uniformlymixed zone, in which the mixing can take place only in the longitudinal direction. Eq. 3 may then be simplified to

$$
C(x, t)=\frac{M}{M_{C}} C_{C}(x, t) \exp (-K t)
$$

Note in eq. 4 that because the flow conditions remain idependent of time at any cross section, an instantaneous injection of mass, $M_{C}$, of conservative tracer at any time produces the same response, $C_{C}(x, t)$, in which $t$ is measured from the instant of injection. Note also that this steadiness assumption does not presume that the discharge is the same at all cross sections. Instead, the condition allows for some inflow in the reach such as ground water seepage as long as such inflow is small and steady and does not disturb the steady mixing pattern. Under such conditions, the normalized response function may be defined as

$$
f(x, t)=\frac{C_{c}(x, t)}{\int_{0}^{\infty} C_{c}(x, t) d t}
$$

Furthermore, the mass continuity for the hypothetical tracer requires that

$$
\int_{O}^{\infty} C_{C}(x, t) d t=\frac{M_{C}}{Q(x)}
$$

where the notation, $\mathrm{Q}(\mathrm{x})$, indicates that the discharge is independent of time but may increase in the downstream direction. Substituting eqs. 5 and 6 into eq. 4 , the latter is reduced to

$$
C(x, t)=\frac{M}{Q(x)} f(x, t) \exp (-K t)
$$


Note that the normalized response function, $f(x, t)$, represents the total effect of advection and mixing, which both conservative and gas tracers undergo after their instantaneous injection at $x=0$ and $t=0$. It has the dimension of time $e^{-1}$ and its integration with respect to time, $\int_{0}^{\infty} f(x, t) d t$, is equal to nondimensional unity in view of eq. 5 .

When the gas tracer is injected continuously rather than instantaneously, the resulting gas concentration may be obtained by applying the principle of superposition to eq. 7 (Wylie, 1951, Taylor, 1959). Assume that a mass of conservative tracer is instantaneously injected for the purpose of measuring the normalized response function, while the gas tracer is continuously injected at a uniform mass inflow rate, $\mathrm{m}$, beginning at $\tau=0$ and ending at $\tau=\tau_{\mathrm{I}}$. The notation $\tau$ designates the time of tracer injection and has the same origin as $t$. Considering that each infinitesimal $\mathrm{md} \tau$ represents an instantaneous mass, $M$, the superposition of all such injections leads from eq. 7 to (Yotsukura and Kilpatrick, 1973)

$$
C(x, t)=\frac{m}{Q(x)} \int_{0}^{\tau} \frac{f}{f}(x, t-\tau) \exp \{-K(t-\tau)\} d \tau
$$

The normalized response function, $f(x, t-\tau)$, is zero for negative values of $(t-\tau)$ so that eq. 8 is valid for all $t$ values including $t \leqslant \tau_{I}$.

Introducing a new variable of integration $\mathrm{p}: \mathrm{t}-\tau$, eq. 8 is transformed to

$$
C(x, t)=\frac{m}{Q(x)} \int_{t-\tau_{I}}^{t} f(x, p) \exp (-K p) d p
$$


In order to see what choices of $\mathrm{t}$ and $\tau_{\mathrm{I}}$ give a steady-state gas concentration, it is convenient to further transform eq. 9 to the form

$$
C(x, t)=\frac{m}{Q(x)}\left[\int_{0}^{t} f(x, p) \exp (-K p) d p-\int_{0}^{t-\tau} f(x, p) \exp (-K p) d p\right]
$$

and to illustrate the integration by means of figure 2. Figure $2 \mathrm{~A}$ describes the instantaneous injection of tracers and the resulting response functions, which are assumed to be positive only between $t_{A}$, the time of leading edge, and $t_{D}$, that of trailing edge, of a tracer cloud. Note also that because of the steadiness assumption, another instantaneous injection of the same mass, say, at $\tau_{i}$ will produce a response which is identical in shape and merely shif ted in time to be between $t_{A}+\tau_{i}$ and $t_{D}+\tau_{i}$

Figure $2 \mathrm{~B}$ illustrates the continuous injection of gas tracer by three figures.

The top one shows that the continuous injection is broken up into a series of instantaneous injections, $\mathrm{md} \tau$. The middle figure shows that two component integrals of eq. 10 can be expressed by means of a single curve. When $t$ and $\tau_{I}$ are chosen as shown in the figure, the notation, $I_{1}$, is the first integral from $p=0$ to $p=t$ and $I_{2}$ is the second integral from $p=0$ to $p=t-\tau_{I}$. If $t$ were chosen to be less than $t_{A}$, both $t$ and $t-\tau_{I}$ will be less than $t_{A}$ so that $I_{1}$ and $I_{2}$ will be both zero. On the other hand, if $t$ were chosen to be larger than $t_{D}, I_{1}$ becomes constant and if $\mathrm{t}-\tau_{\mathrm{I}}$ were larger than $\mathrm{t}_{\mathrm{D}}, \mathrm{I}_{2}$ likewise becomes constant.

The bottom figure of figure $2 \mathrm{~B}$ shows a total response to the continuous uniform injection shown in the top figure of figure $2 \mathrm{~B}$. Note that the steadystate gas concentration occurs between $t=t_{D}$ and $t=t_{A}+\tau_{I}$. The rising side of the response curve is exactly the same as the $\mathrm{I}_{1}$ curve with $\mathrm{I}_{2}$ being zero 

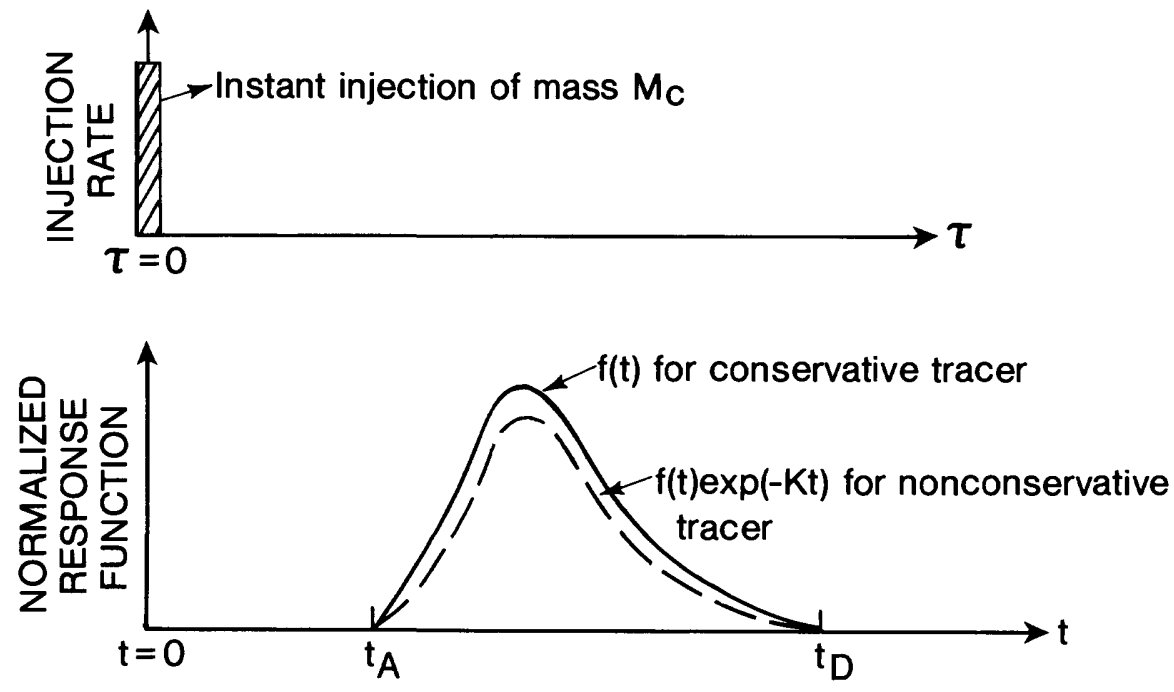

A) Input-output relation for an instantaneous injection
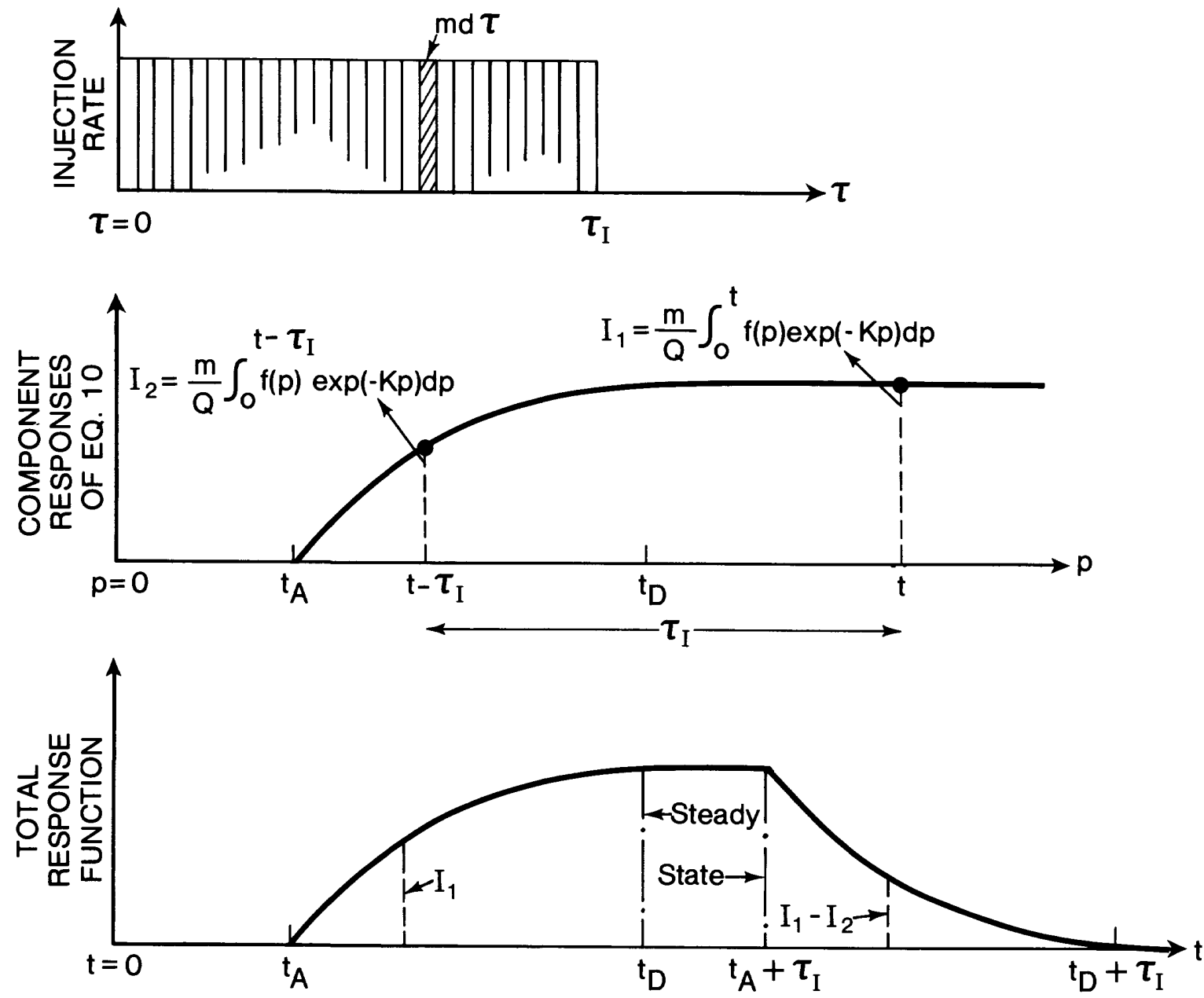

B) Input-output relation for a continuous injection

Figure 2. The principle of linear superposition by equation 10 
and the declining side is simply given by $\mathrm{I}_{1}-\mathrm{I}_{2}$ according to eq. 10 . It is seen from figure $2 \mathrm{~B}$ that the first condition for steady-state gas concentration is that $t \geqslant t_{D}$ so that the first integral, $I_{1}$, becomes constant. The second condition is that $t-\tau_{I} \leqslant t_{A}$ so that the second integral, $I_{2}$, remains zero. These two conditions may be combined to show that the duration for continuous injection, $\tau_{I}$, must be greater than the duration of conservative tracer cloud, $t_{D^{-t}}{ }_{A}$, and that the duration of steady-state gas concentration is $\tau_{I^{-t}} D^{+t} A$. Thus, in order to estimate the required duration of tracer injection for steady-state gas concentration, one must know the cloud duration, $t_{D^{-t}}{ }_{A}$, for a conservative tracer, preferably at the most downstream location, and add some time length desired for collection of steady-state data, which is equal to the duration of steady-state concentration, $\tau_{I}-t_{D}+t_{A}$

For the convenience of notation, the steady-state gas concentration, $\mathrm{C}(\mathrm{x})$, will be denoted by

$$
C(x)=\frac{m}{Q(x)} \int_{0}^{\infty} f(x, p) \exp (-K p) d p
$$

which is obtained by letting $\mathrm{t}$ and $\tau_{\mathrm{I}}$ approach infinity simulataneously in eq. 9 .

\section{Equation for Straight Prismatic Channel}

Eq. 11 derived in the previous section is not convenient for a direct calculation of desorption coefficients because of integral form involved. Here, one may add the assumption of a straight prismatic channel in order to obtain an analytical form for the normalized response function, $f(x, t)$. Consider the one-dimensional advection-dispersion equation (Fischer and others, 1979),

$$
\frac{\partial C_{c}}{\partial t}+U \frac{\partial C_{c}}{\partial x}=D \frac{\partial^{2} C_{c}}{\partial x^{2}}
$$


where $U$ is the cross-sectional average velocity and $D$ is the longitudinal dispersion coefficient. If the channel geometry is straight and prismatic, the parameters $\mathrm{U}$ and $\mathrm{D}$ of eq. 12 may be considered as constant. Then, for an instantaneous injection of tracer mass at $x=0$ and $t=0$, eq. 12 has the well-known analytical solution, which may be written as a normalized response function (Sayre, 1968)

$$
f(x, t)=\frac{U}{\sqrt{4 \pi D t}} \exp \left\{-\frac{(x-U t)^{2}}{4 D t}\right\}
$$

Substituting eq. 13 into eq. 8 and integrating with respect to $\tau$ from zero to infinity (Nuclear Regulatory Commission, 1977), one obtains

$$
\mathrm{C}(\mathrm{x})=\frac{\mathrm{m}}{\mathrm{Q} \sqrt{1+\alpha}} \exp \left\{-\frac{\mathrm{Kx}}{\mathrm{U}} \cdot \frac{2}{\alpha}(\sqrt{1+\alpha}-1)\right\}
$$

in which $\alpha$ is the nondimensional parameter, $4 \mathrm{DK} / \mathrm{U}^{2}$. Eq. 14 is also identical to the analytical solution given by O'Conner and Lawler (1965) to the one-dimensional steady-state advection-dispersion-decay equation. Because the value of $\alpha$ is normally less than 0.1 in a turbulent channel flow, eq. 14 may be adequately approximated (Fischer,1973) by

$$
C(x)=\frac{m}{Q} \exp \left(-\frac{K x}{U}\right)
$$

Eq. 15, in which $\mathrm{Q}$ is assumed constant, is the most commonly used form for the steady-state gas concentration and allows a direct calculation of $\mathrm{K}$ from observed data. Eq. 11, on the other hand, does not require a constant $\mathrm{Q}$ and is more general than eq. 15, however, its form is awkward for calculation of $\mathrm{K}$. Mathematically, it is expected that, for a typical form of $f(x, t)$, the integral of eq. 11 is closely approximated by $\exp (-K \bar{t})$, where $\bar{t}=\int_{0}^{\infty} \mathrm{tfdt}$, with some restrictive conditions similar to $\alpha$ being much smaller than unity. Because this mathematical analysis has not been completed, the present study will use both eqs. 11 and 15 for the calculation of $\mathrm{K}$ from observed data, employing a trial-and-error solution for eq. 11 . 
In the above connection, it is worthwhile to note again that a $\mathrm{K}$ value calculated from eqs. 11 and 15 represents an averaged value over a test reach and /or tracer residence time. Therefore, such $\mathrm{K}$ values are limited in the capacity of resolving the influence of flow variations observable at smaller distances and /or time scales than used in a field test.

\section{DESCRIPTION OF FIELD TESTS}

The feasibility of the steady-state gas tracer method was examined by three field tests conducted in a 5.2- $\mathrm{km}$ reach of the Cowaselon Creek. The first two field tests were made on June 30 and July 1, 1981. These two tests were primarily designed to examine the reproducibilty of tracer concentrations and gas desorption coefficients under steady channel flow conditions. The third field test made on October 20 to 21,1981 , was a single run of a 24-hour duration. This test was designed primarily to investigate the effect of diurnal wind speed variations on the desorption coefficient and secondarily to detect any effect of biodegradation on the propane gas tracer. The expectation was that a large difference in water temperature between October and June-July could induce a correspondingly lower biomass consumption of gas tracer in the October test.

For all three tests, the injection site and the three tracer sampling sites remained at fixed locations as indicated in figure 1. The injection site was located $70 \mathrm{~m}$ downstream from Hardwood Island Road where the creek narrows down to approximately $5 \mathrm{~m}$ in width and $1 \mathrm{~m}$ in depth. This site was chosen to obtain the best absorption and quick mixing of propane gas by taking advantage of constrictionexpansion of the channel width. The three cross sections for tracer sampling were fixed at $610 \mathrm{~m}, 2740 \mathrm{~m}$, and $5180 \mathrm{~m}$ downstream from the injection site. These cross sections are referred to in this report as sections 1,2 , and 3, respectively. 
At 8:20 a.m., June 30, 1981, approximately 0.4 liter of rhodamine WT 20 percent solution, used as the conservative tracer, was released instantaneously at midstream as a $2-\mathrm{m}$ long line source perpendicular to the flow direction. The midstream location was estimated by discharge and not by distance. A continuous injection of instrument-grade propane gas was also started at 8:20 a.m. and lasted for 7 hours and 40 minutes. The propane gas was injected from a 4-kg tank through a single stage regulator and rotameter to two different gas diffusers. These diffusers were flat-plate porous-tile gas diffusers with a 2-micron diameter pore size. The two diffusers were anchored on the streambed to form a 2-m line source as mentioned above. The gas injection rate was kept constant by maintaining the rotameter and line pressure gage readings at constant levels. Approximately $6.9 \mathrm{~kg}$ of propane was injected into the creek during the study. Except for a 2-minute interruption at about 12:10 p.m., when the injection was switched from one tank to another, the propane gas injection was maintained at a steady inflow rate.

River discharge measurements preceded the tracer sampling at the three cross sections. Based on these measurements, three transverse sampling locations were determined at each cross section on the basis of the cumulative discharge rather than the transverse distance. The relative cumulative discharge selected for sampling were at 10,50 , and 90 percent of the total discharge referenced from the left bank looking downstream. These locations were then marked on the tag line suspended across the channel width. The sampling locations in a cross section are designated as the left, center, and right location, respectively. 
In order to verify that the stream flow remained steady during the field test, a temporary staff gage was installed at each cross section. Stage readings were taken throughout the day at all three sampling sections. A maximum stage change of less than $10 \mathrm{~mm}$ was observed during the entire test period so that the change in discharge was small. As an additional check on the discharge variation, a second discharge measurement was made at section 1 after the tracer sampling was completed. The difference between the two discharge measurements at section 1 was less than 4 percent, which is within the limits of measurement accuracy.

The sampling of rhodamine WT dye tracer was begun at 9:00 a.m. at the first cross section. Because section 1 was only 610 m downstream of the injection site, the passage of dye cloud through the section was fast, requiring sampling at the three transverse sampling locations at 2-minute intervals on the rising side and past the peak dye concentration. As the time rate of change of dye concentration decreased on the falling side of dye cloud, the sampling interval was changed to 5 minutes and later to 10 minutes. A portable Turner Design Model 10 fluorometer 1 was set up at section 1 for an in situ concentration reading to monitor passage of the dye cloud, even though all dye samples were retained for later laboratory analysis. The sampling of gas tracer concentration was started at 10:30 a.m. at section 1, when the in situ reading of dye concentration dropped below 1 percent of the peak value. The dye sampling was terminated $1 / 2$ hour later at 11:00 a.m. Gas samples were collected at the center sampling location at a 15-minute interval and at the left and right locations every 30 minutes. Propane sampling at section 1 ended at 2:00 p.m.

$1 /$ The use of brand name is for identification purposes only and does not constitute endorsement by the U.S. Geological Survey. 
The tracer sampling at the second and third cross sections was done following a procedure similar to that for section 1--namely, only dye samples were collected at three sampling locations during the passage of dye cloud with the time interval varying between 5 and 30 minutes. The portable fluorometer was used to determine suitable time intervals for sampling by carefully observing the rate of change of dye concentration with time. Because the attenuation of concentration on the falling side of the dye cloud became increasingly slower as the distance from the injection site increased, the sampling of the gas tracer at sections 2 and 3 was started when dye concentration dropped below 0.5 to $1 \mu \mathrm{g} \mathrm{L}^{-1}$ (microgram per liter) by the fluorometer reading. There was about a 1-hour period at section 3, during which both dye and gas samples were collected simultaneously. The propane gas samples at sections 2 and 3 were taken at the similar 15-and 30-minute intervals as at section 1. These gas samples were collected at section 2 between 3:15 p.m. and 6:30 p.m. and at section 3 from 7:15 p.m. until 10:45 p.m., when the field test ended.

Both dye and gas samples were collected by manually dipping a 40-mL (milliliter) glass vial into the water. No use was made of the dissolved gas sampler for gas sampling. However, the procedure for injection of formalin preservative and sealing of septum cap vial followed specifications given by Rathbun (1979).

The wind speed was measured at a station located $6 \mathrm{~km}$ upstream from the mouth of the Cowselon Creek at Oneida Lake and about halfway between sections 2 and 3. The instruments used for this purpose were cup anemometers, which had been carefully calibrated in a wind tunnel prior to the field experiment. As illustrated in figure $3 \mathrm{~A}$, two anemometers were mounted on a mast $0.56 \mathrm{~m}$ (POS 1) and $2.16 \mathrm{~m}$ (POS 2), respectively, above the water surface at the center of the channel. A third anemometer (POS 3) was mounted $6.30 \mathrm{~m}$ above ground 


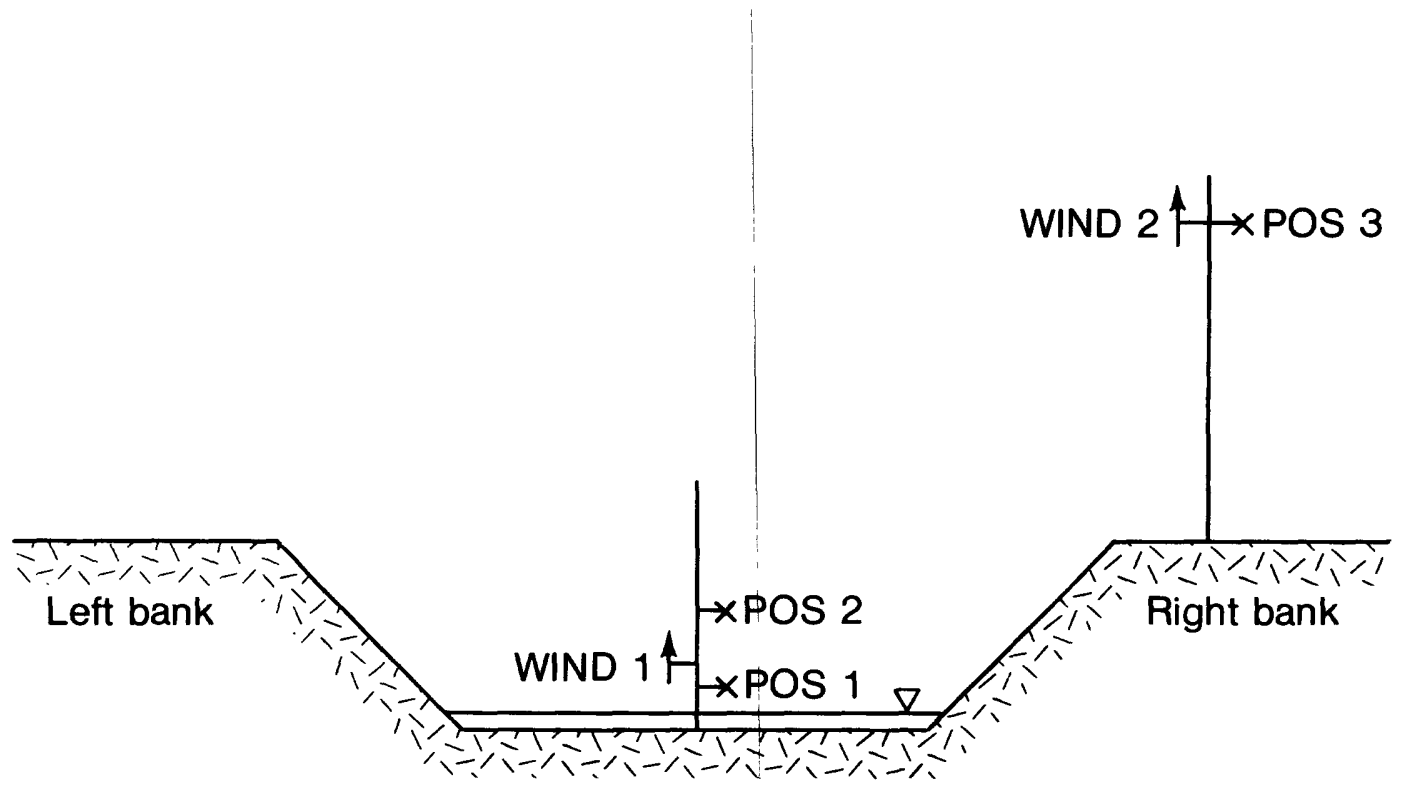

A) Wind station for June 30 and July 1

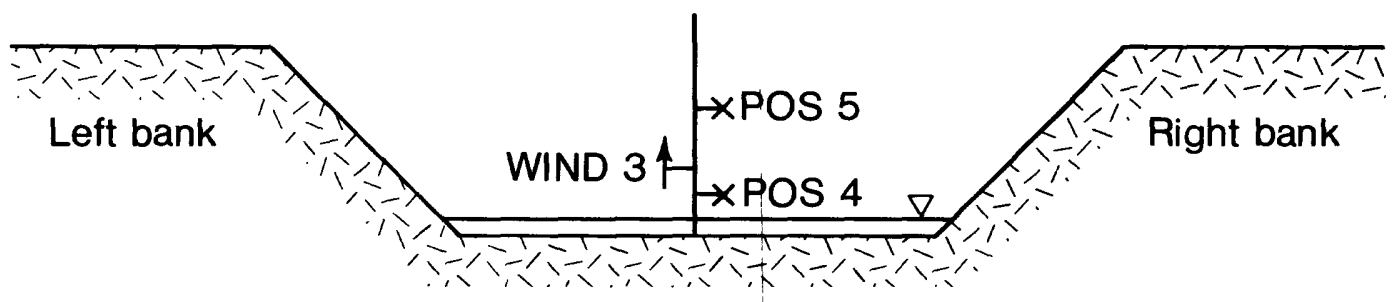

B) Additional station for July 1

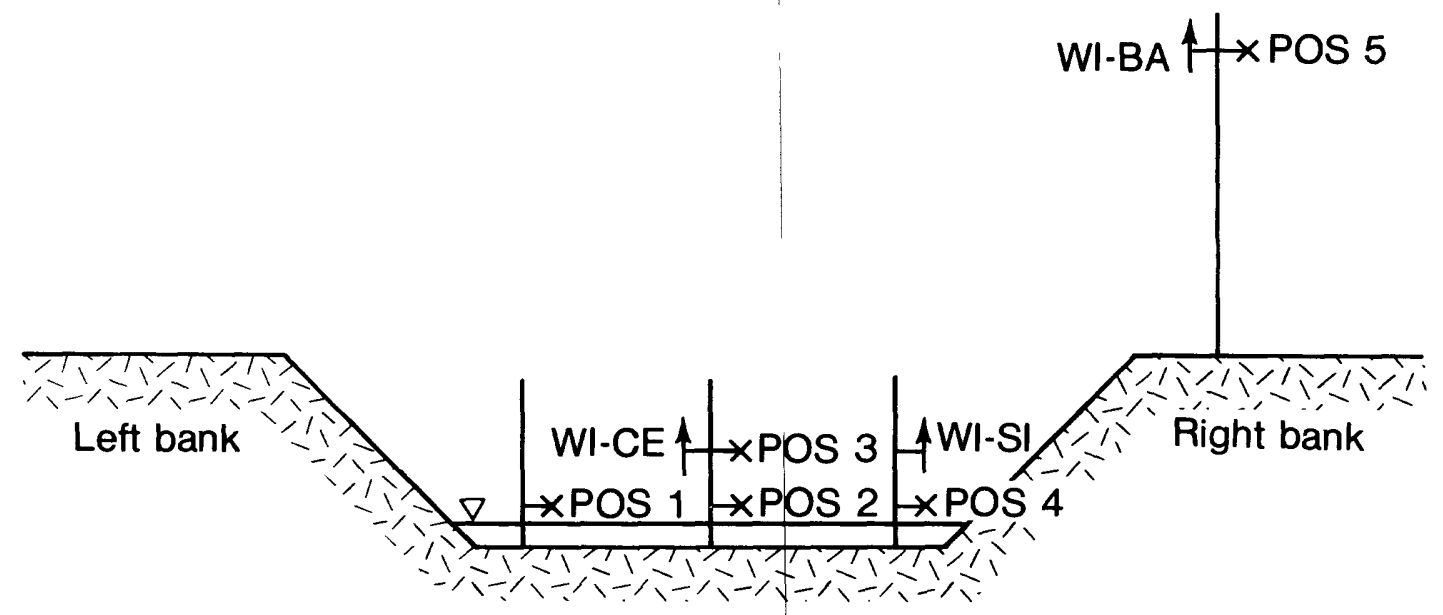

C) Wind station for October 20-21

$\vdash \times$ ANEMOMETER

H WIND vanes

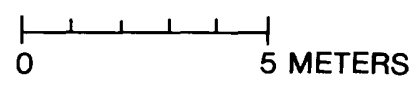

Figure 3. Sketch of wind instrument arrangement 
level on the bank; ground level waj approximately $3.5 \mathrm{~m}$ above the water level of the Cowaselon Creek. The wind direction was measured by means of wind vanes $1.0 \mathrm{~m}$ above the water surface (WIND 1) and $6.3 \mathrm{~m}$ above the bank (WIND 2). The Cowaselon Creek is essentially a straight channel with the direction of flow from ESE to WNW.

$$
\text { July 1, 1981, Test }
$$

At 6:50 a.m., July 1, 1981, approximately 0.4 liter of rhodamine WT, 20 percent solution, was released instantaneously into the Cowaselon Creek at the same injection site and in the same configuration as the June 30 test. A continuous injection of propane gas tracer also started at 6:50 a.m. and lasted for 7 hours and 40 minutes. During the test a total of $6.9 \mathrm{~kg}$ of propane gas was injected into the creek. The control of gas injection rate followed the same procedure used in the June 30 test and again there was one interruption for one minute at 10:30 a.m. while the tanks were switched. The propane gas used in the July 1 test was of commercial grade which was purchased at a local fuel store in the town of Canastota. The commercial grade propane was used because the June 30 test exhausted the entire supply of instrument-grade propane gas prepared in advance for the 2-day test.

Because the July 1 test was designed as an exact repetition of the June 30 test, all aspects of discharge measurements, stage observations, and dye and gas sampling were the same as the June 30 test. The only exception to this was that a second discharge measurement at section 1 was not made at the end of the July 1 study because the maximum stage variation during the day was again less than $10 \mathrm{~mm}$. Because of the experience gained during the previous day, the field work was more efficiently carried out and the test was completed at 10:00 p.m., July $1,1981$. 
As for wind measurement of July 1, beside the station installed on June 30 , a second station was set up approximately $8.5 \mathrm{~km}$ upstream from the mouth of the Cowaselon Creek, that is, between section 1 and section 2. At this station two anemometers were mounted $0.49 \mathrm{~m}$ (POS 4) and $2.25 \mathrm{~m}$ (POS 5) above the water surface on the mast located at midstream; a wind vane mounted $1.0 \mathrm{~m}$ (WIND 3) above the water surface was used to measure the wind direction. A general sketch of this second station is shown in figure $3 \mathrm{~B}$.

In addition to the steadiness of channel discharge, the weather conditions remained very similar on June 30 and July 1 , making the natural conditions ideal for replicate tracer tests. Both days were hot and sunny with only a light breeze blowing all day. The air temperature on July 1, 1981, during the field test varied from $24^{\circ} \mathrm{C}$ in the early morning to $36^{\circ} \mathrm{C}$ by mid-afternoon and on June 30,1981 , from $22^{\circ} \mathrm{C}$ to $34^{\circ} \mathrm{C}$.

\section{October 20-21,1981, Test}

At 7:29 a.m., October 20, 1981, approximately 0.8 liter of rhodamine WT 20 percent solution, was instantaneously injected at the same injection site as the June 30 and the July 1 tests. The slug release of dye tracer was followed immediately by the start of the continuous injection of propane gas tracer. A primary purpose of the test was to evaluate the effect of wind shear on the gas desorption rate by taking advantage of an expected diurnal wind speed variation. For this reason the gas injection at the constant rate was continued for the duration of 24 hours until 7:35 a.m., Ocotber 21, 1981 .

The same injection procedures and equipment were used during this field test as the summer tests, except that a slightly higher gas injection rate and a 45-kg propane tank were used. Approximately $30 \mathrm{~kg}$ of commercial grade propane 
gas was injected during the 24-hour injection period. There were no freezing problems with the regulator or rotameter during the injection, even though the air temperature was as low as $9^{\circ} \mathrm{C}$. Indeed, the temperature of propane gas at the rotameter during all three tests seemed to stay at or slightly below the air temperature and thus kept the injection system completely free from freezing.

Discharge measurements were made October 20 at all three sampling sites prior to water sampling. However, as stage readings were taken at each cross section during the 24-hour field test, a decrease in stage of $30 \mathrm{~mm}$ was observed. Because this was a significant change in stage, the second set of discharge measurements was made on October 21 at the three cross sections. The river discharge was found to be declining with time and slightly unsteady during the study period. Therefore, a second instantaneous injection of rhodamine W T dye was made at 7:31 a.m., October 21,1981 , to obtain data which could be appropriate for the latter half of the test.

In the October test, dye and gas samples were collected only at one sampling location at each cross section, which was located at the 50 percent cumulative discharge point. This decision was partly based on the observation in the June 30 and July 1 tests that the transverse variations of the dye concentration-time curve and of the steady-state gas concentration were not significant at all cross sections. Even though the discharge for the October test was considerably higher than that for the summer tests and thus the distance for transverse uniform mixing was expected to be longer, an estimate based on the channel width of $10.7 \mathrm{~m}$, depth of $0.46 \mathrm{~m}$, velocity of $0.30 \mathrm{~m} \mathrm{sec}^{-1}$ (meter per second), and shear velocity of $0.06 \mathrm{~m} \mathrm{sec}^{-1}$ gave the mixing distance of 305 to $460 \mathrm{~m}$ from the injection site (Yotsukura and Cobb, 1972). The distance between the injection site and section 1 was $610 \mathrm{~m}$, which was longer than the estimated mixing distance. 
The collection of dye and gas samples was carried out by the same procedure used in the summer tests. Because of experience gained from the summer tests, however, all gas samples were collected by use of the dissolved gas sampler and special precautions were taken to ensure that septum cap vials were sealed immediately to prevent gas venting and air bubble formation in the sample. Also, some extra efforts were made in the October 20 dye injection to collect data for the falling side of dye cloud in order to delineate the effect of "long tail" on low order moments of the concentration distribution.

Because of the above additional effort and care in data collection, the overall quality of dye and gas data of the October test is judged to be better than those of the summer tests. On the other hand, the channel discharge was not as steady as in the summer tests so that it was anticipated that the analysis of the October test data would be a little more complicated than for the summer tests.

The windspeed measurements were made approximately $7 \mathrm{~km}$ upstream from the mouth of the Cowaselon Creek, that is, approximately $200 \mathrm{~m}$ downstream from section 2. The positioning of wind speed measurements in the October test was changed from that of the two summer tests. This was done in order to allow an estimate of the wind velocity variation over the cross section of the air flow channel enclosed by the steep banks and the water surface. As sketched in figure $3 \mathrm{C}$, three anemometers were mounted $0.35 \mathrm{~m}$ above the water surface, viz, one at $1.5 \mathrm{~m}$ from the left edge of water (POS 1), one at midstream (POS 2), and one at $1.5 \mathrm{~m}$ from the right edge of the water (POS 4). On the center mast an anemometer was also mounted $1.54 \mathrm{~m}$ above the water surface (POS 3). A fifth anemometer was mounted $6.30 \mathrm{~m}$ above the ground surface on the right bank. The wind direction was measured by means of wind vanes inside the sheltered channel $1.5 \mathrm{~m}$ above the water surface. 
One wind vane (WI-CE) was installed at midstream and the other one (WI-SI) was at the right edge of the water. A third wind vane (WI-BA) measured the wind direction $6.30 \mathrm{~m}$ above the ground level of the bank. The atmospheric stability is an important factor governing the shear stress exerted by the wind at the water surface. To allow the inclusion of this effect in the calculation, the temperatures of air and water were measured and recorded throughout the 24-hour test period.

\section{PRESENTATION OF DATA}

\section{June 30,1981 , Test}

After the test, all dye samples were brought back to the New York Subdistrict Laboratory, USGS, for fluorometer analysis by the standard procedure. Selected gas samples were shipped to the Central Laboratory, USGS, Atlanta, Georgia, for gas chromatograph anaylsis, the funding limitations being the reason for not shipping all gas samples.

Figures 4, 5, and 6 illustrate the variation of dye concentration with time observed at section 1, 2, and 3, respectively. Each figure contains three dye clouds observed at three transverse sampling locations in the cross section. Note also that the "long tail" of dye cloud is extrapolated. This was necessary because field data collection near the trailing edge of a dye cloud is always terminated before the concentration declines to a background level. The procedure for extrapolation is explained in the first section of the chapter "Analysis of data."

Figures 7,8, and 9 show time series data of propane gas concentration at section 1,2 , and 3, respectively. In order to estimate the steady-state period 


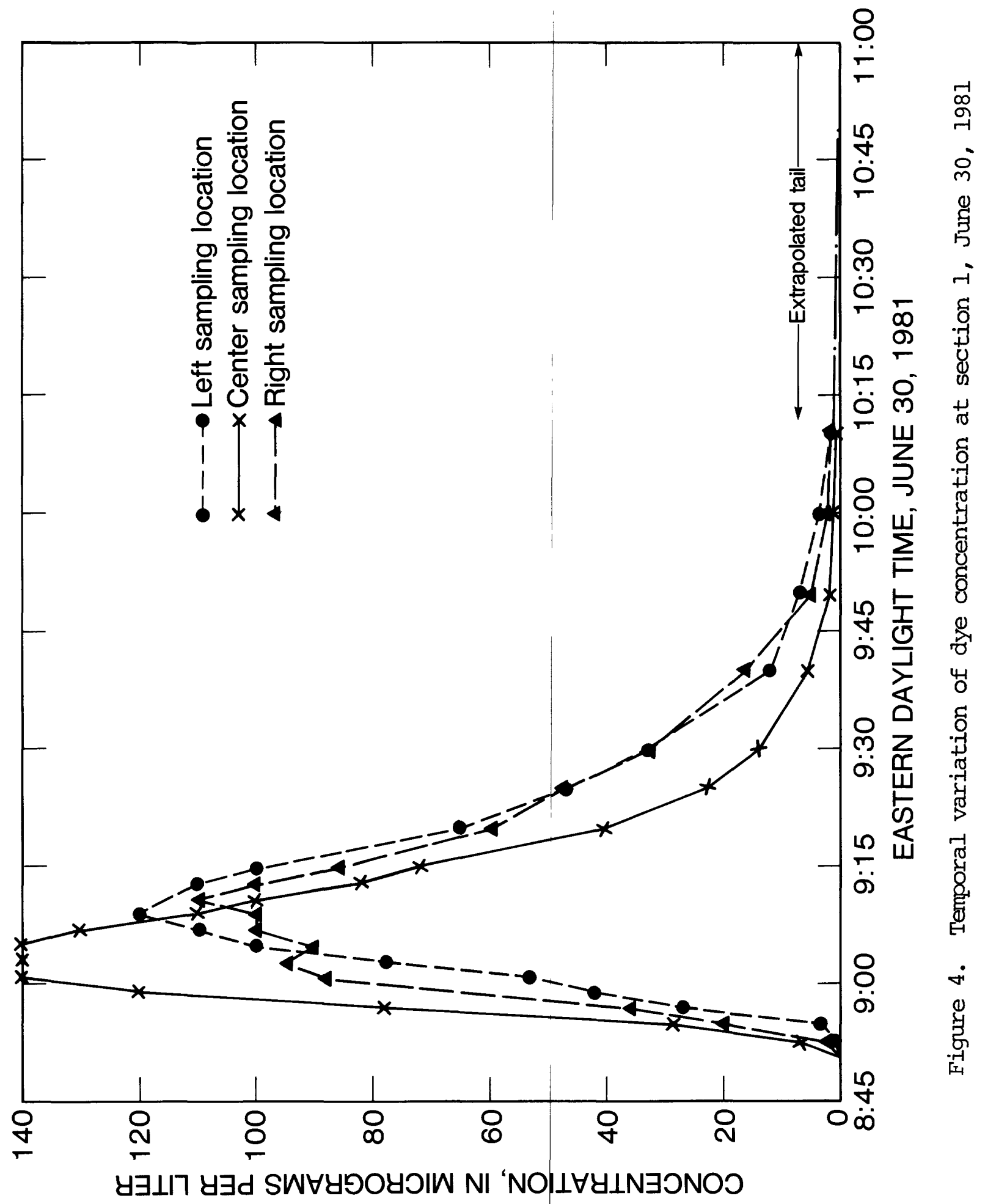




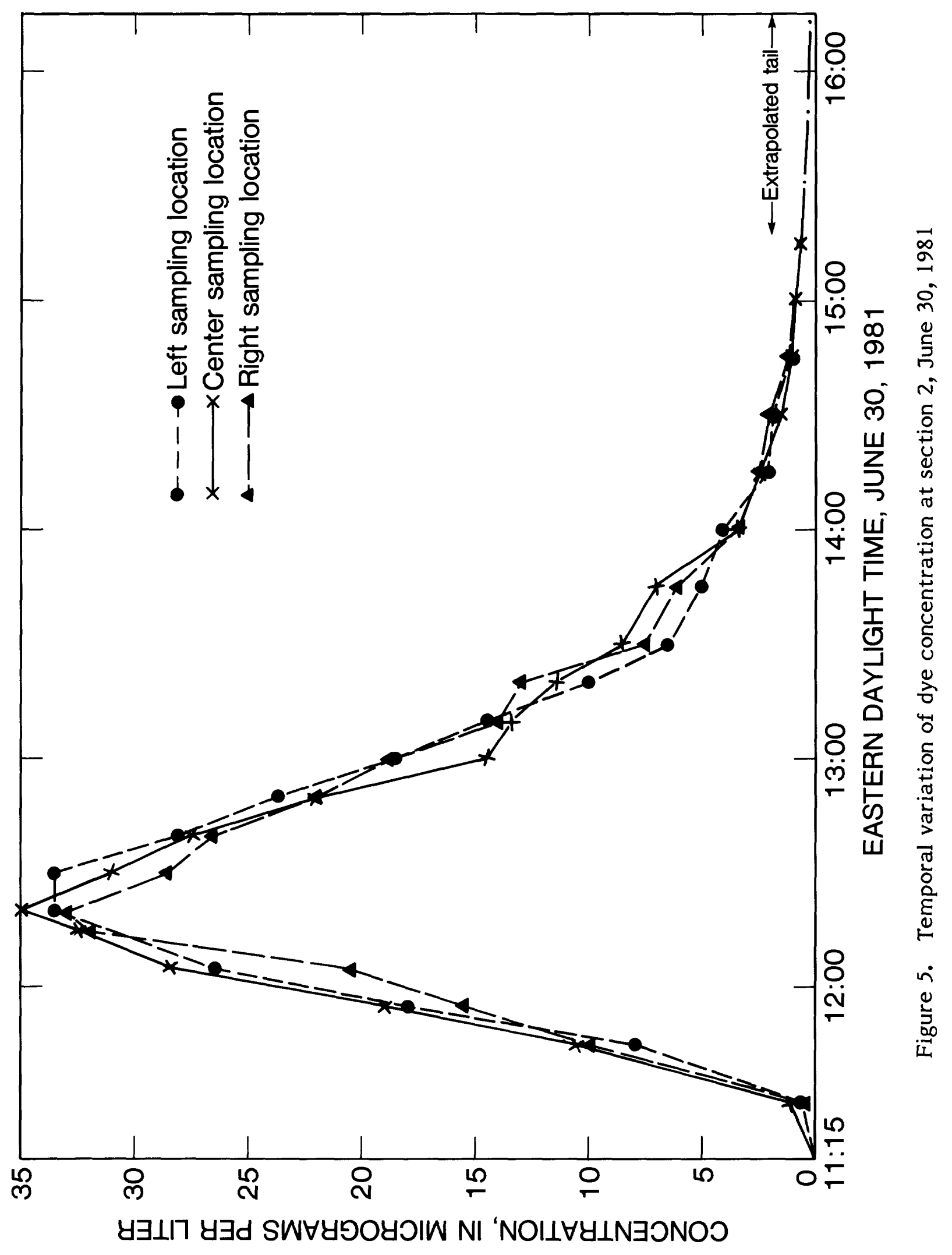




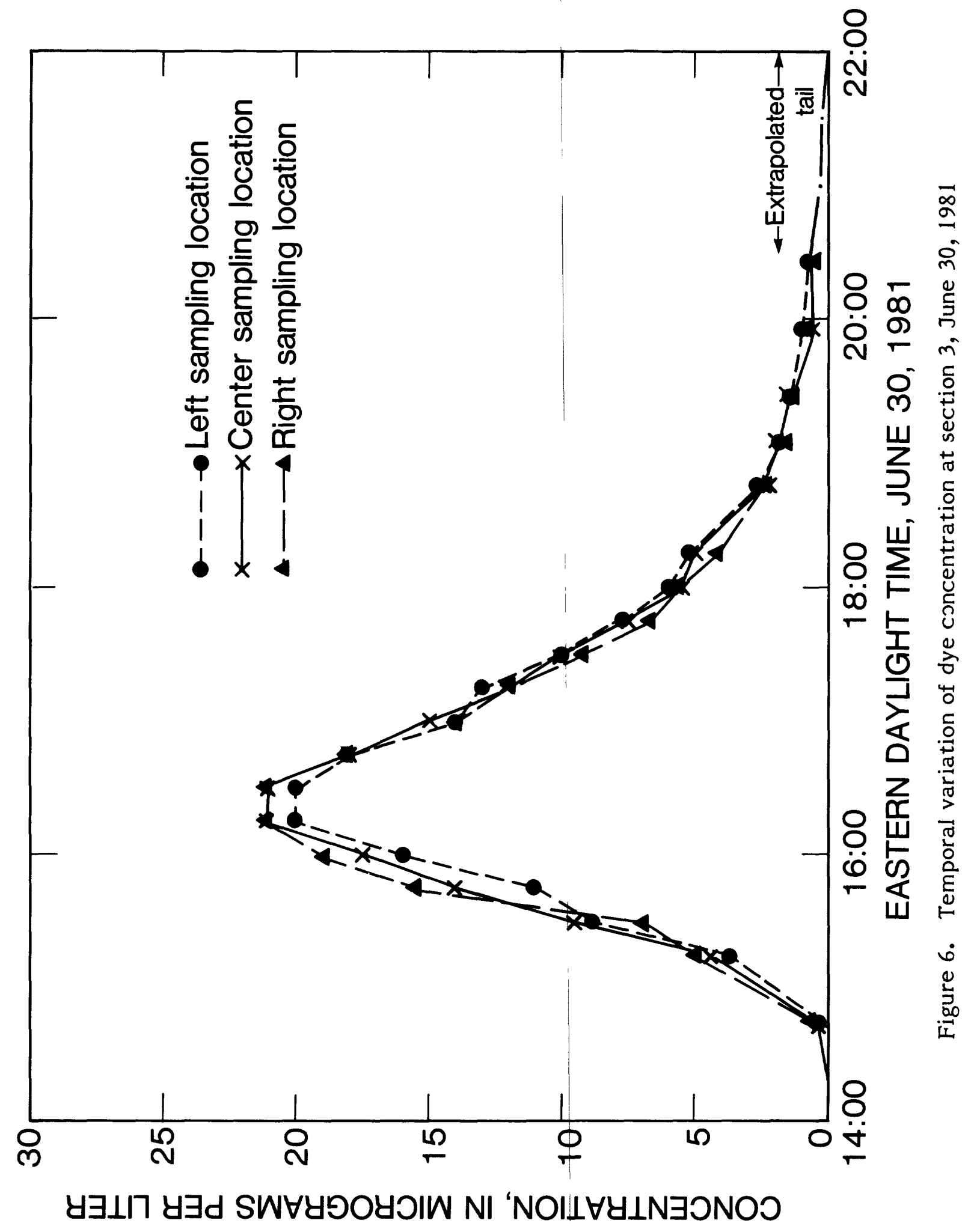




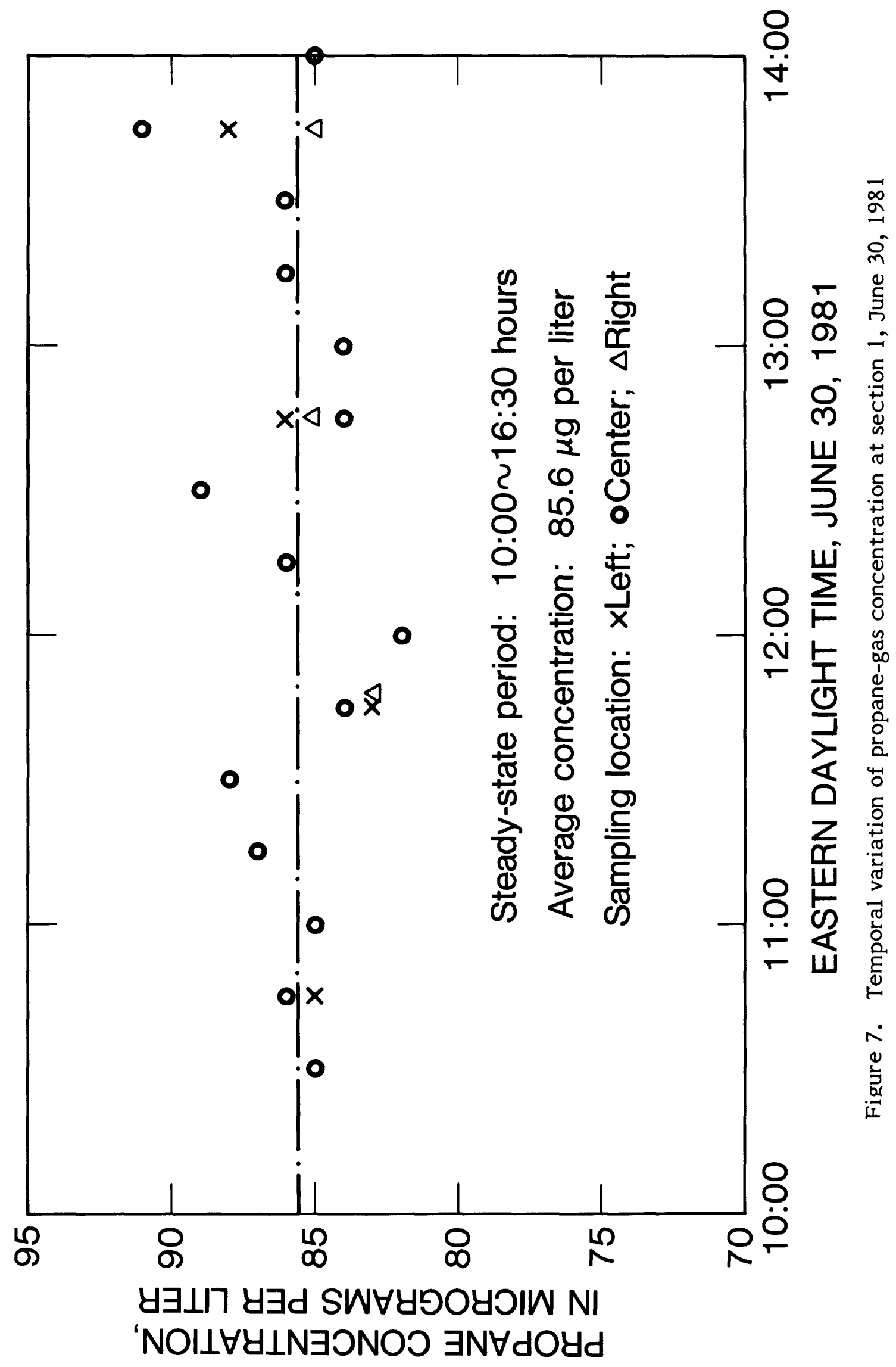




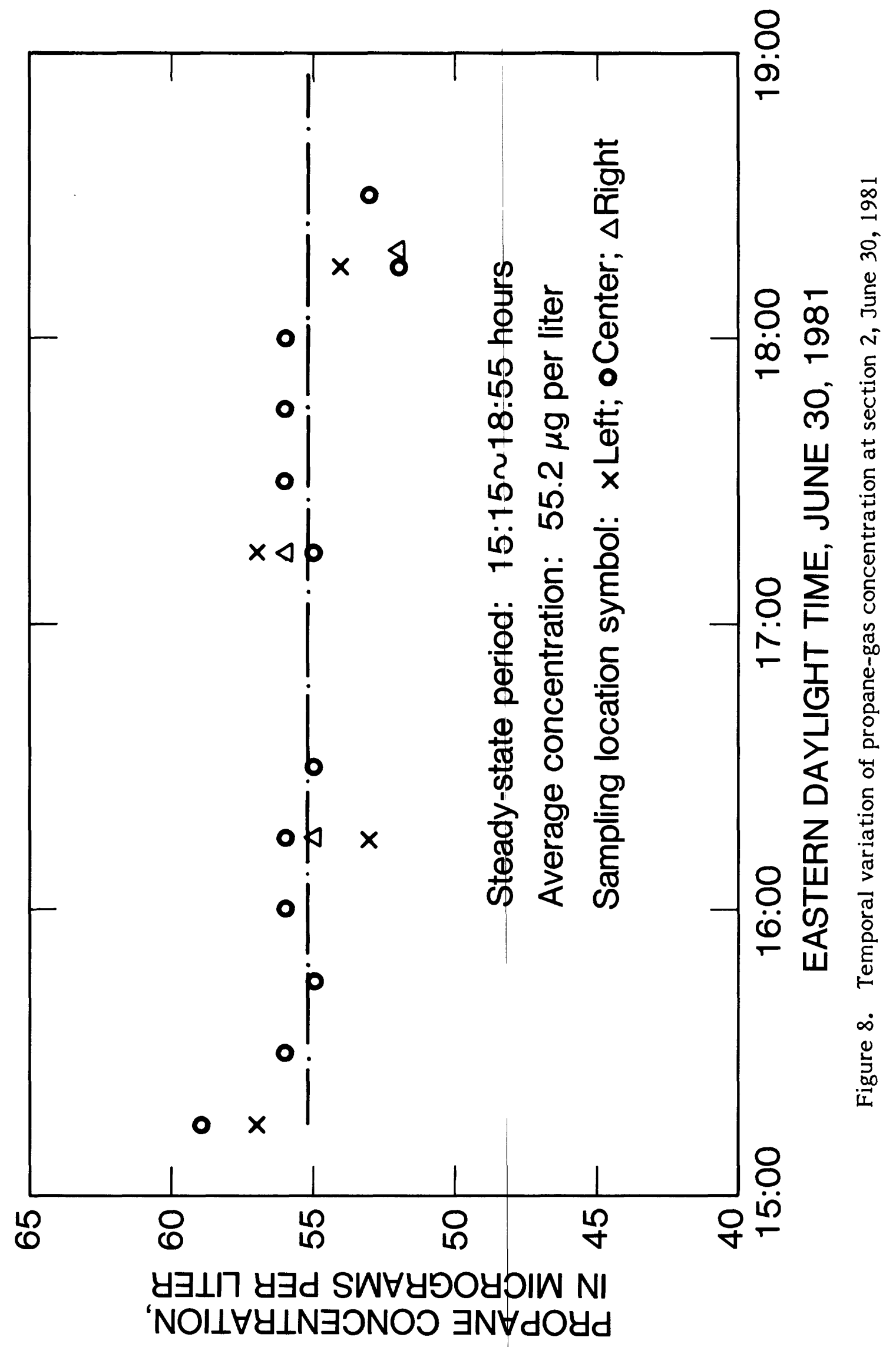




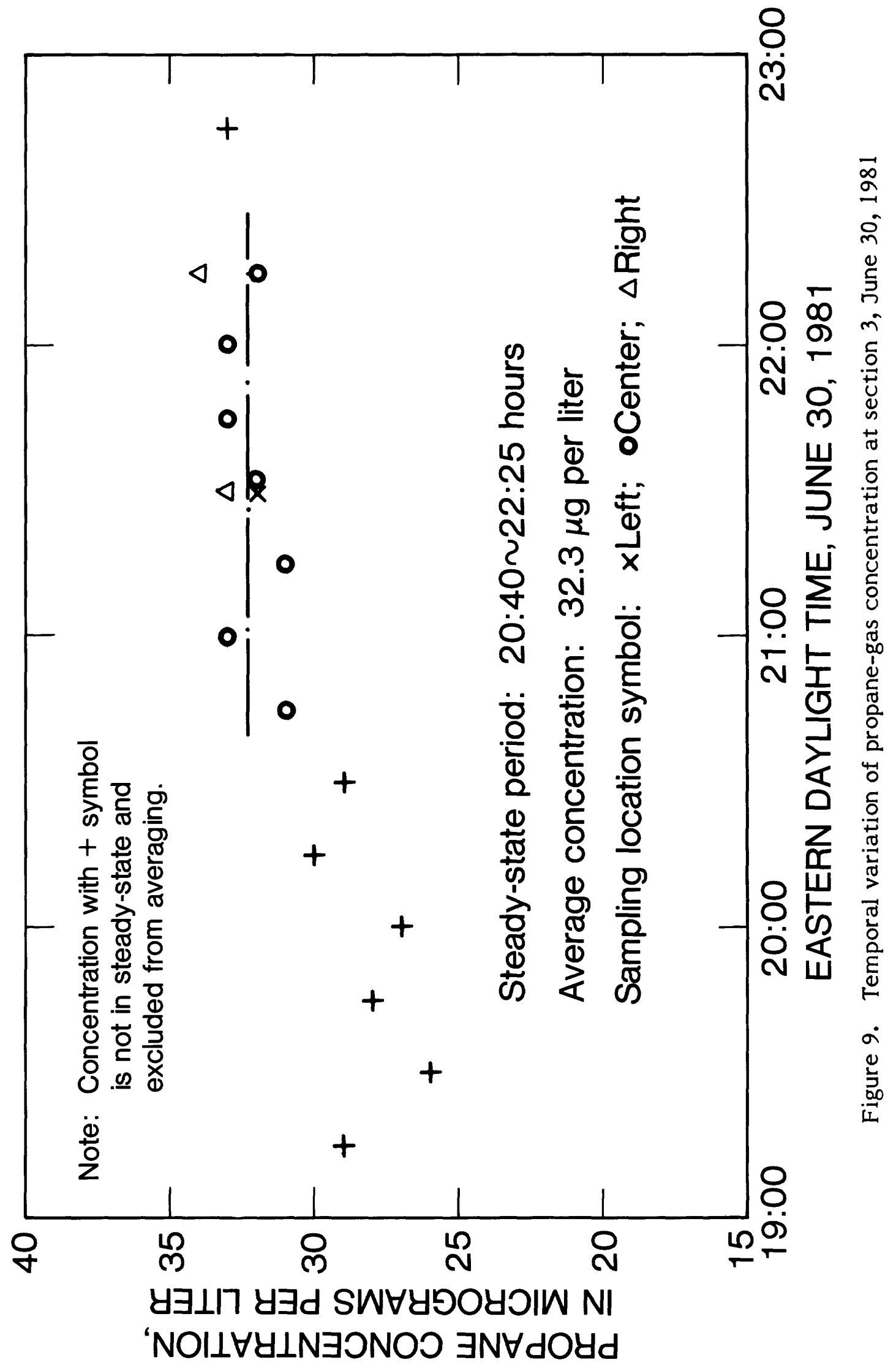


for gas concentration, the superposition principle was applied with certain modifications. Namely, the dye cloud duration was determined from figures 4,5 , and 6 as the time length between the arrival time of leading edge and the time when the concentration declined to 2 percent of the peak concentration. The beginning and end of a steady-state period for gas, which are indicated in figure $2 B$ as $t_{D}$ and $t_{A}+\tau_{I}$, were determined from dye data by knowing that $\tau_{\text {I }}$ was 7 hours and 40 minutes. The steady-state periods are noted on figures 7,8 , and 9. Note that, while all concentrations in figures 7 and 8 are at steady state, some concentrations in figure 9 were measured either before or after the period of steady-state. The above method of determining the steady-state period for gas concentration from dye cloud duration was used uniformly for all data reported in the present report. A justification for this modification will also be given in the next chapter "Analysis of data."

The standard deviation of steady-state gas concentration was found to be 3 percent of the mean for all cross sections, based on 22, 19, and 12 data points at section 1, 2, 3, respectively. The majority of propane data in figures 7,8 , and 9 are from the center location at 50 percent cumulative discharge, even though some data observed at 10 and 90 percent cumulative discharge locations are shown for comparison. A detailed examination of all propane data showed that no systematic transverse variations in gas concentration was detectable at any cross section.

The Cowaselon Creek discharge was remarkably steady on June 30 and July 1,1981 , as described earlier. One or two discharge measurements made on each date at each cross section agreed within 3 percent, which is within the limit of accuracy in discharge measurements. The change of water surface elevation 
for two days was practically zero at sections 2 and 3, while the maximum change at section 1 was about $10 \mathrm{~mm}$. However, the discharge accretion in the downstream direction was noticeable, amounting to almost 10 percent from section 1 to section 3. Table 1 tabulates the discharge and channel geometries measured at the three cross sections, which were determined from the total of seven discharge measurements. These values are to be used for the analysis of data for both June 30 and July 1 tests. Table 1 also lists the variation of water temperature as a function of time observed at the three cross sections on June 30 and July 1.

Table 2 shows the wind speed and wind direction data for half-hourly time intervals for the June 30 test. The wind speeds are given in $\mathrm{m} \mathrm{sec}^{-1}$. POS.1, POS. 2 and POS. 3 refer to the positions of anemometers shown in figure 3A; WIND 1 and WIND 2 refer to the wind vane positions. Figure 10 illustrates the variation of wind speed with time at POS.1, that is, $0.56 \mathrm{~m}$ above the water surface at midstream; it can be seen that the wind speed was generally low on the order of $1 \mathrm{~m} \mathrm{sec}^{-1}$ with a maximum of $2.2 \mathrm{~m} \mathrm{sec}^{-1}$ around 4:00 p.m. and a minimum of about $0.1 \mathrm{~m} \mathrm{sec}^{-1}$ around 7:00 p.m. The variation of wind speed outside the channel sheltered by the banks, that is, $6.3 \mathrm{~m}$ above the ground surface on the bank, is shown in figure 11 . Comparison of figures 10 and 11 reveals that the banks of the creek provided considerable sheltering and therefore greatly reduced the effect of wind on the gas exchange rate at the water surface.

$$
\text { July 1, 1981, Test }
$$

Figures 12,13, and 14 show dye concentration as a function of time for the July 1 test at the three cross sections and are comparable with figures 4 , 5 , and 6 of the June 30 test, respectively. The dye clouds are very similar between the two tests, except near the leading edges at section 3, where it is believed that discrepancies are mostly due to the sample timing. 
Table 1.--Discharge, channel geometries, and water temperature at three cross sections, June 30 and July 1,1981

\begin{tabular}{|c|c|c|c|c|c|}
\hline & $\begin{array}{c}\text { Discharge } \\
\text { in } \mathrm{m}^{\mathrm{q}_{\mathrm{s}}-1}\end{array}$ & $\begin{array}{c}\text { Cross - } \\
\text { sectional } \\
\text { area } \\
{ }^{A} \\
\text { in } \mathrm{m}^{2}\end{array}$ & $\begin{array}{c}\text { Surface } \\
\text { Width } \\
\text { in }_{\mathrm{m}}^{\mathrm{B}}\end{array}$ & $\begin{array}{l}\text { Depth } \\
\text { A/B } \\
\text { in } m\end{array}$ & $\begin{array}{l}\text { Velocity } \\
\text { Q/A } \\
\text { in } \mathrm{m} \mathrm{s}^{-1}\end{array}$ \\
\hline Sec. 1 & 0.564 & 3.30 & 10.7 & 0.31 & 0.17 \\
\hline 2 & 0.583 & 4.16 & 7.9 & 0.53 & 0.14 \\
\hline 3 & 0.617 & 2.47 & 11.3 & 0.22 & 0.25 \\
\hline
\end{tabular}

\begin{tabular}{|ccccccccccc|}
\hline \multicolumn{7}{|c|}{ Water temperature in ${ }^{\circ} \mathrm{C}$, June 30,1981} \\
\hline Time & $11: 00$ & $12: 00$ & $13: 00$ & $14: 00$ & $15: 00$ & $16: 00$ & $17: 00$ & $18: 00$ & $19: 00$ \\
\hline Sec. 1 & 22 & 23 & 24 & 25 & - & - & - & - & - \\
& & -- & 23.5 & -- & 26 & 26 & 26.5 & -- & 26 & - \\
3 & -- & -- & -- & -- & 26.5 & 27.5 & 27 & 27 & 27 \\
\hline
\end{tabular}

\begin{tabular}{|cccccccccccc|}
\hline \multicolumn{10}{|c|}{ Water temperature in ${ }^{\circ} \mathrm{C}$, July 1,1981} \\
\hline Time & $8: 00$ & $9: 00$ & $10: 00$ & $11: 00$ & $12: 00$ & $13: 00$ & $14: 00$ & $15: 00$ & $16: 00$ & $17: 00$ \\
\hline Sec. 1 & 20.5 & 21 & 22 & 22.5 & 23.5 & -- & 26 & -- & 25 & 26 \\
& & -- & -- & 21 & 21.5 & 24 & -- & -- & -- & -- & -- \\
3 & -- & -- & -- & -- & -- & -- & -- & -- & -- & -- \\
\hline
\end{tabular}


Table 2.--Temporal variations of wind speed and direction, June 30, 1981

\begin{tabular}{|c|c|c|c|c|c|c|}
\hline No. & Time & $\begin{array}{c}\text { Wind speed } \\
\text { at } \\
\text { POS } 1 \\
\text { in } \mathrm{ms}^{-1}\end{array}$ & $\begin{array}{c}\text { Wind speed } \\
\text { at } \\
\text { POS } 2 \\
\text { in } \mathrm{ms}^{-1}\end{array}$ & $\begin{array}{c}\text { Wind direc- } \\
\text { tion at } \\
\text { WIND } 1\end{array}$ & $\begin{array}{c}\text { Wind speed } \\
\text { at } \\
\text { POS } 3 \\
\text { in } \mathrm{ms}^{-1}\end{array}$ & $\begin{array}{l}\text { Wind direc- } \\
\text { tion at } \\
\text { WIND } 2\end{array}$ \\
\hline 1 & $8: 30-09: 00$ & -- & -- & * & -- & * \\
\hline 2 & $9: 00-09: 30$ & .71 & 1.23 & * & 2.07 & * \\
\hline 3 & $9: 30-10: 00$ & .74 & 1.22 & $E$ & 2.07 & * \\
\hline 4 & $10: 00-10: 30$ & 1.05 & 1.41 & $\mathrm{E}$ & - & ESE \\
\hline 5 & $10: 30-11: 00$ & 1.27 & 1.64 & $E$ & -- & NE \\
\hline 6 & $11: 00-11: 30$ & 1.01 & 1.27 & $E$ & -- & $E$ \\
\hline 7 & $11: 30-12: 00$ & .95 & 1.25 & $E$ & -- & NNE \\
\hline 8 & $12: 00-12: 30$ & .95 & 1.30 & * & -- & N \\
\hline 9 & $12: 30-13: 00$ & .95 & 1.33 & * & -- & * \\
\hline 10 & $13: 00-13: 30$ & 1.07 & 1.33 & * & 2.46 & $\star$ \\
\hline 11 & $13: 30-14: 00$ & 1.15 & 1.22 & $\bar{E}$ & 2.62 & $\mathrm{SE}$ \\
\hline 12 & $14: 00-14: 30$ & .67 & 1.25 & $\mathrm{E}$ & 1.81 & SE \\
\hline 13 & $14: 30-15: 00$ & 1.31 & 1.42 & SE & 1.99 & SE \\
\hline 14 & $15: 00-15: 30$ & 1.44 & 1.86 & SE & 2.39 & SE \\
\hline 15 & $15: 30-16: 00$ & 2.20 & 2.52 & $E$ & 3.12 & $s$ \\
\hline 16 & $16: 00-16: 30$ & 1.77 & 2.20 & $E$ & 2.89 & s \\
\hline 17 & $16: 30-17: 00$ & .83 & 1.27 & $E$ & 2.08 & SE \\
\hline 18 & $17: 00-17: 30$ & .88 & 1.43 & ESE & 2.10 & $\star$ \\
\hline 19 & $17: 30-18: 00$ & 1.04 & 1.54 & ESE & 2.16 & $E$ \\
\hline 20 & $18: 00-18: 30$ & .43 & .99 & ESE & 1.70 & $E$ \\
\hline 21 & $18: 30-19: 00$ & .11 & .26 & VAR & .79 & ESE \\
\hline 22 & $19: 00-19: 30$ & 1.26 & 1.81 & WNW & 4.22 & $W$ \\
\hline 23 & $19: 30-20: 00$ & .40 & 2.40 & $\star$ & 4.22 & t \\
\hline
\end{tabular}

Note: * designates variable wind direction -- designates no measurement 


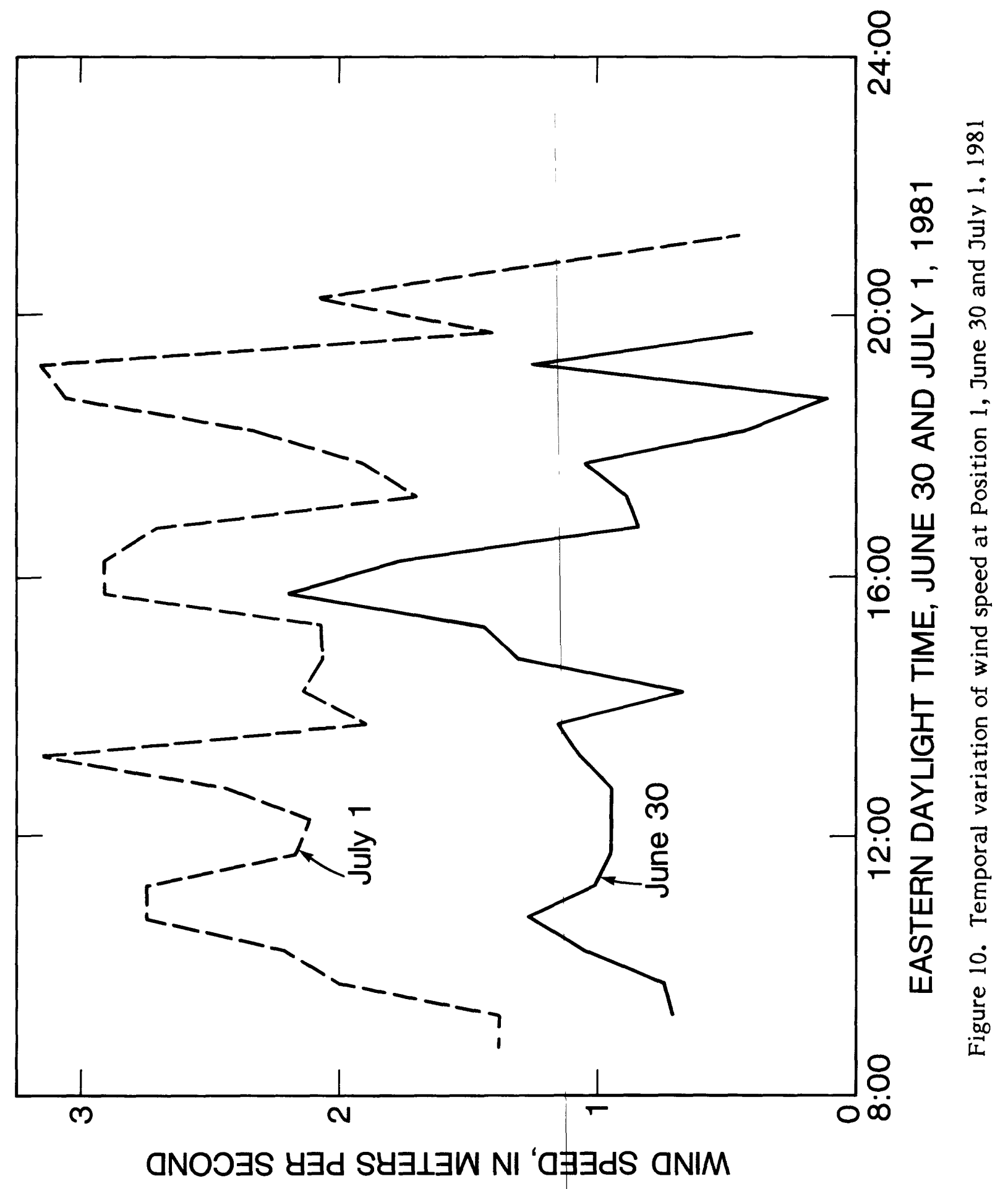




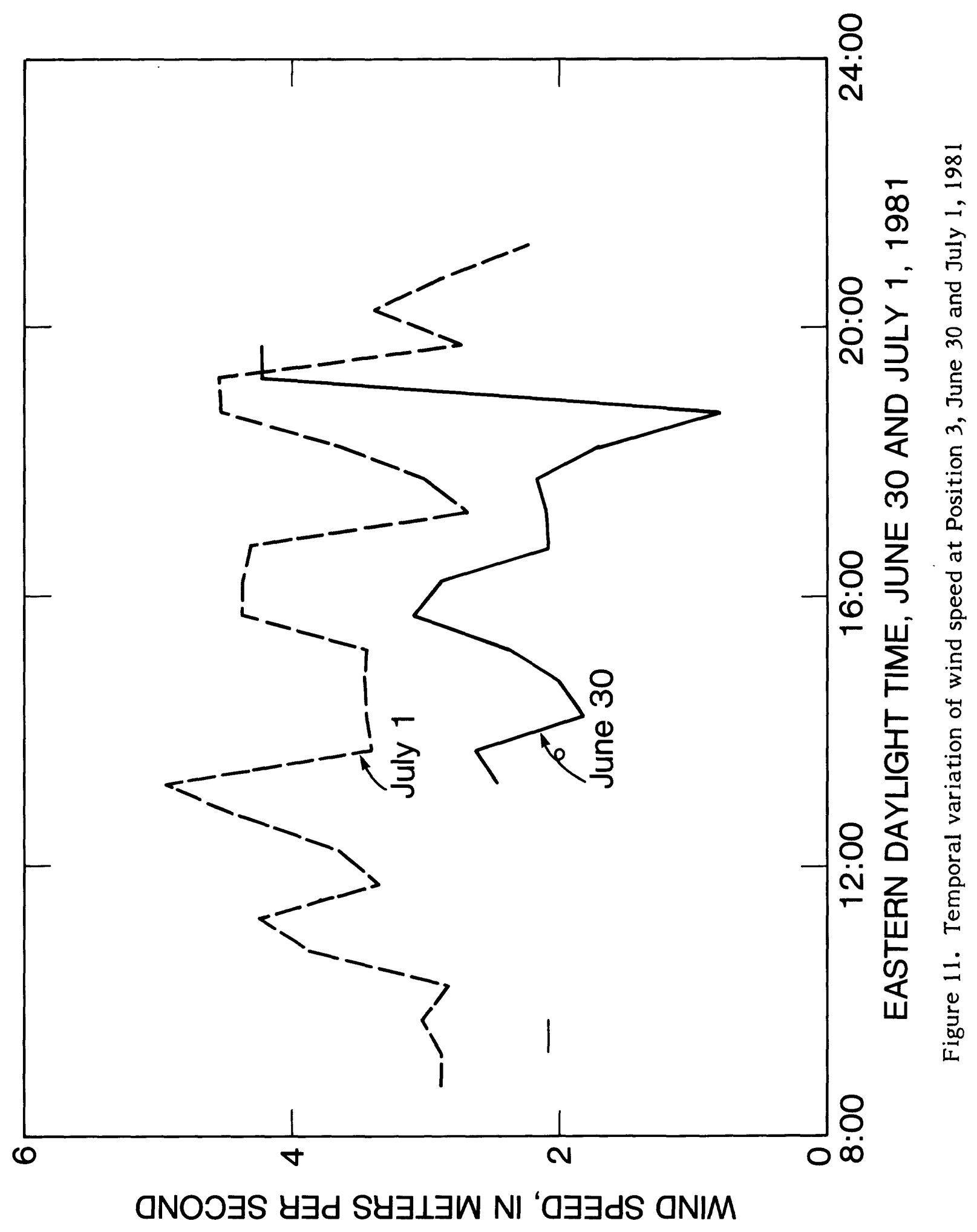




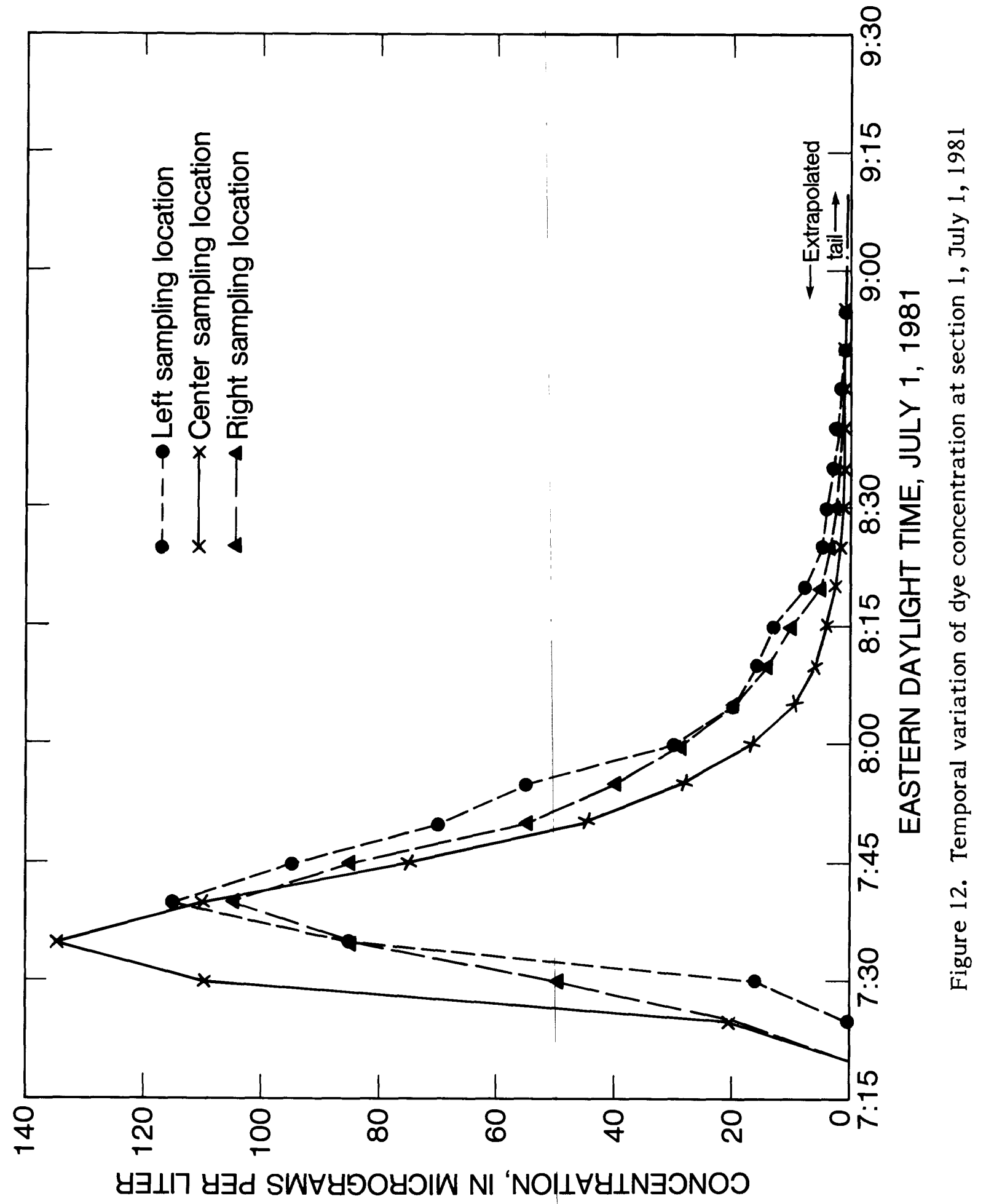




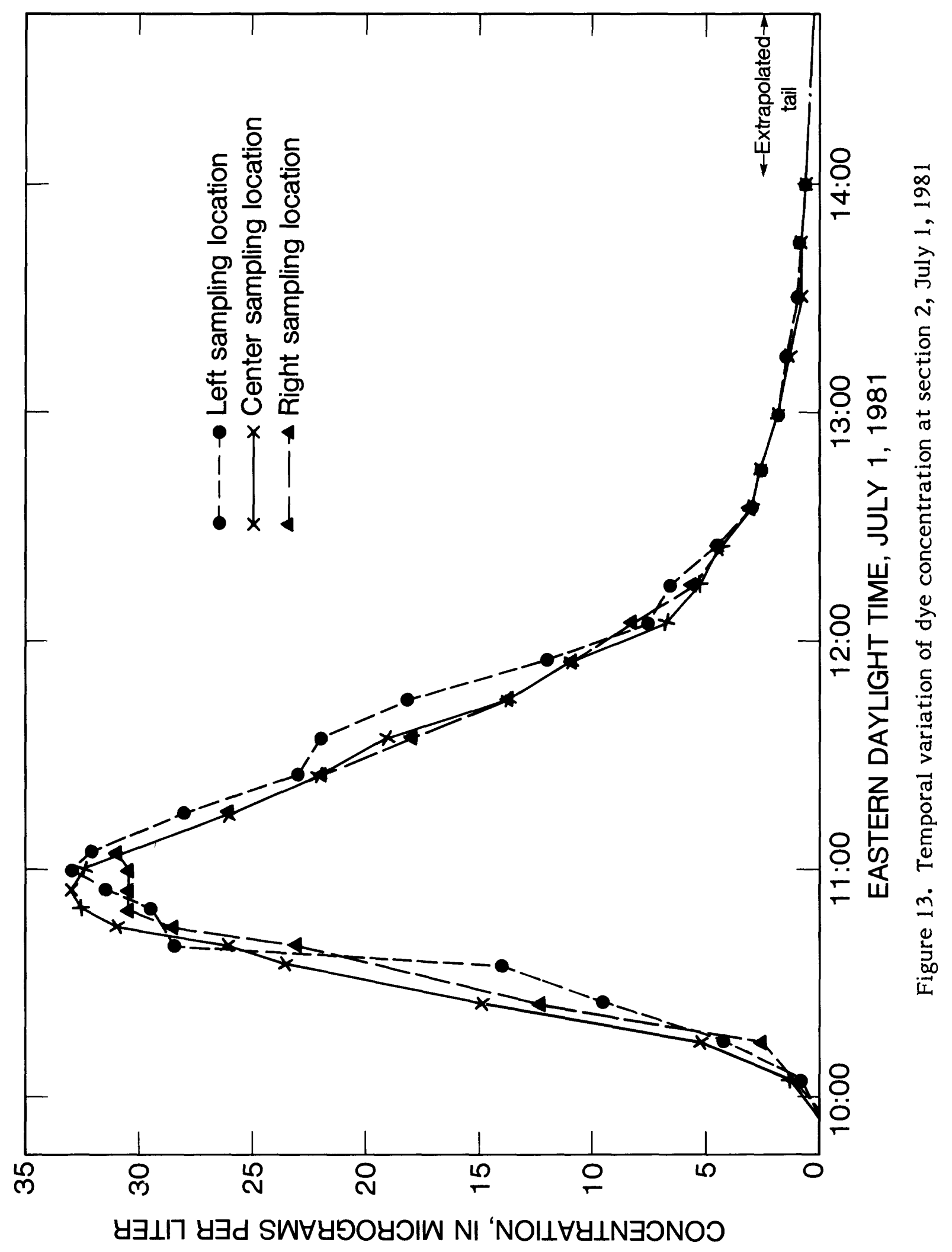




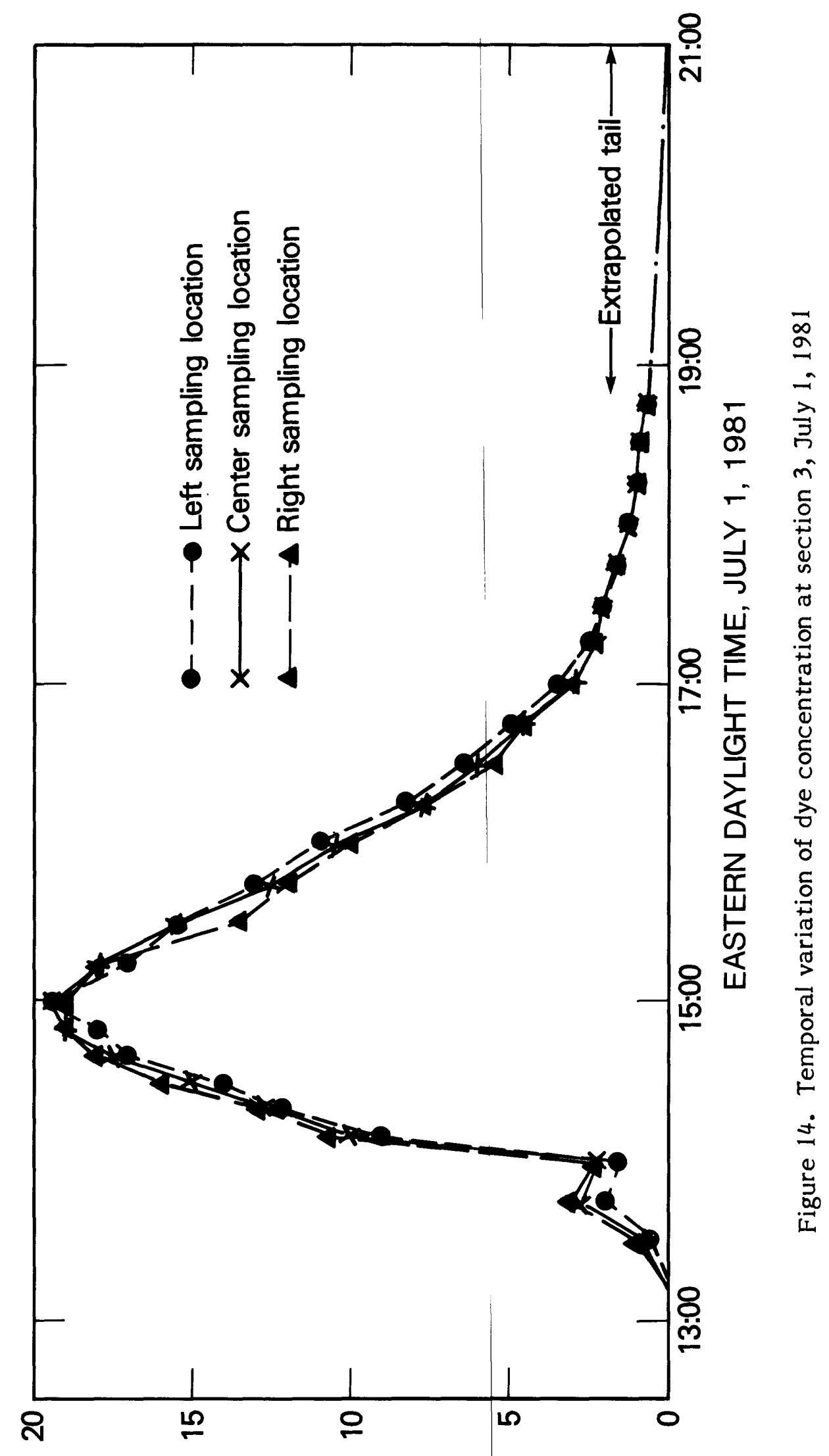

$y \exists \perp 7\urcorner$ y 
Figures 15,16 , and 17 show time series data for propane gas concentration at the three cross sections. These figures are comparable to figures 7,8 , and 9 , respectively, of the June 30 test. The beginning and end of the steady-state period for each section were determined from the dye cloud data of figures 12 , 13,14 , and are noted in each figure. All gas concentrations in figures 16 and 17 are seen to be at steady-state, except the one sampled at 10:00 p.m. at section 3. Random variation of these concentrations is on the order of \pm 5 percent of the mean and is about the same as in the June 30 test. Also, the transverse variation of gas concentration within a cross section was not discernible in the July test as it was not in the June 30 test.

As for the data at section 1 shown in figure 15 , one notices that a 17 percent discrepancy in concentration exists between the set of samples collected before 11:00 a.m. and those after 11:00 a.m. In view of all other data, which display steady-state values within a few percent variation, it is obvious that one of the two sets of samples was erroneous. Causes for this unexpected result at section 1 were investigated by reviewing field notes, discussions with field personnel, and reanalyses of spare gas samples at the Central Laboratory. The conclusion was that the gas samples collected at section 1 on July 1 were not properly handled after 11:00 a.m. when a new field member took over the sampling. This was due to inadequate instruction given to him concerning the need for avoiding air bubbles and for immediate sealing of the gas samples. Further discussion on this sampling mishap will be given in the chapter "Discussion."

Therefore, the steady-state gas data at section 1 , the July 1 test, to be used for analysis are limited to those samples collected before 11:00 a.m. Gas data obtained after 11:00 a.m. are shown in figure 15 to illustrate the magnitude 


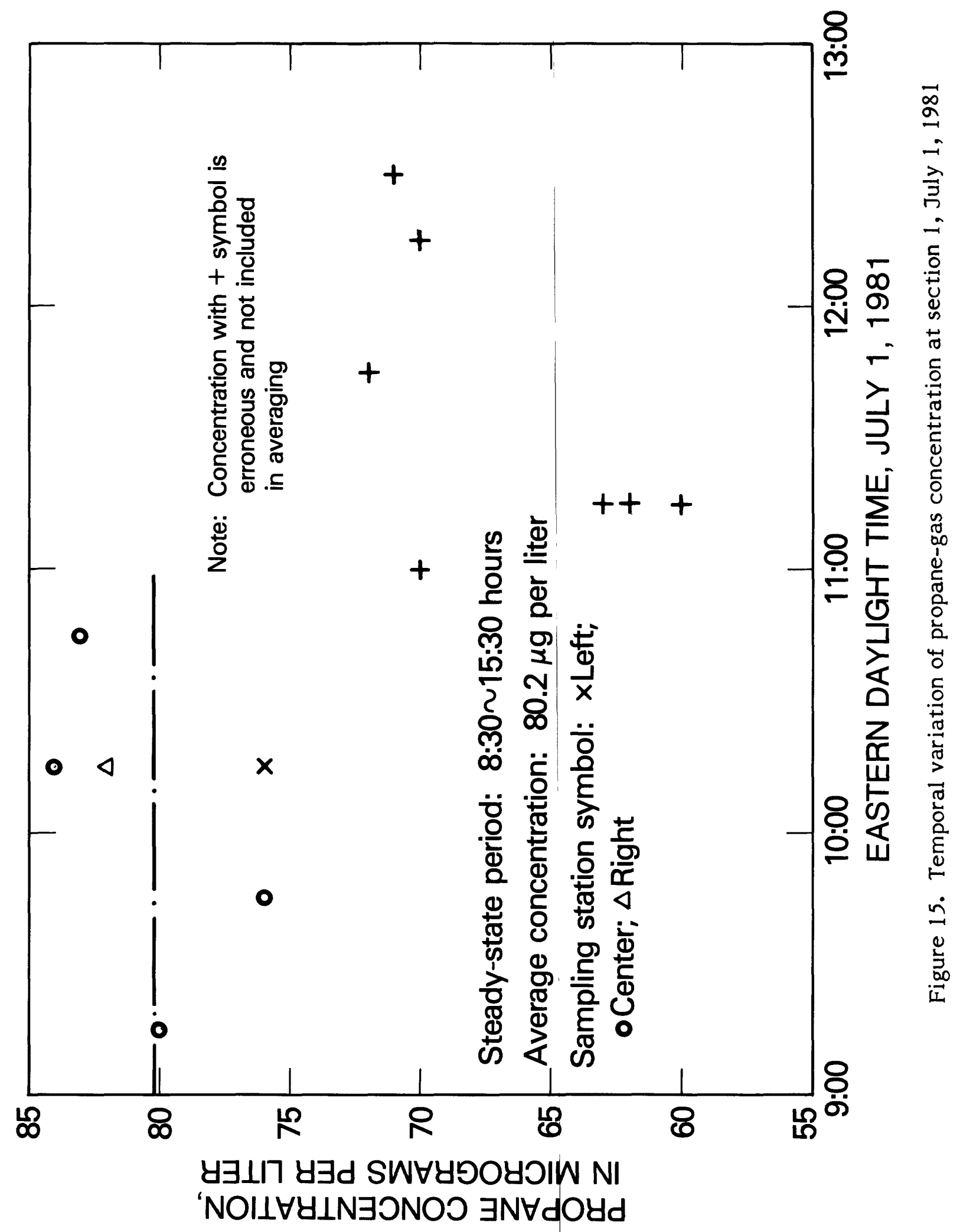




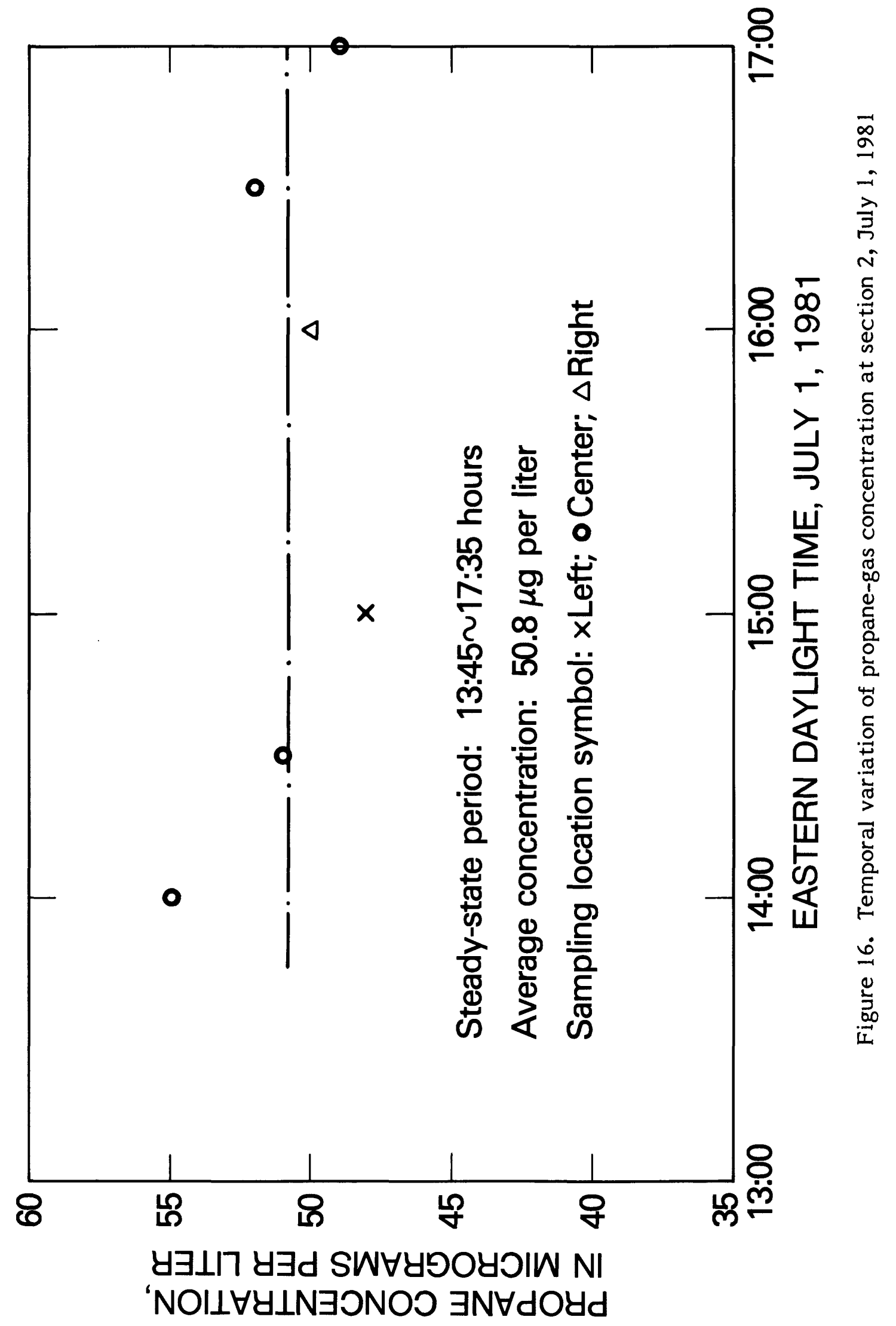




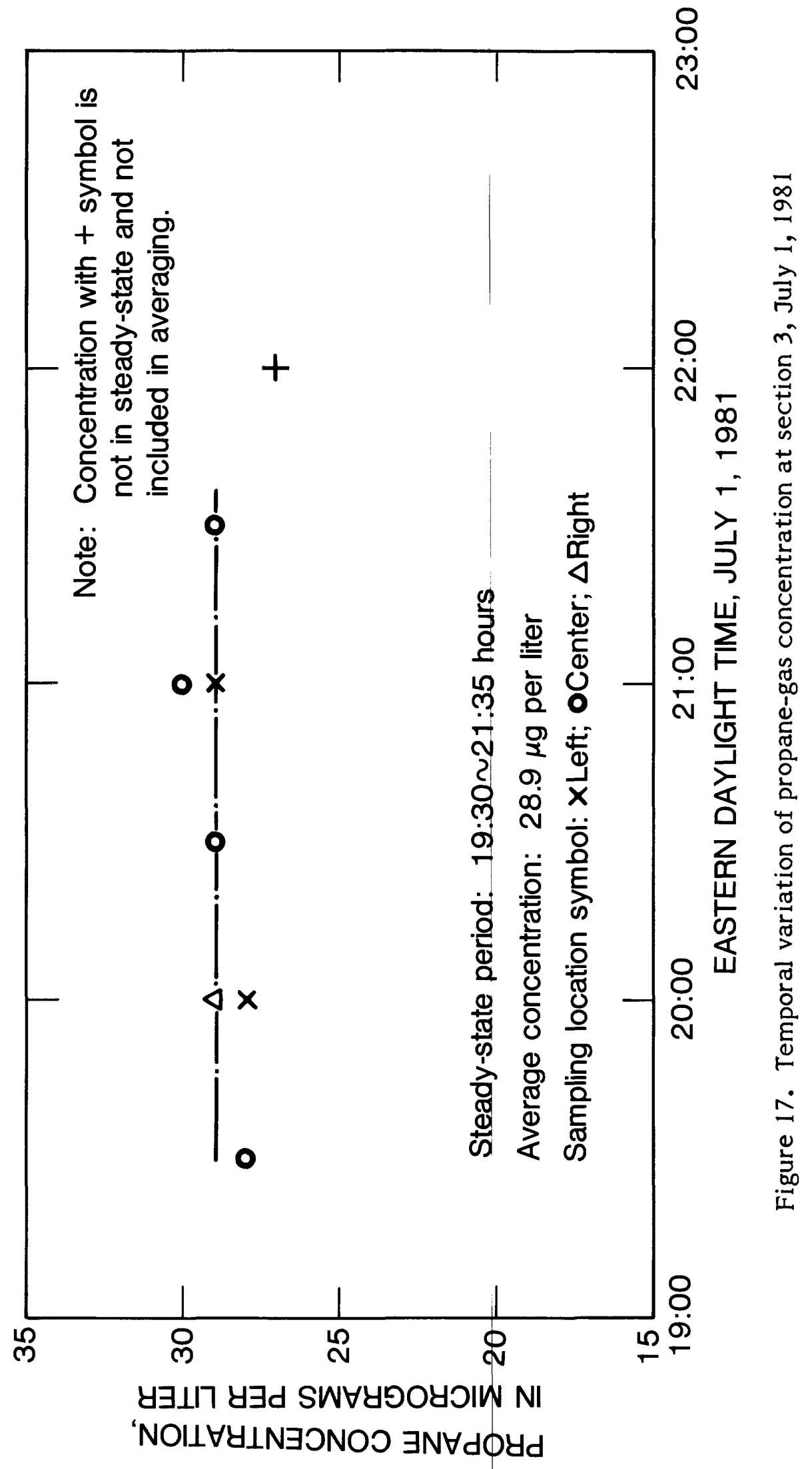


of error one could anticipate from improper sealing of septum cap vials. As stated previously, discharge, channel geometries, and water temperature data for the July 1 test are tabulated in table 1.

Table 3 shows the wind speed and wind direction data for the July 1 test. POS. 1 , POS. 2 and POS. 3 are the same as for the June 30 test and shown in figure $3 \mathrm{~A}$. The second station, operated only on July 1 , has POS. 4 and POS. 5 , and WIND 3, which were described previously and also illustrated in figure 3B. The wind speed at POS. 1 on July 1 is illustrated in figure 10 for comparison with that of June 30. The wind speed at POS. 3 for July 1 is similarly compared with June 30 in figure 11. Figure 18, on the other hand, illustrates wind speed variations on July 1 observed at POS. 4 of the new station located $8.5 \mathrm{~km}$ upstream of the mouth or between sections 1 and 2 as described previously.

\section{October $20-21,1981$, Test}

Figures 19, 20, 21 present dye concentration versus time data observed at the three cross sections. Each figure contains two dye curves, one observed from the October 20 dye injection and the other from the October 21 injection as described in the previous chapter. Note that the long tail of dye cloud was

carefully monitored to the level of $0.05{\mu \mathrm{gL}^{-1}}^{-1}$ for the October 20 dye injection. The extrapolation of tail was done only for the October 21 dye data.

The top figures of figures 22,23 , and 24 illustrate time series data of propane gas concentration observed at section 1, 2, and 3, respectively. Because the October test employed a 24-hour continuous gas injection, the duration of steadystate gas concentration was supposed to continue for 23 hours at section 1, 22 hours at section 2, and 21 hours at section 3 . 


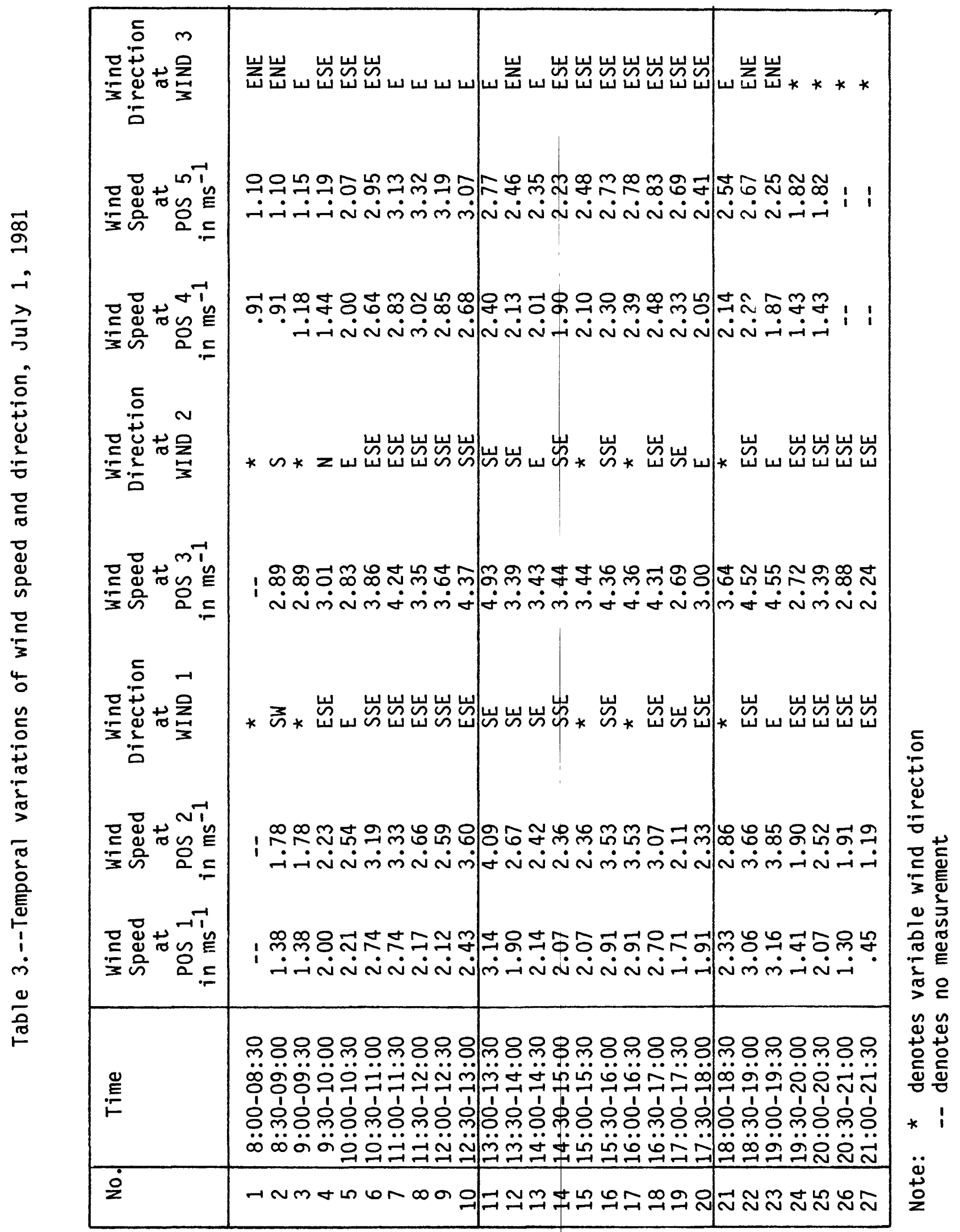




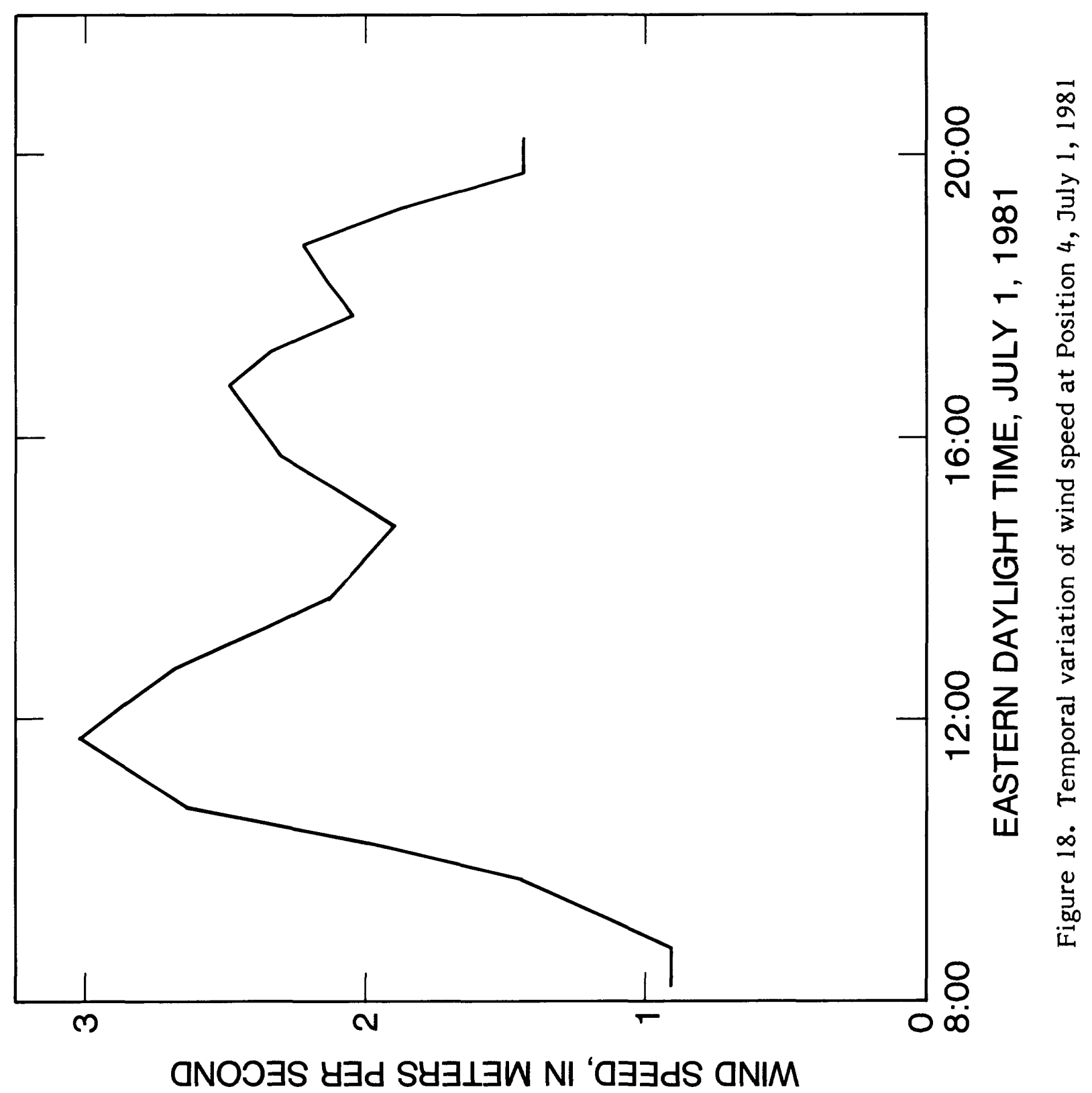




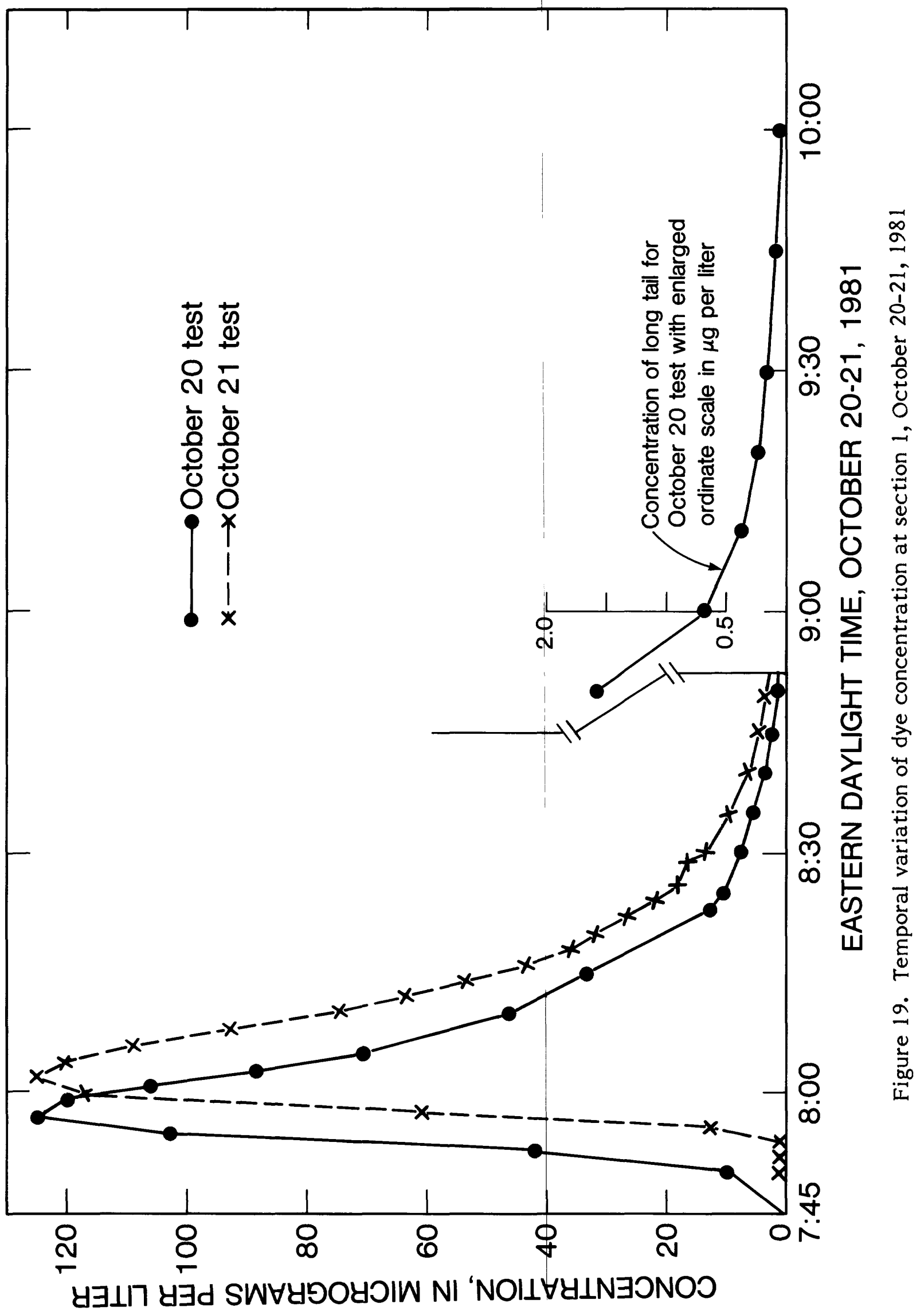




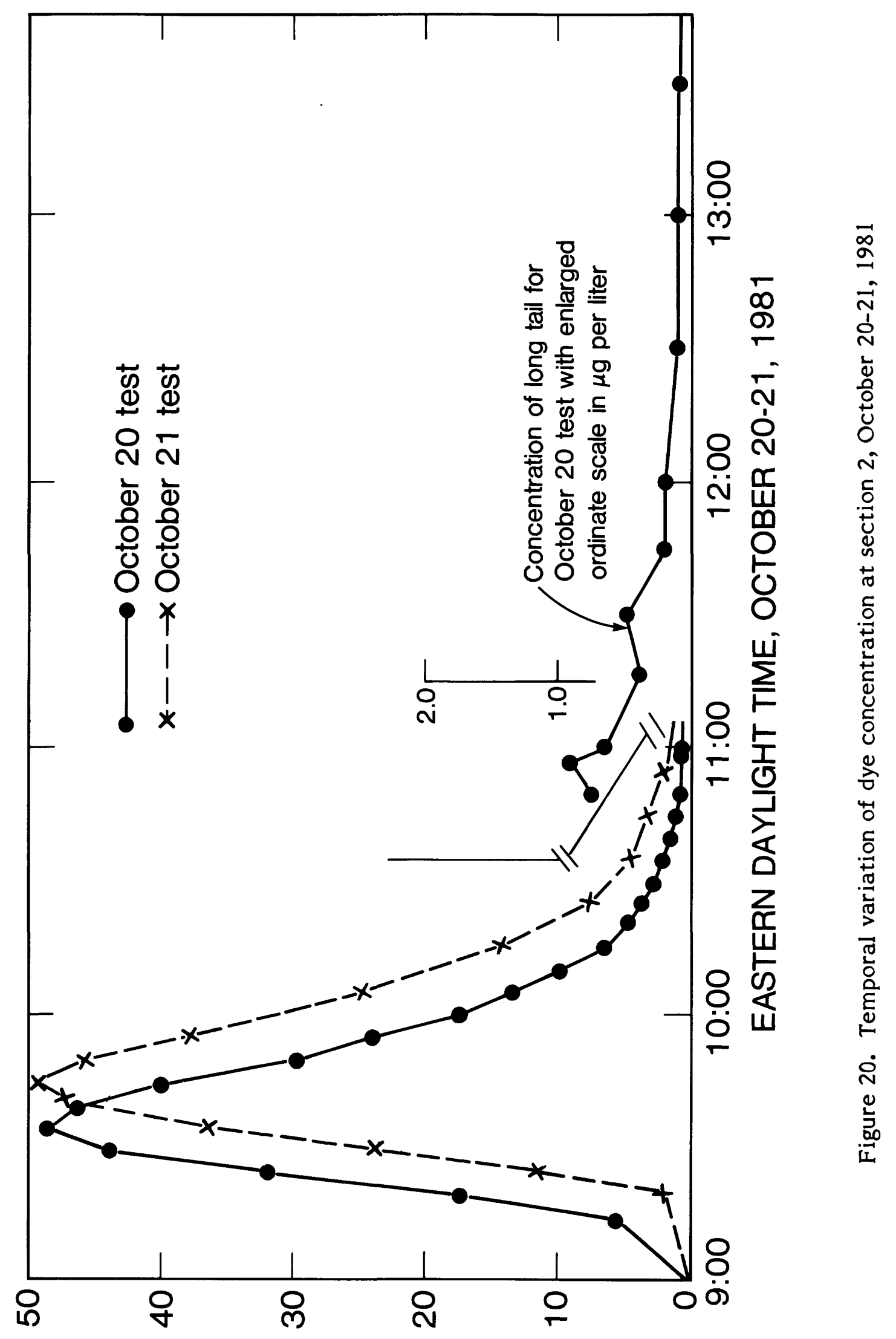

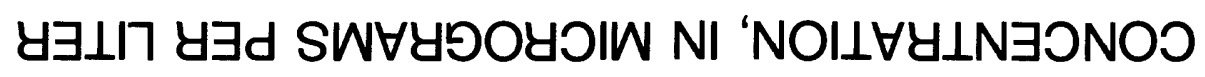




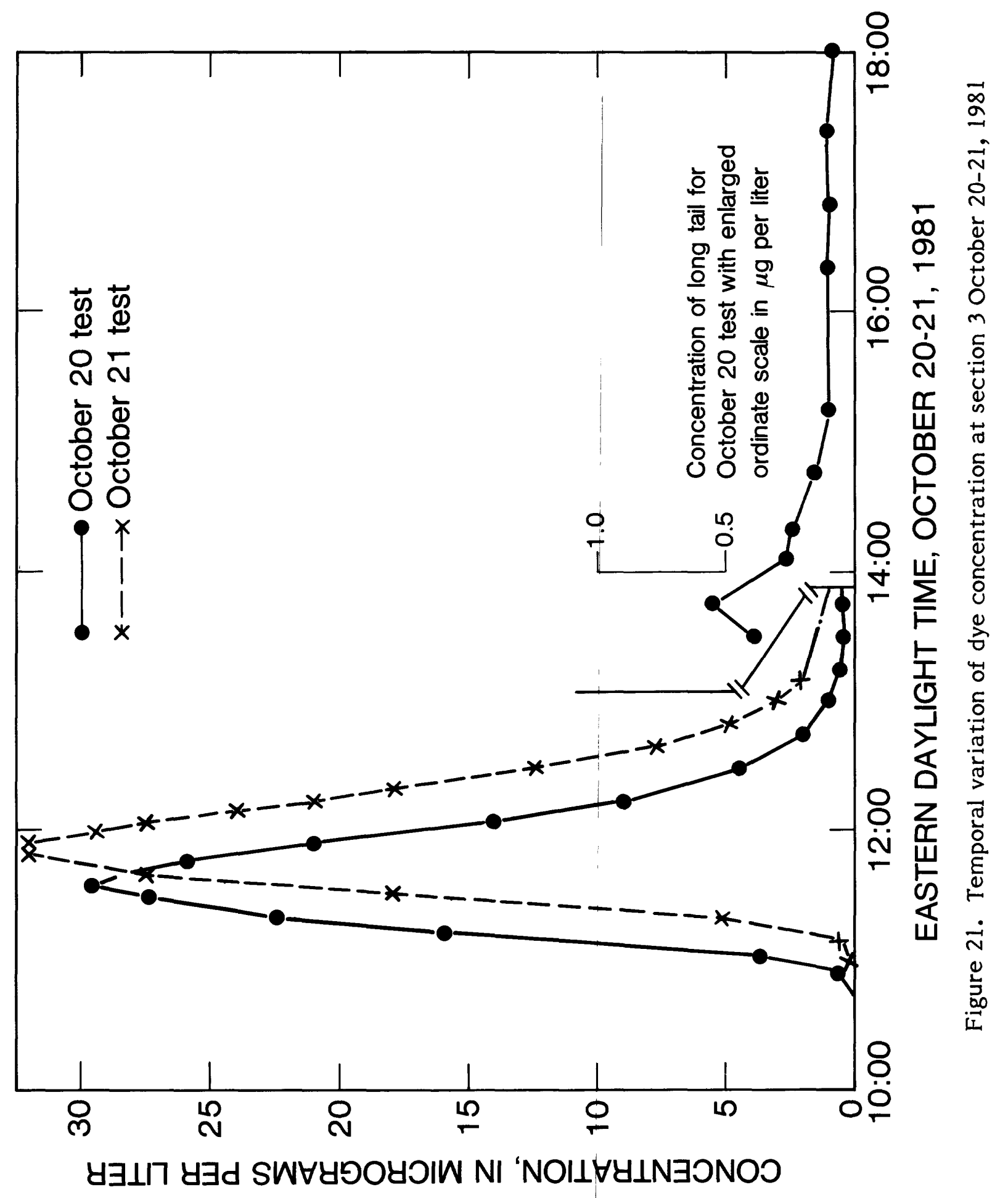




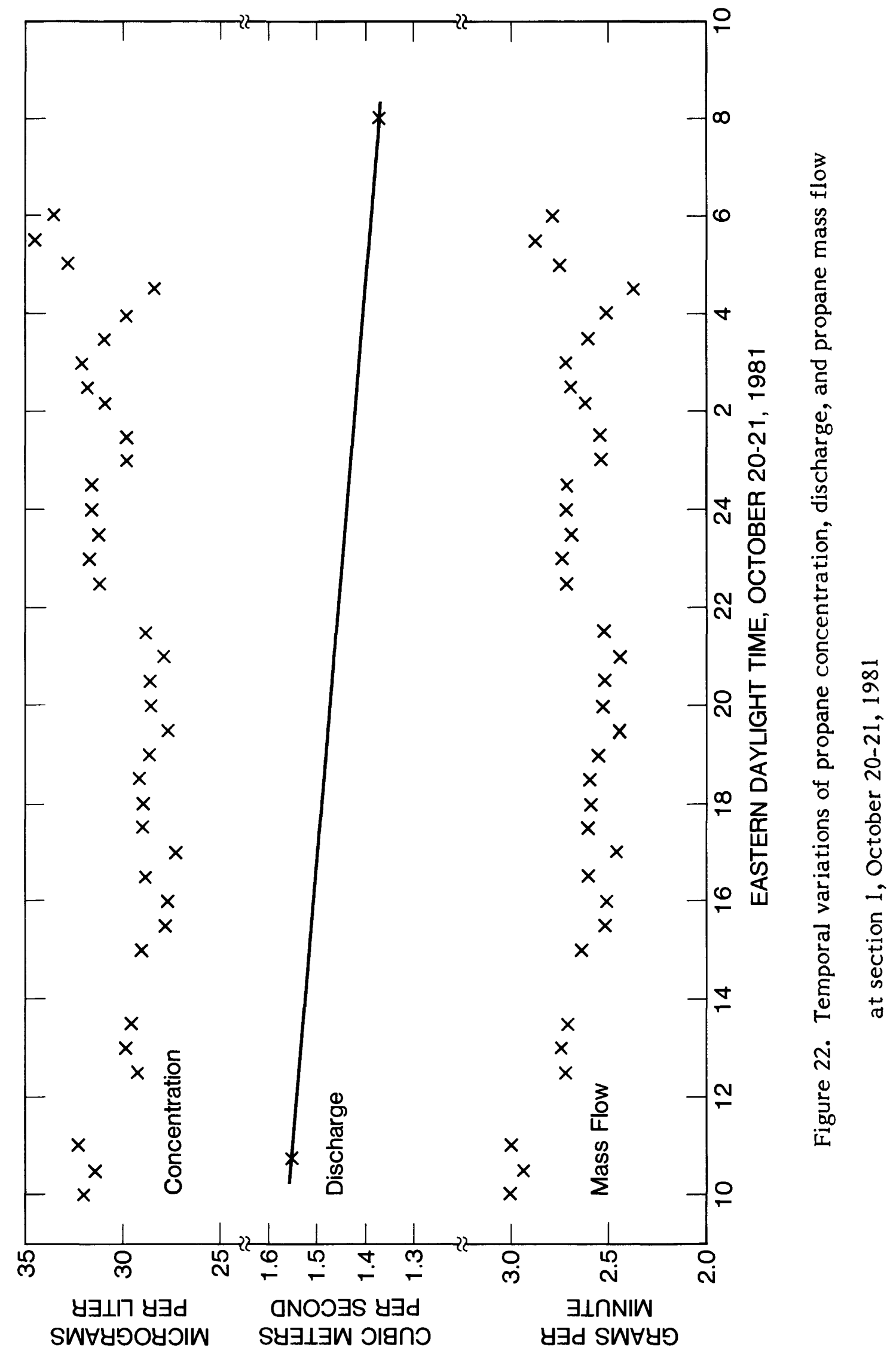




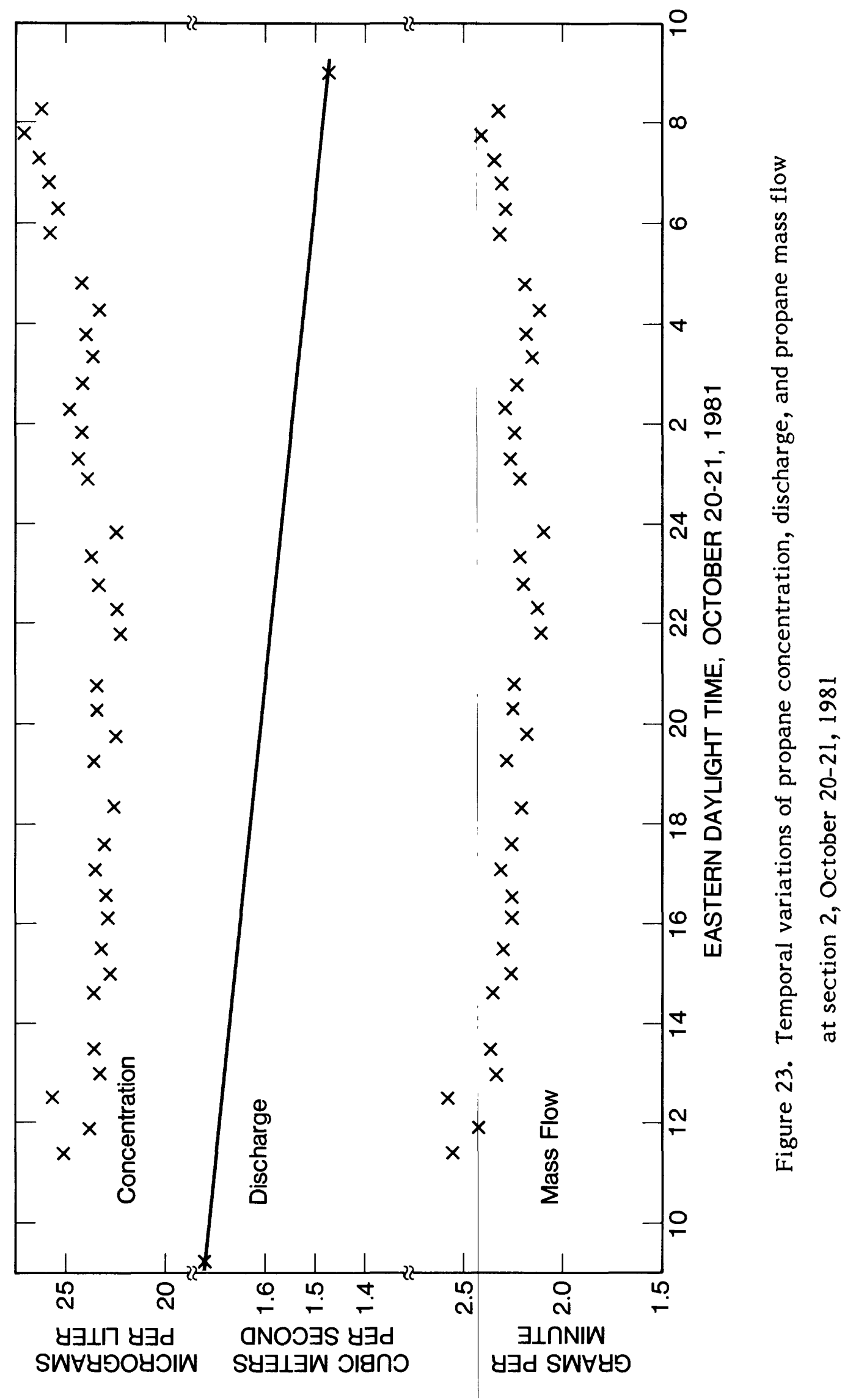




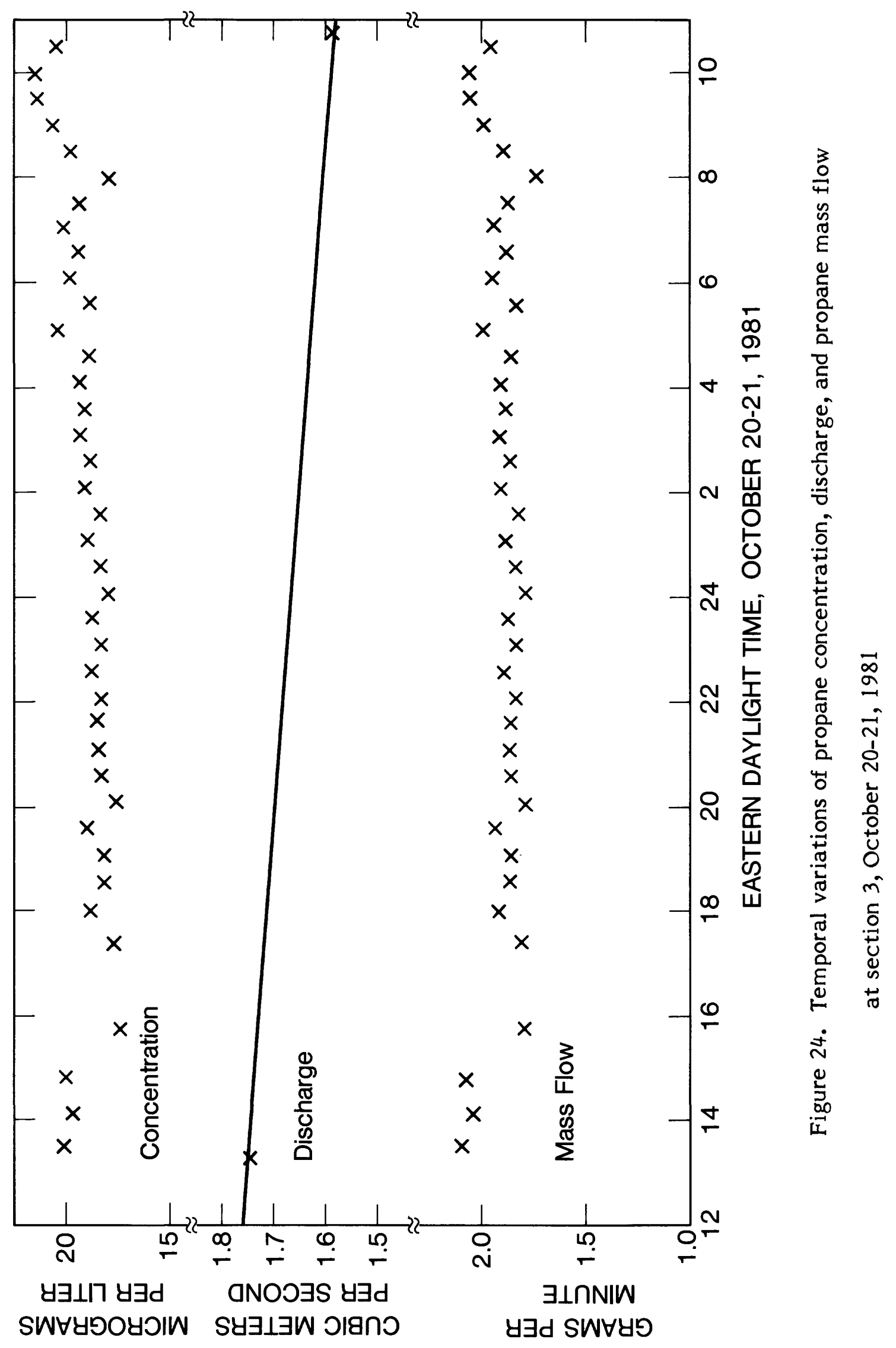


Even though the actual sample collection period did not exactly coincide with the steady-state period at every section, the large number of gas measurements in the October test present a better visual demonstration of the steady-state tracer method than those of the summer tests. Use of the dissolved gas sampler in the October test was helpful in reducing the number of discarded gas samples containing air bubbles. In comparison, the proportion of discarded gas samples was higher in the summer tests.

The river discharge in the October test did not remain as steady as in the summer tests. Table 4 lists the discharge and channel geometries as measured at each cross section on both days of the October test. Also listed in table 4 are time varying water temperature data at these cross sections.

When the discharge declined 10 percent or more over a 24-hour period, it is more logical to consider the mass flow rate, $\mathrm{QC}$, as suggested by eqs. 11 and 15 , rather than just the concentration, C. Because the observed change of water surface elevation was gradual over the 24-hour period, the channel discharge was assumed to vary linearly with time; the relation of $\mathrm{Q}$ with time at section 1,2 , and 3 is shown in the middle part of figures 22,23 , and 24 , respectively. This assumption also is supported by the recession of measured discharge at section 3 between October 19 and 21 . The mass flow rate of dissolved propane gas, QC, was computed as the product of concentration and discharge at a given time at a given cross section. The mass flow rate is plotted against time at the bottom of figures 22,23 , and 24 .

Particularly noticeable in these figures is the remarkable steadiness of QC observed at section 3 for a period of 16 hours starting at 4:00 p.m., October 20 , and ending at 8:00 a.m., October 21 . As one moves upstream to sections 
Table 4.--Discharge, channel geometries, and water temperature at three cross sections, October 20-21, 1981.

\begin{tabular}{|c|c|c|c|c|c|c|c|}
\hline & Date & Time & $\begin{array}{c}\text { Discharge } \\
\\
Q \\
\text { in } \mathrm{m}^{3} \mathrm{~s}^{-1}\end{array}$ & $\begin{array}{l}\text { Cross- } \\
\text { sectional } \\
\text { area } \\
\mathrm{A} \\
\text { in } \mathrm{m}^{2}\end{array}$ & $\begin{array}{c}\text { Surface } \\
\text { Width } \\
\text { B } \\
\text { in } m\end{array}$ & $\begin{array}{l}\text { Depth } \\
A / B \\
\text { in } m\end{array}$ & $\begin{array}{c}\text { Velocity } \\
Q / A \\
\text { in } \mathrm{ms}^{-1}\end{array}$ \\
\hline \multirow[t]{2}{*}{ Sec. 1} & 0ct. 20 & $10: 45$ & 1.55 & 5.30 & 11.3 & 0.47 & 0.29 \\
\hline & oct. 21 & $08: 00$ & 1.37 & 5.00 & 11.3 & 0.44 & 0.27 \\
\hline \multirow[t]{2}{*}{ Sec. 2} & oct. 20 & $09: 15$ & 1.72 & 5.08 & 8.5 & 0.60 & 0.34 \\
\hline & 0ct. 21 & $09: 00$ & 1.47 & 4.81 & 8.5 & 0.56 & 0.31 \\
\hline \multirow[t]{2}{*}{ Sec. 3} & oct. 20 & $13: 15$ & 1.74 & $5: 11$ & 11.6 & 0.44 & 0.34 \\
\hline & 0ct. 21 & $10: 45$ & 1.59 & 5.65 & 12.2 & 0.46 & 0.28 \\
\hline
\end{tabular}

\begin{tabular}{|c|c|c|c|c|c|c|}
\hline \multicolumn{7}{|c|}{ Water temperature in ${ }^{\circ} \mathrm{C}$, October $20-21,1981$} \\
\hline Time & $07: 25$ & $10: 59$ & $12: 00$ & $13: 00$ & $14: 30$ & $20: 30$ \\
\hline Sec. 1 & 6.5 & 7 & 7.5 & 8 & 8.5 & 8.5 \\
\hline Sec. 2 & -- & -- & 7.5 & 9 & 9 & -- \\
\hline Sec. 3 & -- & - & -- & 9 & 9.5 & -- \\
\hline Time & $21: 00$ & $24: 00$ & $02: 00$ & $04: 00$ & 08:00 & $10: 00$ \\
\hline Sec. 1 & 8.5 & 9 & 9.5 & 10 & 9 & -- \\
\hline Sec. 2 & -- & -- & -- & -- & 9 & 9.5 \\
\hline Sec. 3 & -- & -- & -- & -- & -- & 9 \\
\hline
\end{tabular}


2 and 1, however, the QC values appear to fluctuate more. Because the channel flow was slightly unsteady and section 1 was located rather close to the point of uniform mixing in the October test, the effect of advection such as meandering and variable travel time was probably responsible for the fluctuations of gas concentration at the upstream cross sections. Such fluctuations were mostly smoothed out by the diffusive effect when gas tracers reached section 3 . One may note, however, that some high concentrations observed at section 1 between 10:00 and 11:00 a.m. October 20, appear to be advected downstream to sections 2 and 3 without being smoothed. The cause of this anomaly is not known. The standard deviation for the QC values at all three sections was less than 4 percent of the mean values.

In table 5 the wind speed and wind direction are shown for the October 20-21 test. The wind measurement station, located approximately $7 \mathrm{~km}$ upstream from the mouth of the Cowaselon Creek at Oneida Lake, is $200 \mathrm{~m}$ downstream from section 2. For this station, POS. 1 through POS. 5 refer to the wind measurement positions as illustrated in figure $3 \mathrm{C}$. Figure 25 shows the wind speed variation obtained at POS. 2 , that is, $0.35 \mathrm{~m}$ above the water surface at midstream and at POS. 5, that is, $6.30 \mathrm{~m}$ above the ground level of the bank. Comparison of these two graphs shows again that the $3.5 \mathrm{~m}$ high banks of the Cowaselon Creek provided considerable sheltering of the water surface. The same can be observed in table 5 by comparing the wind directions recorded just above the water surface with the wind directions recorded $6.3 \mathrm{~m}$ above the bank. Inspection of the temperatures in table 5 shows that both air and water temperatures displayed a diurnal variation with the maximum around 2:00 p.m. and the minimum at night. However, as expected, the variation in the air was much larger than in the water, the respective amplitudes being approximately $8^{\circ} \mathrm{C}$ and $2^{\circ} \mathrm{C}$. 


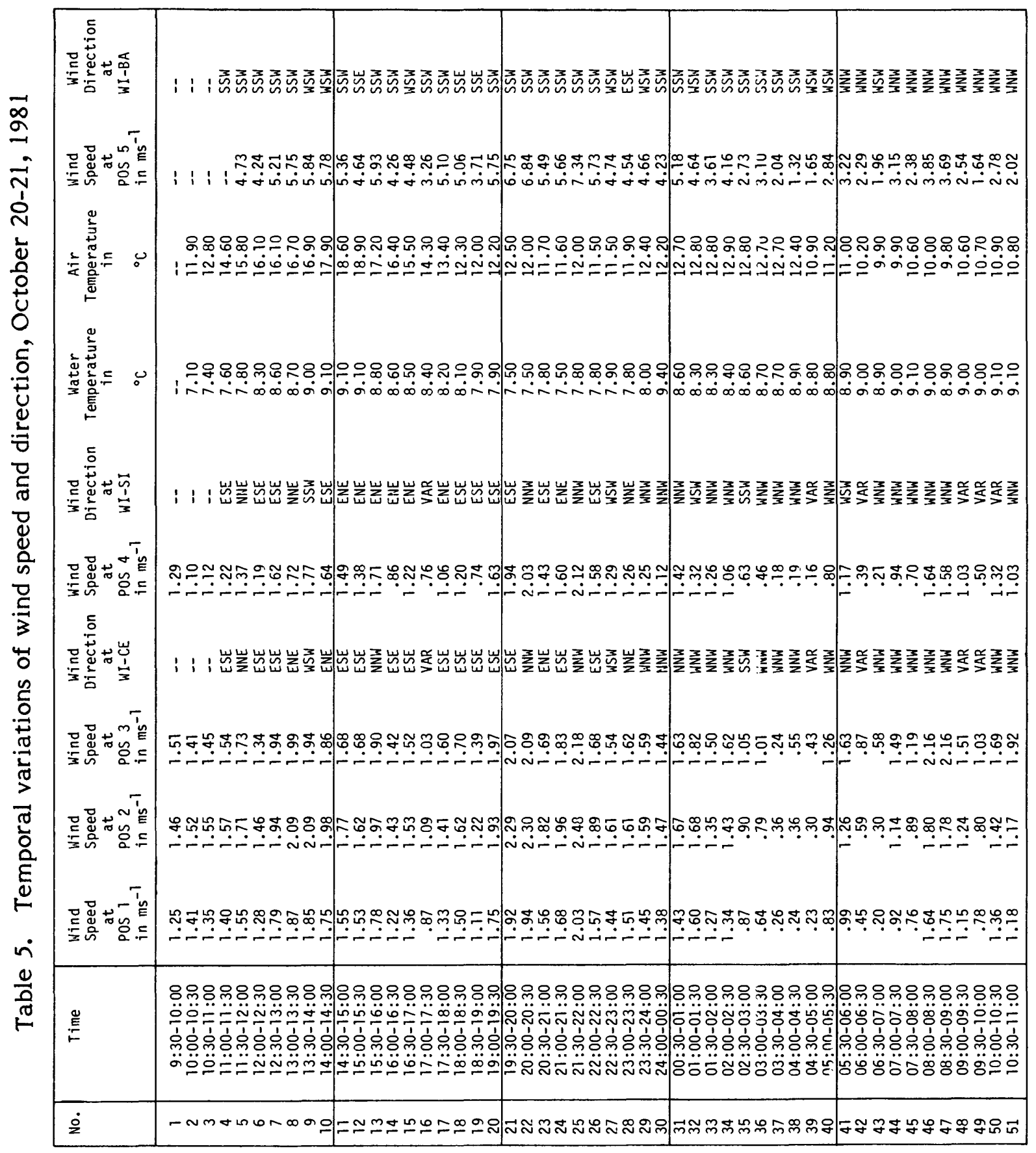




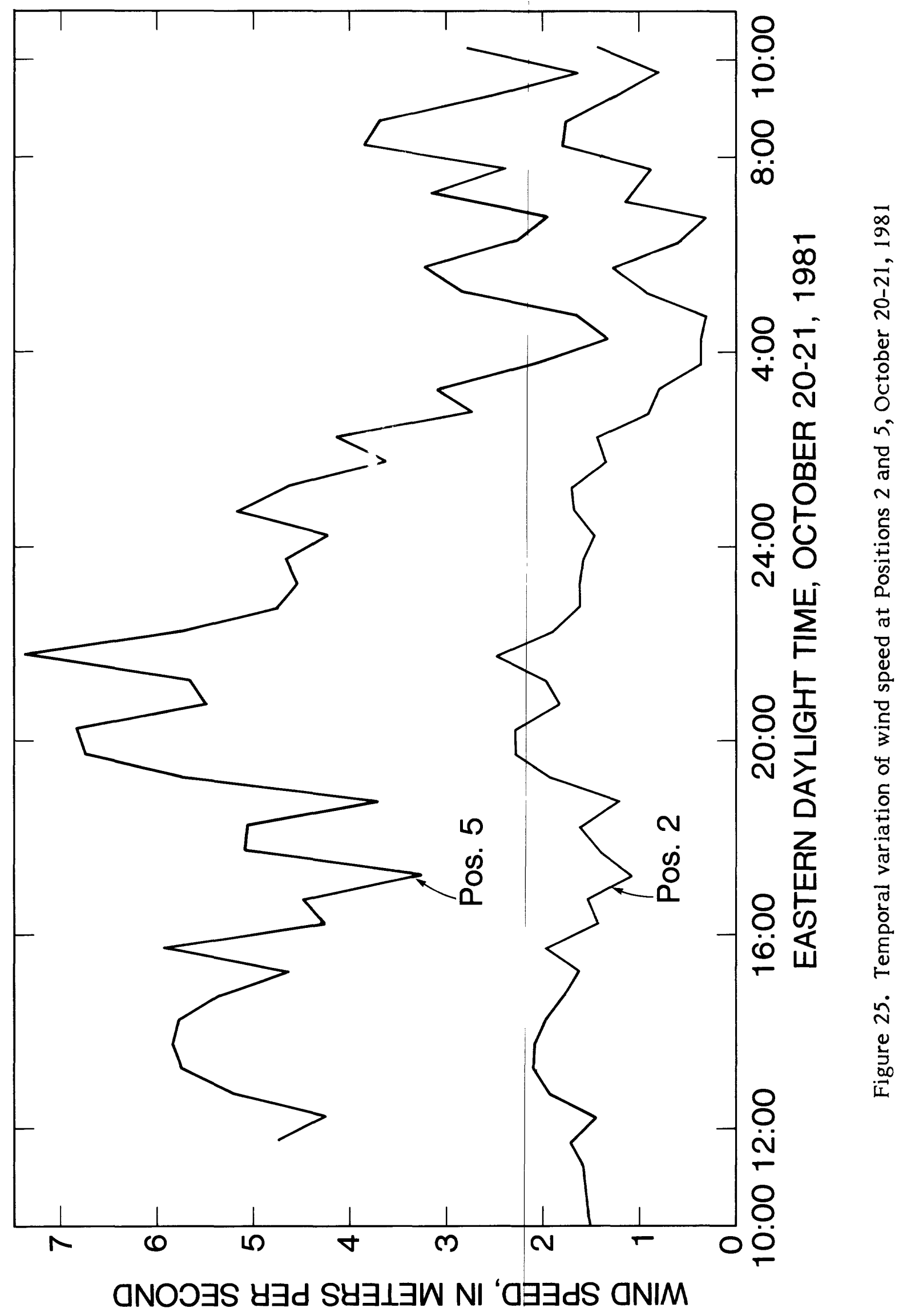




\section{ANALYSIS OF DATA}

\section{Calculations from Dye Data}

Because rhodamine WT dye employed in field tests is not a truly conservative tracer, some explanations are needed to justify extraction of the information from dye data. As for the decay of dye in water, the fractional loss, $L(x)$, relative to the injected mass, $M_{r}$, will be assumed to remain constant during the passage of dye cloud through a cross section. It is calculated by

$$
L(x)=\frac{M_{r}-Q(x) f_{0}^{\infty} C_{r}(x, t) d t}{M_{r}}
$$

where $\mathrm{C}_{\mathrm{r}}$ is the concentration of rhodamine $\mathrm{WT}$. The relation between the nonconservative dye and the hypothetical conservative tracer may be represented by eq. 4 by substituting $C_{r}$ and $M_{r}$ to $C$ and $M$, respectively. In view of eq. 16, however, the exponential decay term of eq. 4, which represents the fractional revovery, is also constant and equal to $(1-L(x))$. Assuming $M_{C}=M_{r}$, eq. 4 is simplified for the dye as

$$
C_{C}(x, t)=\frac{C_{r}(x, t)}{1-L(x)}
$$

For a dye cloud duration much less than 24 hours, eq. 17 is a very reasonable approximation because the dye loss involved is normally small (Smart and Laidlaw, 1977).

Another problem with a dye concentration-time curve is how to handle the long tail. Recent studies of the solute transport mechanics in natural channels indicate overhwelmingly that the long tail is due to the mechanism of solute storage in the dead water areas of channel boundaries. For example, the simulation 
study by Bencala and Walters (1983) shows that the long tail of a chloride tracer plume behaves as if it is due to a first-order decay. Apparently a slow diffusive transfer of tracer from the storage area to the main channel is the responsible mechanism, which causes the logarithm of concentration to decrease as a linear function of time.

In the June and July tests, data collection for the long tail was continued until the concentration was about 1 percent of the peak dye concentraticn at section 1 and about 4 percent at sections 2 and 3. All of these tail data showed that there is one linear relation for the range of concentration between 70 and 10 percent of the peak dye concentration and another one with a smaller slope for the concentration range between 10 and 1 percent of the peak concentration. In the October 20 dye injection, the tail below 1 percent of the peak concentration was monitored extensively and this range of low concentrations was observed to form a third linear relation with an even smaller slope, even though the scatter of data was considerable due to the extremely low level of concentration, which was close to the limit of fluorometer detection.

The effect of a long tail on low-order moments of the concentration-time distribution was studied empirically from all data. It was determined that the part of the tail with concentrations less than 2 percent of the peak did not significantly affect calculation of the 0 th and 1st order moments. Therefore, all concentrationtime curves near the trailing edge of dye cloud were extrapolated by means of a straight line drawn through a plot of the logarithm of concentrations below 10 percent and above 1 percent of the peak against time. These extrapolated data points are included in figures $4,5,6,12,13,14,19,20$, and 21 . Also, the beginning of steady-state gas concentration, $t_{D}$, was approximated by the time 
when the dye concentration declined to 2 percent of the peak. At this concentration point, the area under the concentration-time curve was about 98 percent of the area including the entire long tail. Thus at this time, the concentration was supposedly at 98 percent of the steady-state value according to the superposition principle.

Three moment-related quantities of a concentration-time curve are calculated by the following equations

$$
\begin{aligned}
& \text { Area of dye cloud: } \\
& a=\sum_{i=1}^{N} C_{r}(i) \Delta t(i)
\end{aligned}
$$

Mean time of dye cloud $\quad \bar{t}=\frac{1}{a} \sum_{i=1}^{N} t(i) C_{r}(i) \Delta t(i)$

(1st moment about $\mathrm{t}=0$ )

Variance of dye cloud: $\quad s^{2}(t)=\frac{1}{a} \sum_{i=1}^{N} t^{2}(i) C_{r}(i) \Delta t(i)-(\bar{t})^{2}$

(2nd moment about $\overline{\mathrm{t}}$ )

In the above equations, $C_{r}(i)$ is the dye concentration observed at time $t(i)$ after the injection. Notation $\Delta t(i)$ is the interval of sampling given by $y(t(t+1)-t(i-1))$. The summation, $\sum_{i=1}^{N}$, indicates that the integer index, $i$, covers all of the samples from the leading edge, $C_{r}(1)=0$, to the trailing edge, $C_{r}(N)=0$, of a dye cloud. Except for extrapolated data points on the tail, observed concentration vs time data were used in the calculation. The normalized response function, defined by eq. 5, was calculated in view of eq. $18-1$ as

$$
f(x, t(i))=\frac{1}{a} C_{r}(x, t(i))
$$

In order to see that $\bar{t}, s^{2}(t)$, and $f(x, t)$, calculated by eqs. 18-2, 18-3, and $18-4$, correctly represent those of conservative tracer, it is only necessary to substitute eq. 17 to eqs. $18-1,18-2,18-3$, and $18-4$, and note that the recovery term, $1-\mathrm{L}(\mathrm{x})$, cancels out between the numerator and denominator. 


\section{Calculation of Gas Desorption Coefficients}

Calculation of desorption coefficients by eqs. 11 and 15 is facilitated by converting the equations to working forms which do not involve the gas inflow rate, $m$, because the precise measurement of $m$ is impossible due to bubbling losses immediately downstream of the injection site. Writing eq. 11 for two cross sections, one upstream of the other, and eliminating $\mathrm{m}$, the following working form is obtained

$$
\frac{C_{u} Q_{u}}{C_{d} Q_{d}}=\frac{\int_{o}^{\infty} f(x, p) \exp (-K p) d p}{\int_{O^{\infty} f_{d}}^{\infty}(x, p) \exp (-K p) d p}
$$

where subscripts $u$ and designate upstream and downstream cross sections respectively. Likewise the working form of eq. 15 is obtained as

$$
\frac{C_{u} Q_{u}}{C_{d} Q_{d}}=\exp \left\{K\left(\bar{t}_{d}-\bar{t}_{u}\right)\right\}
$$

in which $\bar{t}_{d}$ and $\bar{t}_{u}$ replace $x_{d} / U$ and $x_{u} / U$ of eq. 15, respectively.

Eq. 15 ' provides a direct means of calculating the desorption coefficient, $\mathrm{K}$, from observed data on steady-state gas concentration, C, channel discharge, $Q$, and the average travel time, $\overline{\mathrm{t}}_{d^{-}} \overline{\mathrm{t}}_{\mathrm{u}}$, which may be determined from $\overline{\mathrm{t}}$ defined by eq. 18-2. On the other hand, the evaluation of $\mathrm{K}$ by means of eq. 11' requires the calculation of $f(x, t(i))$ values defined by eq. 18-4. A short computer program is needed to carry out the numerical integration, $\sum_{i=1}^{N} f(x, t(i)) \exp (-K t(i)) \Delta t(i)$, for both upstream and downstream cross sections. The process involves calculations employing a number of trial $\mathrm{K}$ values estimated from the one determined by eq. $15^{\prime}$. When the ratio of numerical integrations on the right hand side of eq. 11' agrees the best with the left hand ratio of observed data, this trial $K$ is considered as the correct desorption coefficient. 
June 30,1981 , Test

Three moment-related quantities calculated from dye data by means of eq. 18-1, 18-2, 18-3 are tabulated in table 6 for all transverse sampling locations. The area of dye cloud, $a$, is the 0th-order moment of the distribution and is related to the injection dye mass. When the average of a in table 6 is multiplied by $Q$ listed in table 1 for each cross section, observed mass values are $98.7,92.8$, and 97.3 grams at section 1,2 , and 3, respectively. Because of the exact weight of dye mass injected was not measured, the fractional recovery, (1-L(x), could not be calculated from the recovered mass, On the other hand, the loss of dye at sections 2 and 3 relative to section 1 is 6 and 1.4 percent, respectively. Since more dye was recovered at section 3 than at section 2, the calculation must have been influenced predominantly by measurement errors.

Another aspect of the area, a, in table 6 is its difference among three transverse locations of a cross section. Because of the principle of superposition, the area, a, is seen to be proportional to the steady-state concentration of dye, if the dye were injected at a constant rate for a long time. Noting that the maximum transverse variation is about 5 percent at section 2 , it may be concluded that the uniform transverse mixing of dye tracer under steady-state condition was realized at all cross sections. This conclusion applies as well to the non-conservative gas tracer, which is subject to the same advection and mixing as the dye tracer.

The mean time of dye cloud, $\bar{t}$, in table 6 is the 1st-order moment of the distribution and represents the time of travel from the injection site to a particular sampling location. The difference in $\overline{\mathrm{t}}$ at three transverse locations is as large as 13 percent at section 1 but decreases to about 1 percent at sections 2 and 3. This is a typical pattern in open channel dispersion. The dye clouds 
Table 6.--Moment-related properties of dye cloud, June 30,1981

\begin{tabular}{|lccc|}
\hline \multicolumn{4}{|c|}{ Area of dye cloud, a, in $\mu g \cdot L^{-1} \cdot \mathrm{hr} .($ eq. $18-1)$} \\
\hline Sec. 1 & Sec. 2 & Sec. 3 \\
Center & 48.6 & 44.4 & 43.0 \\
Right & 48.8 & 45.2 & 44.4 \\
\hline Average & 48.5 & 43.0 & 43.9 \\
\hline
\end{tabular}

\begin{tabular}{|c|c|c|c|}
\hline \multicolumn{4}{|c|}{ Mean time of dye cloud, $\bar{t}$, in $\mathrm{hr}$. (eq. 18-2) } \\
\hline & Sec. 1 & Sec. 2 & Sec. 3 \\
\hline Left & 0.94 & 4.38 & 8.55 \\
\hline Center & 0.83 & 4.36 & 8.47 \\
\hline Right & 0.93 & 4.41 & 8.43 \\
\hline \multicolumn{4}{|c|}{ Travel time between cross sections, $\bar{t}_{d}-\bar{t}_{u}$, in $\mathrm{hr}$. } \\
\hline & Sec. 1 to 3 & Sec. 1 to 2 & Sec. 2 to 3 \\
\hline Left & 7.61 & 3.43 & 4.18 \\
\hline Center & 7.64 & 3.53 & 4.11 \\
\hline Right & 7.50 & 3.48 & 4.02 \\
\hline Average & 7.58 & 3.48 & 4.10 \\
\hline
\end{tabular}

\begin{tabular}{|lccc|}
\hline & \multicolumn{2}{|c|}{ Variance of dye cloud, $\mathrm{s}^{2}(\mathrm{t})$, in $^{2} \mathrm{hr}^{2}$ (eq. 18-3) } \\
\hline Left & Sec. 1 & Sec. 2 & Sec. 3 \\
Center & 0.0545 & 0.495 & 1.18 \\
Right & 0.0401 & 0.518 & 1.11 \\
& 0.0547 & 0.522 & 1.11 \\
\hline
\end{tabular}


at section 1, though they obtained a uniform transverse mass distribution, are still advected under the influence of local velocities so that the center dye cloud is moving downstream faster than the left or right dye clouds.

For the present purpose, the travel time between cross sections, $\bar{t}_{d}-\bar{t}_{u}$, is of more importance than the mean time of dye cloud. The third item in table 6 tabulates travel time between cross sections. The transverse variation of the travel time is seen to be less than 4 percent and the average travel time listed at the bottom is to be used in connection with eq. $15^{\prime}$.

The variance, $s^{2}(t)$, in table 6 is the 2 nd-order moment of the distribution with respect to the mean. This was calculated in order to estimate the dispersion coefficient, $\mathrm{D}$, of eq. 12 and the nondimensional number, $\alpha$, of eq. 14. The transverse variation in $s^{2}(t)$ is from 4 to 36 percent and is much larger than that for the 1st-order moments. The estimation of $\mathrm{D}$ and $\alpha$ will be discussed later in the analyses of the July 1 test, where the variances of the June dye clouds are combined with those of the July dye clouds.

The desorption coefficient was first calculated by eq. 15', which allows a direct calculation of $\mathrm{K}$ from the data. The gas concentration, $\mathrm{C}$, was taken as the arithmetic mean of data at steady-state shown in figures 7,8 , and 9 and $\mathrm{Q}$ was taken from table 1. As for $\overline{\mathrm{t}}_{\mathrm{d}^{-}} \overline{\mathrm{t}}_{\mathrm{u}}$, the averaged travel time given in the third item of table 6 was used. The calculated $\mathrm{K}$ values from eq. 15' are tabulated at the top of table 7.

As explained earlier, the evaluation of $\mathrm{K}$ by means of eq. $11^{\prime}$ was a trialand-error process employing the $f(x, t(i))$ vs $t(i)$ data calculated by eq. $18-4$. The best fit $\mathrm{K}$ values are tabulated as the second item in table 7 . Note that $K$ values are evaluated along the left, center, and right locations. This is because the 
Table 7.--Desorption coefficient of propane, June 30,1981

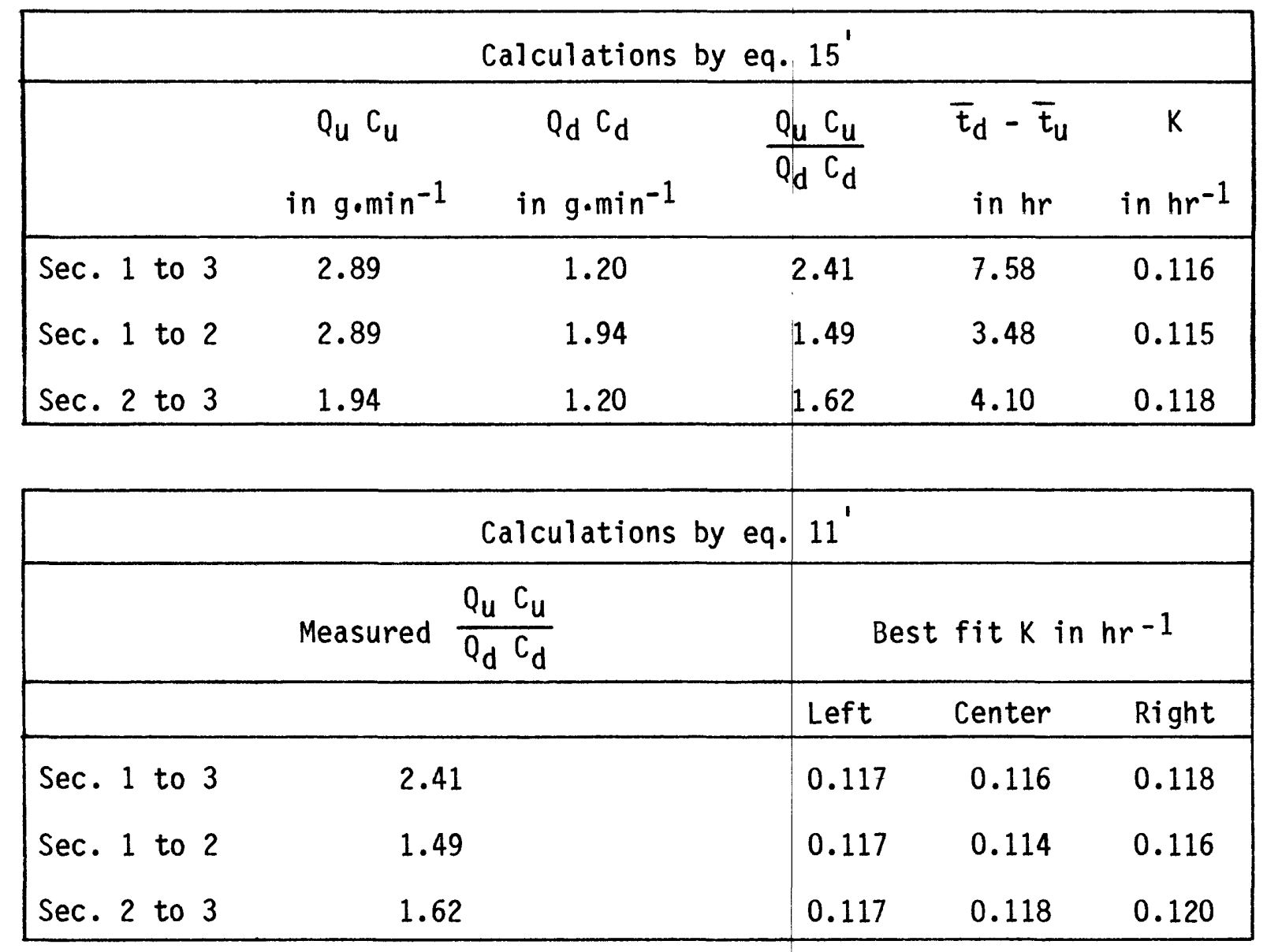

\begin{tabular}{|lccc|ccc|}
\hline \multicolumn{5}{|c|}{ Trial-and-error calculations by eg. $11^{\prime}$} & for Sec. 1 to 3 , Center \\
\hline $\begin{array}{l}\text { Assumed } \\
\text { K in } \mathrm{hr}^{-1}\end{array}$ & 0.106 & 0.113 & 0.119 & 0.122 & 0.125 & 0.128 \\
$\begin{array}{l}\text { Calculated } \\
Q_{u} C_{u} /\left(Q_{d} C_{d}\right)\end{array}$ & 2.234 & 2.355 & 2.464 & 2.520 & 2.578 & 2.636 \\
\hline
\end{tabular}


normalized response function was measured independently at three transverse sampling locations. Therefore, $\mathrm{K}$ evaluated along the lef $\mathrm{t}$, for example, represents the one along the stream line with 10 percent cumulative discharge.

An example of numerical solutions of eq. $111^{\prime}$ is shown at the bottom of table 7. From these trial-and-error solutions, the best fit $\mathrm{K}$ for the center location, section 1-3, corresponding to the observed $\mathrm{C}_{\mathrm{u}} \mathrm{Q}_{\mathrm{u}} / \mathrm{C}_{\mathrm{d}} \mathrm{Q}_{\mathrm{d}}=2.41$ was selected as $0.116 \mathrm{hr}^{-1}$. Other best fit $\mathrm{K}$ values were determined in a similar manner.

Note that the above calculations of $\mathrm{K}$ by eq. $15^{\prime}$ utilized the cross-sectional average values of $\bar{t}_{d}-\bar{t}_{u}$ while those by eq. $11^{\prime}$ were made by utilizing three sets of the $f(x, t(i))$ vs $t(i)$ data, which were measured at three transverse locations, each of which represented a different stream line longintudinally. The agreement of $\mathrm{K}$ values by eq. $15^{\prime}$ and $11^{\prime}$ is very satisfactory for all calculations and establishes that eqs. 11 and 15 are quite compatible with each other in a steady-flow natural stream. The representative desorption coefficient for the June 30 test is $0.116 \mathrm{hr}^{-1}$ taken from the calculation between section 1 and section 3 . The variation of $\mathrm{K}$ for short reaches such as section 1-2 and section $2-3$ is seen to be less than 1 percent of $\mathrm{K}$ for section $1-3$.

July 1, 1981, Test

Table 8 tabulates three moment-related quantities from dye data for the July 1 test and is comparable to table 6 for the June 30 test. The area of the dye cloud, a, in table 8 shows that the transverse variation in a cross-section is within 7 percent, indicating that both dye and gas tracer concentrations are uniformly mixed at all sections. The observed dye mass is $92.7,90.8$, and 88.5 grams at sections 1, 2, and 3, respectively. The dye mass decreases in the downstream direction and the loss between section 1 and section 3 is on the order of 5 percent. 
Table 8.--Moment-related properties of dye cloud, July 1, 1981

\begin{tabular}{|c|c|c|c|}
\hline \multicolumn{4}{|c|}{ Area of dye cloud, a, in $\mu g \cdot L^{-1} \cdot h r$. (eq. 18-1) } \\
\hline & Sec. 1 & Sec. 2 & Sec. 3 \\
\hline Left & 45.2 & 43.8 & 39.8 \\
\hline Center & 47.5 & 43.9 & 40.1 \\
\hline Right & 44.4 & 42.0 & 39.6 \\
\hline Average & 45.7 & 43.2 & 39.8 \\
\hline \multicolumn{4}{|c|}{ Mean time of dye cloud, $\bar{t}$, in $\mathrm{hr}$. (eq. 18-2) } \\
\hline & Sec. 1 & $\operatorname{Sec} \cdot 2$ & Sec. 3 \\
\hline Left & 0.98 & 4.50 & 8.68 \\
\hline Center & 0.85 & 4.42 & 8.63 \\
\hline Right & 0.94 & 4.46 & 8.59 \\
\hline
\end{tabular}

\begin{tabular}{|lccc|}
\hline & \multicolumn{4}{|c|}{ Travel time between cross sections, $\bar{t}_{d}-\bar{t}_{\mathrm{u}}$, in $\mathrm{hr}}$. \\
\hline Left & Sec. 1 to 3 & Sec. 1 to 2 & Sec. 2 to 3 \\
Center & 7.70 & 3.52 & 4.18 \\
Right & 7.78 & 3.57 & 4.21 \\
\hline Average & 7.66 & 3.53 & 4.13 \\
\hline
\end{tabular}

\begin{tabular}{|lccc|}
\hline & \multicolumn{2}{|c|}{ Variance of dye cloud, $\mathrm{s}^{2}(t)$, in $\mathrm{hr}^{2}{ }^{2}$ (eq. 18-3) } \\
\hline Left & Sec. 1 & Sec. 2 & Sec. 3 \\
Center & 0.0598 & 0.463 & 1.15 \\
Right & 0.0405 & 0.469 & 1.14 \\
& 0.0636 & 0.466 & 1.16 \\
\hline
\end{tabular}


As for the mean time, $\overline{\mathrm{t}}$, shown as the second item of table 8 , a similar difference as in table 6 is observed at section 1 among the center, left and right sampling locations. However, these differences become insignificant when the travel times between sections, $\overline{\mathrm{t}}_{\mathrm{d}^{-}} \overline{\mathrm{t}}_{\mathrm{u}}$, are calculated as shown in the third item. By comparing tables 6 and 8, the average travel time between sections is about 1.7 percent larger for the July 1 test than for the June 30 test. Because these travel times were determined from the 1st-order moment of 18 dye clouds, the reliability of measurement is statistically high. This level of accuracy in measuring a reach-averaged travel time can only be obtained by tracer tests. In comparison, a travel time, which was estimated from discharge measurement at three cross sections, was 6 to 7 percent smaller than those listed in tables 6 and 8 .

The variance, $s^{2}(t)$, of dye clouds shown at the bottom of table 8 shows a large variability in a cross section. Because the present study is only concerned with the order of magnitude of the longitudinal dispersion coefficient, $D$, the plot of variance, $s^{2}(t)$, against the mean time, $\bar{t}$, shown in figure 26 combines all data at three sampling locations and for the June 30 and July 1 tests. One may choose to draw two straight lines, namely the one between section 1 and 2 , and the other between section 2 and 3. The slope of the straight line is steeper for the latter line. Assuming the average velocity, $U$, of $0.17 \mathrm{~m} \mathrm{sec}^{-1}$ and considering $D=\left(U^{2} / 2\right)\left(d s^{2}(t) / d t\right), D$ is estimated to be $8.3 \mathrm{~m}^{2} \mathrm{sec}^{-1}$ between sections 2 and 3 , and $6.2 \mathrm{~m}^{2} \mathrm{sec}^{-1}$ between sections 1 and 2 for these tests.

The desorption coefficient, $\mathrm{K}$, for the July 1 test was calculated by means of eqs. $15^{\prime}$ and $11^{\prime}$ in a manner similar to the June 30 test. As mentioned previously, the gas data collected after 11:00 a.m. at section 1 were considered erroneous and were not included in the calculation. The results are tabulated in table 9. 


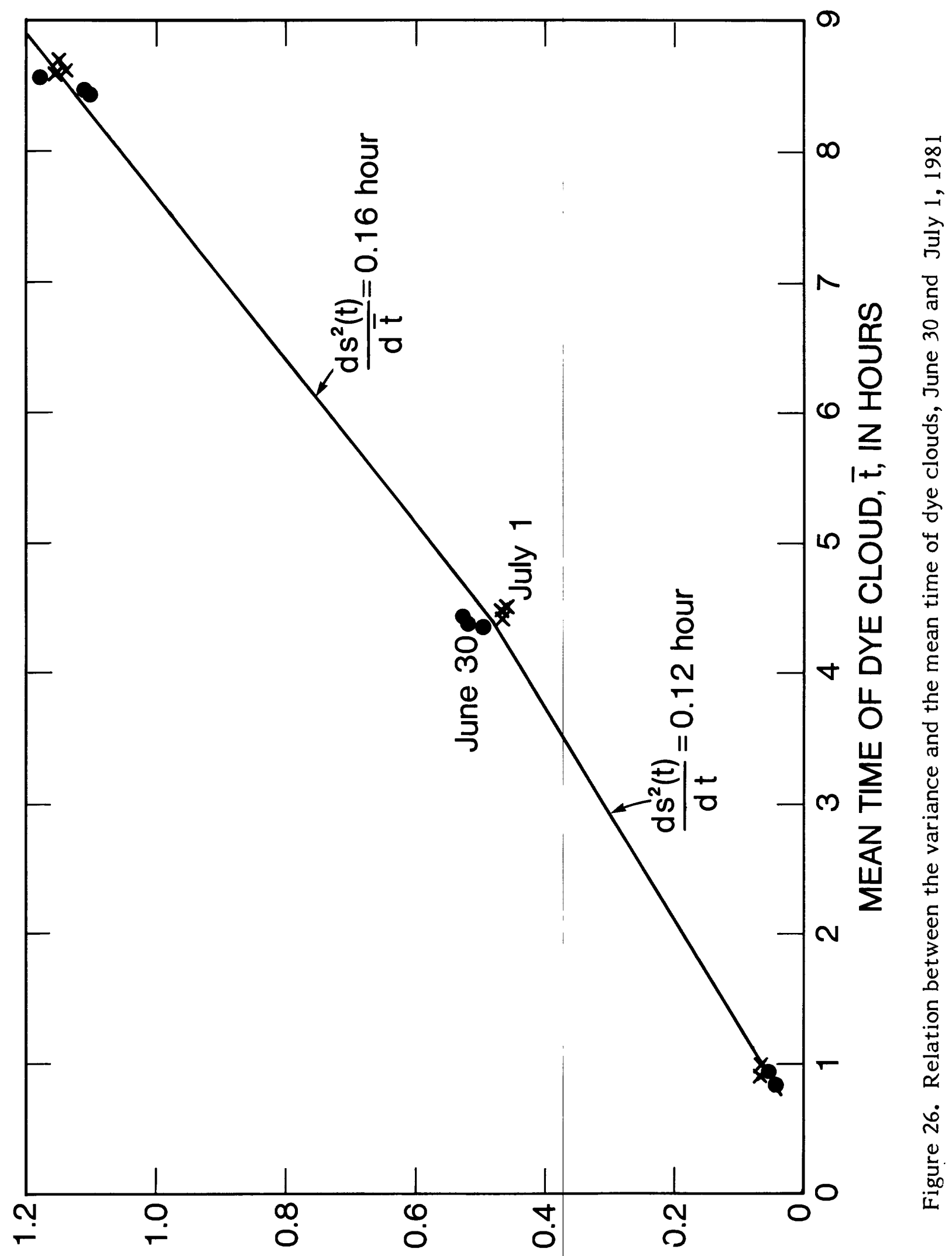

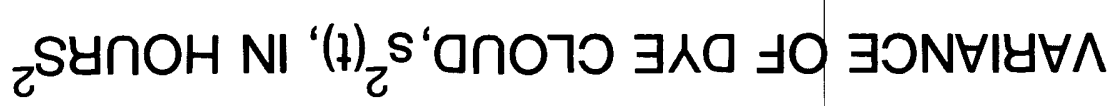


Table 9.--Desorption coefficient of propane, July 1, 1981

\begin{tabular}{|lcccccc|}
\hline \multicolumn{7}{|c|}{ Calculations by eq. 15' } \\
\hline & $Q_{u} C_{u}$ & $Q_{d} C_{d}$ & $\frac{Q_{u} C_{u}}{Q_{d} C_{d}}$ & $\bar{t}_{d}-\bar{t}_{u}$ & $k$ \\
in g.min & in $\mathrm{hr}$ & in $\mathrm{hr}^{-1}$ \\
\hline Sec. 1 to 3 & 2.72 & 1.07 & 2.54 & 7.71 & 0.121 \\
Sec. 1 to 2 & 2.72 & 1.78 & 1.53 & 3.54 & 0.120 \\
Sec. 2 to 3 & 1.78 & 1.07 & 1.66 & 4.17 & 0.122 \\
\hline
\end{tabular}

\begin{tabular}{|lllll|}
\hline \multicolumn{4}{|c|}{ Calculations by eq. $11^{\prime}$} \\
\hline & Measured $\frac{Q_{u} C_{u}}{Q_{d} C_{d}}$ & & Best fit $k$ in $\mathrm{hr}^{-1}$ \\
\hline & & Left & Center & Right \\
\hline Sec. 1 to 3 & 2.54 & 0.122 & 0.121 & 0.123 \\
Sec. 1 to 2 & 1.53 & 0.121 & 0.119 & 0.122 \\
Sec. 2 to 3 & 1.66 & 0.123 & 0.121 & 0.124 \\
\hline
\end{tabular}


These results in table 9 show that the agreement between the calculations by eqs. $15^{\prime}$ and $11^{\prime}$ is as excellent as in the June 30 test. Also, the variation of desorption coefficients for shorter reaches was insignificant relative to that for section $1-3$, just like the June 30 test. The representative $K$ value for the July test is $0.121 \mathrm{hr}^{-1}$ obtained for section $1-3$.

This value is about 4 percent higher than 0.116 hour $^{-1}$ obtained for the June 30 test. This small difference may possibly be due to the difference in wind speed. A reference to figure 10 shows that the average wind speed was on the order of $1 \mathrm{~m} \mathrm{sec}^{-1}$ on June 30 and $2 \mathrm{~m} \mathrm{sec}^{-1}$ on July 1 . Also a critical wind speed in the Cowaselon Creek was tentatively estimated to be $1 \mathrm{~m} \mathrm{sec}^{-1}$ before the test. Further anaylsis of this problem, however, requires much more detailed examination of data because the perce' it difference in desorption coefficients could be a purely random error.

Based on the data analyses presented in tables 6 through 9, one may conclude that the average desorption coefficient, $K$, for the June 30 and July 1 tests was $0.119 \mathrm{hr}^{-1}$ as calculated between section 1 and section 3 . Using $\mathrm{K}=0.119 \mathrm{hr}^{-1}$, $D=8 \mathrm{~m}^{2} \mathrm{sec}^{-1}$, and $U=0.17 \mathrm{~m} \mathrm{sec}^{-1}$, the value of $\alpha$ as defined in equation 14 is on the order of 0.04 . Therefore, the approximation of eq. 14 by eq. 15 is adequatey justified.

\section{October $20-21,1981$, Test}

Table 10 tabulates moment-related quantities from dye data obtained from two injections. The recovered dye mass was $0.20,0.19$, and $0.18 \mathrm{~kg}$ at section 1,2 , and 3, respectively, for October 20 , and $0.19,0.17$ and $0.18 \mathrm{~kg}$ at these cross sections for October 21 . For these calculations, $Q$ at the time of dye peak was read off from the $Q$ versus $t$ curves of figures 22,23 , and 24 . The loss of dye 
Table 10.--Moment-related properties of dye clouds, October 20-21, 1981

\begin{tabular}{|cccc|}
\hline & Area of dye cloud, a, in $\mu g \cdot L^{-1} \cdot h r .($ eq. 18-1) \\
\hline Date & Sec. 1 & Sec. 2 & Sec. 3 \\
\hline 0ctober 20 & 35.5 & 31.1 & 28.4 \\
October 21 & 37.9 & 32.9 & 31.6 \\
\hline
\end{tabular}

\begin{tabular}{|cccc|}
\hline \multicolumn{4}{|c|}{ Mean time of dye cloud, $\bar{t}$, in hr. (eq. 18-2) } \\
\hline Date & Sec. 1 & Sec. 2 & Sec. 3 \\
\hline October 20 & 0.613 & 2.28 & 4.40 \\
October 21 & 0.694 & 2.41 & 4.56 \\
\hline
\end{tabular}

\begin{tabular}{|cccc|}
\hline & Travel time between cross sections, $\bar{t}_{d}-\bar{t}_{u}$, in $\mathrm{hr}$. \\
\hline Date & Sec. 1 to 3 & Sec. 1 to 2 & Sec. 2 to 3 \\
\hline October 20 & 3.79 & 1.67 & 2.12 \\
October 21 & 3.87 & 1.72 & 2.15 \\
\hline Average & 3.83 & 1.69 & 2.14 \\
\hline
\end{tabular}

\begin{tabular}{|cccr|}
\hline & Variance of dye cloud, $\mathrm{s}^{2}(\mathrm{t})$, in $\mathrm{hr}^{2}$ (eq. 18-3) \\
\hline Date & Sec. 1 & Sec. 2 & Sec. 3 \\
\hline October 20 & 0.0456 & 0.242 & 0.767 \\
October 21 & 0.0534 & 0.126 & 0.200 \\
\hline
\end{tabular}


mass at section 3 relative to section 1 is on the order of 11 percent on October 20. This is a much larger dye loss in comparison with the summer tests, in which the maximum loss was less than 5 percent. On the ather hand, the loss between sections 1 and 3 on October 21 was only 6 percent. The cause of this discrepancy could not be explained.

The travel time between cross sections shown as the third item of table 10 shows that its difference between the October 20 and October 21 dye injections was only about 2 percent, despite the fact that the channel discharge shown in table 4 declined between 10 and 17 percent over the 24 -hour period. The average travel time was calculated as a simpla average of two travel times measured on two days.

There are large differences in varianc: $s^{2}(t)$, of dye cloud, in particular, at section 3 between the October 20 and October 21 measurements. One obvious reason for this was that the "long tail" of the dye cloud was monitored extensively on October 20 whereas it was truncated on October 21. Assuming that the long tail below 2 percent of the peak concentration monitored in the October 20 dye measurements is entirely due to storage and not to dispersion, the dispersion coefficient, D, was estimated using the October 21 data only. Noting that the slope, $\mathrm{ds}^{2}(\mathrm{t}) / \mathrm{dt}$, was $0.05 \mathrm{hr}$ and $U$ was $0.33 \mathrm{~m} \mathrm{sec}^{-1}$, D was found to be $9.8 \mathrm{~m}^{2}$ sec. $^{-1}$. This is about 20 percent larger than $\mathrm{D}$ calculated for the summer data. Again, the scope of this study is only concerned with the order of magnitude of $\mathrm{D}$, which affects the value of $\alpha$ in eq. 14. Thus no further analysis was considered necessary on this aspect.

The calculation of the desorption coefficient, $K$, by eq. $15^{\prime}$ requires that one select the observed values of $\mathrm{C}_{\mathrm{u}} \mathrm{Q}_{\mathrm{u}}$ and $\mathrm{C}_{\mathrm{d}} \mathrm{Q}_{\mathrm{d}}$, which are separated by the 
travel time, $\bar{t}_{d}-\bar{t}_{u}$. Because of the steadiness of QC values observed at section 3 , however, it was decided to calculate one representative value of $\mathrm{K}$ averaged over the period of 16.8 hours, which covers a substantial part of the test period. Considering that the average travel time is 1.69 hours for section $1-2$, and 3.82 hours for section 1-3, the average was calculated from observed QC values at section 1 between 12:00 a.m., October 20, and 4:50 a.m., October 21, at section 2 between 1:40 p.m., October 20, and 6:30 a.m., October 21, and at section 3 between 3:50 p.m., October 20 and 8:40 a.m., October 21. The number of QC values averaged was 30 for section 1,28 for section 2 , and 31 for section 3 . These QC values, as well as the calculated $\mathrm{K}$ values by eq. 15', are listed at the top of table 11 .

Two sets of trial-and-error solutions for $\mathrm{K}$ by eq. 11 ' were obtained from two independent dye clouds observed on October 20 and October 21 . Because the observed ratio, $\mathrm{C}_{\mathrm{u}} \mathrm{Q}_{\mathrm{u}} / \mathrm{C}_{\mathrm{d}} \mathrm{Q}_{\mathrm{d}}$ is common for the October 20 and October 21 calculations, two separate sets of the best fit $\mathrm{K}$ values demonstrate the sensitivity of $\mathrm{K}$ to different normalized response functions. Agreement between the solutions of eq. $15^{\prime}$ and $11^{\prime}$ is again excellent and one may conclude that, for a typical response function observed in a natural stream such as the Cowaselon Creek, eq.15' is a very satisfactory approximation of eq.11'. In the October test, $\alpha$ of eq. 14 is 0.009 , which again justifies the approximation of eq. 14 by eq. 15 .

A special remark is warranted for $K$ values marked with asterisks in table 11. These $\mathrm{K}$ values should be considered as fortuitous values. Suppose one had $Q_{d} C_{d}=2.35$ at section 2, which is only 5 percent larger than 2.24 listed in table 11. If this hypothetical value were used with $\mathrm{Q}_{u} C_{u}=2.60$ and $\bar{t}_{d}-\bar{t}_{u}=1.69$, $\mathrm{K}$ calculated by eq. $15^{\prime}$ for section $1-2$ would be 0.0598 instead of 0.0882 listed 
Table 11.--Desorption coefficient of propane averaged over 16.8-hr. period, October 20-21, 1981.

\begin{tabular}{|c|c|c|c|c|c|}
\hline \multicolumn{6}{|c|}{ Calculations by eq. $15^{\prime}$} \\
\hline & $\begin{array}{c}Q_{u} C_{u} \\
\text { in } g \text { min-1 }\end{array}$ & $\begin{array}{c}Q_{d} C_{d} \\
\text { in } g \text { min-1 }\end{array}$ & $\frac{Q_{u} C_{u}}{Q_{d} C_{d}}$ & $\begin{array}{l}\bar{t}_{d}-\bar{t}_{u} \\
\text { in } h r\end{array}$ & $\begin{array}{c}K \\
\text { in } h r^{-1}\end{array}$ \\
\hline Sec. 1 to 3 & 2.60 & 1.87 & 1.39 & 3.82 & 0.0863 \\
\hline Sec. 1 to 2 & 2.60 & 2.24 & 1.16 & $i .69$ & $0.0882^{\star}$ \\
\hline Sec. 2 to 3 & 2.24 & 1.87 & 1.20 & 2.13 & $0.0848^{*}$ \\
\hline \multicolumn{6}{|c|}{ Calculations by eq. 111 ' } \\
\hline Date & \multicolumn{3}{|c|}{ 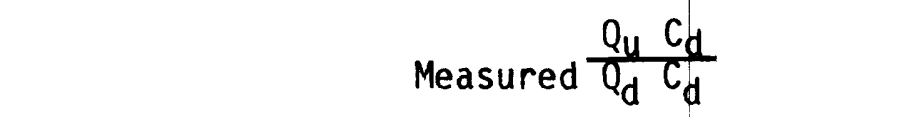 } & \multicolumn{2}{|c|}{ Best fit $K$ in $h r^{-1}$} \\
\hline \multirow{3}{*}{ 0ct. 20} & Sec. 1 to 3 & 1.39 & & \multicolumn{2}{|c|}{0.0877} \\
\hline & Sec. 1 to 2 & 1.16 & & \multicolumn{2}{|c|}{$0.0894 *$} \\
\hline & Sec. 2 to 3 & 1.20 & & \multicolumn{2}{|c|}{$0.0871 *$} \\
\hline & Sec. 1 to 3 & 1.39 & & \multicolumn{2}{|c|}{0.0854} \\
\hline oct. 21 & Sec. 1 to 2 & 1.16 & & \multicolumn{2}{|c|}{$0.0868 *$} \\
\hline & Sec. 2 to 3 & 1.20 & & \multicolumn{2}{|c|}{$0.0848^{\star}$} \\
\hline
\end{tabular}

Note:* See---p. 73 on $K$ values with asterik. 
in table 11. In other words, a small error of 5 percent in measurements would produce a large error of 32 percent in calculated $K$. The problem of error propagation from measurements to calculations is discussed in the next chapter. The calculations for sections 1-2 and 2-3 are shown in table 11 only for the comparison of eqs. 11' and 15 .

Even though the above calculated $\mathrm{K}$ of $0.0863 \mathrm{hr}^{-1}$ appeared to be the best average for the entire test period, additional analysis by means of moving averages was considered useful because of the availability of a large number of steadystate data. The major interest was to try to detect any influence of wind shear on desorption coefficients in view of the availability of continuous wind data shown in table 5. For this purpose, an interval of 2 hours was chosen for averaging so that a set of 3 to 4 QC values could be selected from the gas data, which were mostly collected at $1 / 2$-hour intervals. Defining the index time $t_{I}$ as located at the half way point of the 3.83-hour travel from section 1 to section 3, QC values at section 1 were chosen between $t_{I^{-}}-2.92$ and $t_{I}-0.92$ hours and $Q C$ values at section 3 were picked between $t_{I}+0.92$ and $t_{I}+2.92$ hours. The averages of these QC were then used together with the travel time of 3.83 hours in eq. 15 ' to calculate $K$, which was then referred to the average at $\mathrm{t}_{\mathrm{I}}$.

The wind speed data shown in table 5 were first averaged by giving equal weight to three values at POS. 1, 2, and 4 assuming that each anemometer covered the same subarea of the water surface. The cross-sectional average wind speeds thus calculated were then averaged over the time between $t_{I}-1.75$ and $t_{I}+1.75$ hours giving the wind speed averaged over 3.5 hours which was close to the travel time of 3.83 hours. This averaged wind speed was also referred to as the average at $\mathrm{t}_{\mathrm{I}^{\bullet}}$ 
Figure 27 illustrates the variation of desorption coefficient and wind speed with index time $t_{I}$ for the period between 6:30 p.m., October 20, and 6:30 a.m., October 21. This was the period during which gas data collection interval was uniform at 30 minutes. Note that the 3.5-hour-averaged wind speed displays a smooth diurnal variation, whereas the desorption coefficient shows abrupt changes. This is because wind speed was measured by anemometer cups that rotated continuously, whereas the gas sampling was done only at 30-minute intervals. Correla ion of the desorption coefficient with the wind speed could have been improved if the gas sampling were done with much smaller time intervals than 30 minutes. Despite this shortcoming of the data, it is difficult to detect an overall trend for the phase correspondence between high wind speeds and high desorption coefficients and vice versa in figure 27. For a channel such as the Cowaselon Creek with a high bed slope on the order of 0.001 and the attendant high bottom shear, the effect of wind shear on gas desorption coefficients may not be detected at wind speeds of less than $2 \mathrm{~m} \mathrm{sec}^{-1}$ by a simple correlation as described above. The randomness in a small number of available gas data appears to overwhelm the steady but weak effect of wind shear.

\section{DISCUSSION}

As mentioned in the beginning of this report, the present assessment of the hydrocarbon gas tracer method was conducted to examine the accuracy and reproducibility of field data and the soundness of field procedure for a steady natural channel flow. The following discussion will consider the assessment of field procedures separately from that of reproducibility and accuracy of desorption coefficients. Also, because the steady-state technique was employed as the most 


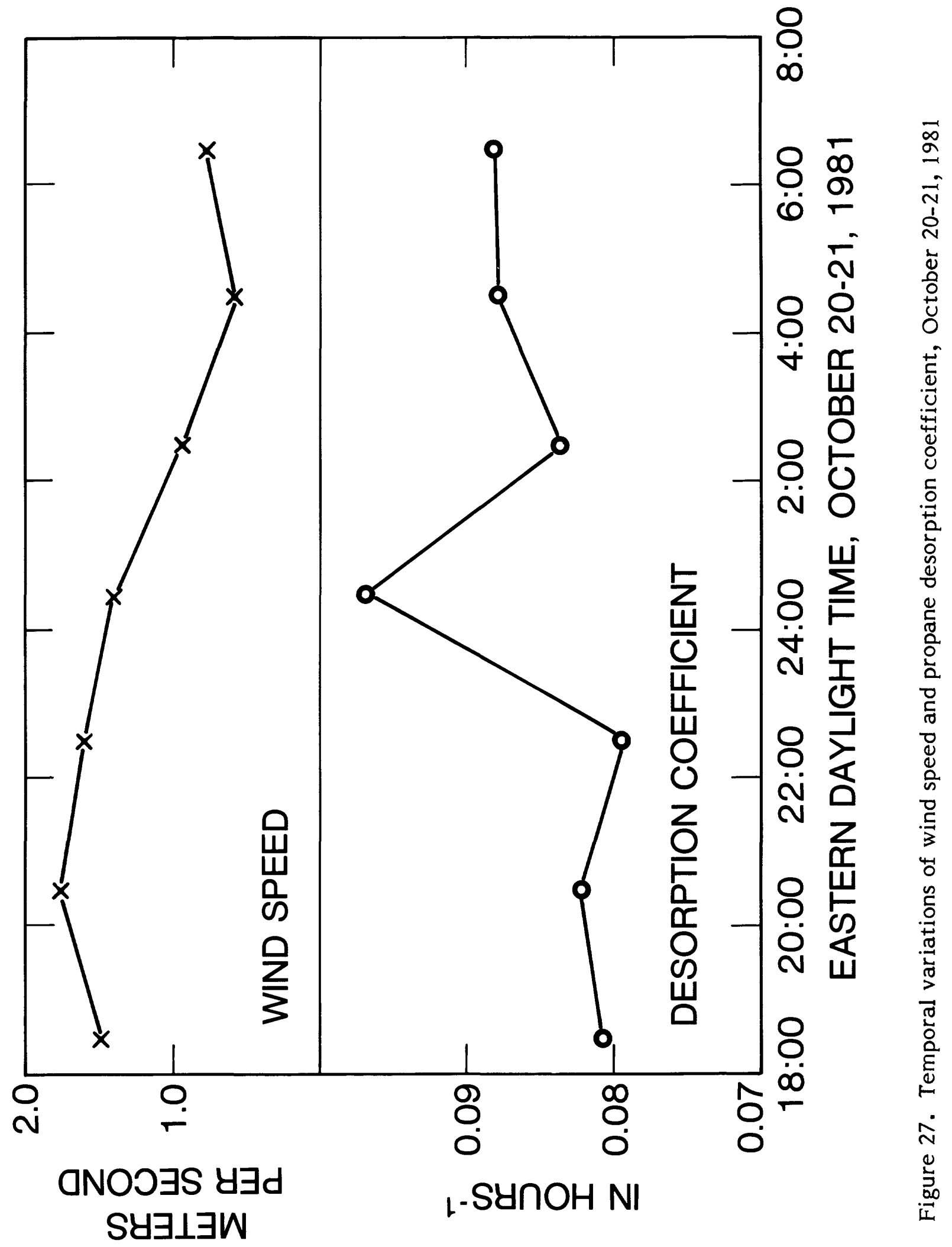


reliable means of assessment, most of the discussion and summary pertain to this specific technique and not to the currently practiced methods of Tsivoglou and Rathbun, which employ a short-duration tracer injection and data collection from a transient tracer plume. A comparison of transient and steady-state techniques will be presented in a future report.

\section{Field Procedures}

An important lesson learned from the Cowaselon Creek tests is that the field gas sampling should be done with use of the dissolved gas sampler and with strict conformity to procedures specified by R. E. Rathbun (1979, U.S. Geological Survey, writtem commun.) When a water sample with dissolved gas is collected by means of grab sampling, the sealing of a vial must necessarily be done in air and it is sometimes difficult to slide a Teflon coated septum across the top of the sample water without entrapping an air bubble. During a few minutes spent in a repeated effort to remove air, considerable desorption of dissolved gas may take place from the surface of the sample water. This appears to have been the difficulty encountered by the sampling crew who took over the gas sampling after 11:00 a.m., July 1. Such a difficulty is eliminated by use of the sampler because the vial and its content are totally immersed in a large volume of water collected in the sampler and the sealing can be done without exposing the top of the vial to air.

It appears that commercial fuel-grade propane can produce as good results as the highly purified instrument-grade propane (R. E. Rathbun, 1979, U.S. Geological Survey written commun.). This can be seen by comparing gas data of the June and July tests. Freezing of the gas tank and resulting interruption of steady gas inflow was not experienced in any tests, even though the air temperature in the October tests was as low as $9^{\circ} \mathrm{C}$. The propane injection rates were approximately 
$15 \mathrm{gram} \mathrm{min}^{-1}$ for the June-July tests and $21 \mathrm{gram} \mathrm{min}^{-1}$ for the October test. According to previous experiences, the freezing apparently took place at a much higher injection rate. In this connection, it would be highly desirable to have a means of weighing the propane tank from time to time to check the mass inflow rate. At the least, the propane tank must be weighed before and after a test (R. E. Rathbun, U.S. Geological Survey 1979, written commun.). This aspect will be important in the steady-state method because of the requirement of a long period injection compared to the short-duration injection method.

The absorption efficiency or the capacity of diffuser in dissolving gas into water observed in the present tests deserves a brief comment. Note that the steady-state mass flow rate of propane at section 1, June 30 , was 2.89 gram $\mathrm{min}^{-1}$ from table 7 . The fractional loss due to desorption between the injection site and section 1 may be estimated from $L=1-\exp (-K t)$, with $K=0.116 \mathrm{hr}^{-1}$ and $t=0.9 \mathrm{hr}$, and is found to be about 10 percent. Therefore, the mass flow rate of dissolved propane immeditely downstream of the injection site but after the initial bubbling loss must have been $3.21 \mathrm{gram} \mathrm{min}^{-1}$. Comparing this with the gas inflow rate of $15 \mathrm{gram} \mathrm{min}^{-1}$ at the tank, the absorption efficiency of the diffuser is seen to be 21 percent, a value much higher than those quoted by Rathbun (1979). It should also be noted that the estimation of gas injection rate for the steady-state method employs the reverse procedure of the above calculation. Thus the calculation will be somewhat simpler than that of the transient method (R. E. Rathbun, 1979, U.S. Geological Survey, written commun.).

As for dye data collection, the explanation in the previous chapter theoretically clarified that the problem of dye loss does not affect the calculation of the information needed by the steady-state method. Nevertheless, the collection of dye loss data as well as the investigation of causes for the loss will become important as the tracer method is increasingly used for a simulation of nonconservative solutes. 
The present tests are not very conclusive about the dye loss. Although the June and July tests show about 5 percent dye loss between sections 1 and 3 for the residence time of 7.5 hours, one of the October dye injections indicated 11 percent loss for the same reach for the residence time of less than 4 hours. It appears that the observed loss is a combination of measurement errors and some physical decay, the cause of which is not well understood at the present time. Remembering that the transverse variation of dye cloud area, a, was as high as 5 to 7 percent at some sections in the summer tests, the reliability of the mass recovery calculation for the October test with only one transverse sampling does not appear to be very high. In a comparable stream test of rhodamine WT, Smart and Laidlaw (1977) reported no loss for the residence time of 3.5 hours and 2 percent loss for 7.4 hours, despite the fact that the stream contained a large growth of weeds. The best current judgement appears to be that the fractional dye loss for the residence time of a few hours is on the order of 5 percent or less.

According to empirical studies done in the present tests, there appears to be no need to collect dye data for the "long tail" beyond the concentration which declined to the level of 2 percent of the peak concentration. The area of the dye cloud and the mean time are hardly affected and also the beginning of the steady-state period can be estimated accurately by this practice. It is always helpful to bring semilogarithmic graph papers to the field so that in-situ readings of dye data can be plotted for assisting decisions on the extent of data collection.

As regards the wind velocity measurements, it appears that the procedure used was quite satisfactory for the conditions encountered at the Cowaselon Creek. The June-July tests showed that it is probably not necessary to measure the wind velocity at more than one station, provided the surrounding terrain is sufficiently uniform. Especially when the banks may cause a complex flow pattern 
over the water surface, it is probably desirable to increase the measuring resolution at one station. Preliminary analysis of the data shows that air and water temperature measurements are highly desirable in order to permit the calculation of the atmospheric stability over the water surface. Actually, in future studies it will be worthwhile considering the measurement of the specific humidity as well in order to allow inclusion of the bouyancy effect due to water vapor stratification.

\section{Desorption Coefficient}

As for the reproducibility of gas desorption data under the same environmental conditions, the results from the June 30 and July 1 tests appear to be excellent. The calculated desorption coefficient for two tests agreed with a 4 percent difference. This is somewhat smaller than the coefficient of variation of propane desorption coefficient expected in mixing tank tests conducted under a controlled laboratory condition. According to the experiments completed at the University of Texas as part of the assessment of the gas tracer method (Rainwater and Holley, 1983), the coefficient of variation for propane desorption coefficient was found to vary from 5 to 13 percent. Some of this variation may have been due to slight changes in mixing speed and water temperature in the mixing-tank tests. In view of such a variability and considering that the summer tests consisted of only two replicate tests, the numerical agreement in calculated coefficients between the June 30 and July 1 tests may be fortuitous. However, when the detailed reproducibility of dye and gas data is taken into consideration, the agreement betwen the June 30 test and the July 1 test is considered to be excellent.

Concerning the accuracy of the desorption coefficient calculated from field data, there is no accepted method for evaluation. However, the following analysis may be helpful in evaluating the effect of measurement errors on calculation errors. For this purpose, eq. 15' will be rearranged as 


$$
K=\frac{1}{\left(\bar{t}_{d}-\bar{t}_{u}\right)} \ln \left\{\frac{\bar{C}_{u} \bar{Q}_{u}}{\bar{C}_{d} \bar{Q}_{d}}\right\}
$$

Eq. 19 indicates that a single value of $\mathrm{K}$ is calculated using the mean values of measured variables on the right-hand side, the upper bar indicating the sample mean.

Assuming that the travel time, $\overline{\mathrm{t}}_{\mathrm{d}}-\mathrm{\tau}_{\mathrm{u}}$, is measured without error and that the measurement errors of $\overline{\mathrm{C}}_{11}, \overline{\mathrm{Q}}_{\mathrm{u}}, \overline{\mathrm{C}}_{\mathrm{d}}$, and $\overline{\mathrm{Q}}_{\mathrm{d}}$, are small, random, and independent of each other, an approximate relation can be derived following standard techniques for the propagation errors (Ang and Tang, 1975),

$$
\frac{\sigma(K)}{K}=\frac{1}{K\left(\bar{t}_{d}-\bar{t}_{u}\right)} \sqrt{\frac{\sigma^{2}\left(\bar{C}_{u}\right)}{\left(\bar{C}_{u}\right)^{2}}+\frac{\sigma^{2}\left(\bar{Q}_{u}\right)}{\left(\bar{Q}_{u}\right)^{2}}+\frac{\sigma^{2}\left(\bar{C}_{d}\right)}{\left(\bar{C}_{d}\right)^{2}}+\frac{\sigma^{2}\left(\bar{Q}_{d}\right)}{\left(\bar{Q}_{d}\right)^{2}}}
$$

in which the notation $\sigma^{2}$ denotes the population variance of the quantity indicated. The square root term on the right-hand side of eq. 20 represents the composite relative error of measurements of gas concentration and discharge.

For all practical purposes, one may assume that the first and third items in the composite error term are the same and so are the second and fourth items. Noting furthermore that $\sigma^{2}(\bar{\phi})=\sigma^{2}(\phi) / \mathrm{n}_{\phi}$, where $\mathrm{n}_{\phi}$ is the number of measurements of a variable $\phi$ to calculate $\bar{\phi}$, eq. 20 can be simplified (Holley, 1977),

$$
\frac{\sigma(K)}{K}=\frac{1}{k\left(\bar{t}_{d}-\bar{t}_{u}\right)} \sqrt{\frac{2 \sigma^{2}(\mathrm{C})}{\mathrm{n}_{C}(\overline{\mathrm{C}})^{2}}+\frac{2 \sigma^{2}(Q)}{\mathrm{n}_{Q}(\bar{Q})^{2}}}
$$

where $n_{C}$ is the number of gas concentration measurements and $n_{Q}$ is the number of discharge measurements. 
In utilizing eq. 21 in an estimate of error in the present study, the relative error of gas concentration measurement, $\sigma(\mathrm{C}) / \overline{\mathrm{C}}$, will be assumed to be 3 percent and that of discharge measurement, $\sigma(\mathrm{Q}) / \bar{Q}$, to be 5 percent. For the June and July tests, in which ${ }{ }_{C}$ was 6 and $n_{Q}$ was one, the composite error is seen to be 7.3 percent. Thus, the relative error $\sigma(\mathrm{K}) / \overline{\mathrm{K}}$, for sections $1-3,1-2,2-3$ are 8,18 , and 15 percent, respectively, using $\mathrm{K}=0.119 \mathrm{hr}^{-1}$ and $\overline{\mathrm{t}}$ 's tabulated in table 6 .

As for the October test, for which $\mathrm{n}_{C}$ was 30 and $\mathrm{n}_{\mathrm{Q}}$ was 2, the composite error of measurements is 5.1 percent. Thus the relative error, $\sigma(\mathrm{K}) / \overline{\mathrm{K}}$, for sections $1-3,1-2,2-3$ are 15,35 , and 29 percent, respectively, using $\mathrm{K}=0.0863 \mathrm{hr}^{-1}$ and t's tabulated in table 10. The above calculations by eq. 21 explain why the probable error of calculated $\mathrm{K}$ for sections $1-2$ and 2-3 of the October test could be high as demonstrated numerically in the previous chapter in connection with table 11. The important fact established by eq. 21 is that the transfer of error from measurement to calculation is singularly controlled by the nondimensional number, $K\left(\bar{t}_{d}-\bar{t}_{u}\right)$, regardless of the method of estimating measurement errors. Apparently, this simple relation has never been clarified in the literature, even though the empirical knowledge existed for some time that the reach length or residence time must be large enough to make the ratio, $\overline{\mathrm{Q}}_{\mathbf{u}} \overline{\mathrm{C}}_{\mathbf{u}} / \overline{\mathrm{Q}}_{\mathbf{d}} \overline{\mathrm{C}}_{\mathbf{d}}$, larger than 2.72, which correspond to the above nondimensional number of unity (Rathbun, 1979). Any exponential decay model contains this intrinsic difficulty in obtaining an accurate estimation of decay coefficient from short reach measurements, whether the problem of concern is reaeration, gas desorption, surface heat exchange, or biochemical decay. Another aspect of eq. 21 is that the composite error of measurements is predominantly influenced by the error of discharge measurement. Under normal field test conditions, it is relatively easy to increase the number of concentration measurement, ${ } \mathrm{C}$, while it is not very common to have the number of discharge measurement, $\mathrm{n}_{\mathrm{Q}}$, beyond two or three. 
The desorption coefficients calculated from the three tests are defined at water temperature, $\mathrm{T}$, of the creek at the time of field tests. In order to convert these coefficients, $\mathrm{K}(\mathrm{T})$, to those at the standard temperature of $20^{\circ} \mathrm{C}, \mathrm{K}(20)$, the well-known formula for temperature correction for the reaeration coefficient (Elmore and West, 1961) may be used for the desorption coefficient of propane (Rathbun and others, 1978).

$$
K(20)=K(T) \cdot 1.0241^{20-T}
$$

The average water temperature observed in the test reach sections $1-3$ for the June test was $25^{\circ} \mathrm{C}$ and $24.5^{\circ} \mathrm{C}$ for the July test. The temperature varied from 6.5 to $10^{\circ} \mathrm{C}$ with an average of $8.5^{\circ} \mathrm{C}$ for the October test. Using the average temperatures as $T$ in eq. 22 , the average $K(20)$ was found to be $0.103 \mathrm{hr}^{-1}$ and $0.109 \mathrm{hrs}^{-1}$ for the June and July tests, respectively, with an average of $0.106 \mathrm{hr}^{-1}$. The $\mathrm{K}(20)$ for the October test was $0.114 \mathrm{hr}^{-1}$. This high $\mathrm{K}(20)$ value for the October test relative to the June-July Tests indicates that either biodegradation of propane was nonexistent or the higher desorption due to higher discharge in the October test overwhelmed any effect of biodegradation. The expectation of detecting biodegradation from the difference of water temperature alone was not fulfilled by the October test.

In order to compare the difference of gas desorption rates between the June-July and October tests, it is essential to convert the desorption coefficient, $K(20)$, to the surface film coefficient, $K_{L}(20)$, defined by eq. 2 . For the JuneJuly tests, $K_{L}(20)$ is $0.0371 \mathrm{~m} \mathrm{hr}^{-1}$ assuming $\mathrm{H}=0.35 \mathrm{~m}$, while for the October test, $\mathrm{K}_{\mathrm{L}}(20)$ is $0.0570 \mathrm{~m} \mathrm{hr}^{-1}$ with $\mathrm{H}=0.50 \mathrm{~m}$. Thus the surface film coefficient 
for the October test is about 50 percent larger than the June-July tests and appears to reflect the effect of a larger channel discharge in the October test. Further analysis on the relation of the surface film coefficient to bulk hydraulic parameters will not be pursued here. Two coefficients under two discharge conditions are not enough for any meaningful correlation work. Also, the depth given above is an arithmetic average of the depth measured at three cross sections and may not be indicative of the true reach averaged depth, which could be defined from the discharge, the mean travel time, and the total surface area of the reach pertaining to the live stream. Similarly, no analysis on the relation of surface film coefficient to wind speed and concomitant wind shear stress will be pursued here, because averaged wind was not variable enough to allow for a simple empirical correlation. The above aspects are currently under investigation and will be reported in separate reports.

\section{SUMMARY}

As a field method of measuring the desorption coefficient of dissolved propane gas, the steady-state method is a reliable and feasible technique. The reproducibility of desorption data and coefficients is very satisfactory. No systematic transverse variations in steady-state gas concentration were detected in a uniformly-mixed plume and the random variation of steady-state gas concentration was observed to be within \pm 5 percent of the mean value. It is highly desirable in gas sample collection to use the dissolved gas samplers and to strictly follow Rathbun's guidelines for field-site processing of gas samples. It is also desirable to locate the first measurement site far beyond the uniform mixing distance in order to obtain smoothed steady-state gas data; however, this may be in conflict with the desirable downstream 
reach length needed for obtaining $Q_{u} C_{u} / Q_{d} C_{d}$ larger than 2.7 for an accurate estimation of $\mathrm{K}$. As for the monitoring of dye clouds, it is recommended that the tail be measured until the concentration becomes 2 percent of the peak dye concentration. The steady-state method used in this report is independent of dye loss in the study reach and no significant information was obtained on the loss of dye beyond what has been known in the literature.

Concerning the accuracy in determination of $\mathrm{K}$, the calculations by eqs. $11^{\prime}$ and $15^{\prime}$ are in excellent agreement so that eq. 15' can be used for a steady natural stream with confidence for the steady-state method. It is difficult to establish the absolute level of accura $y y$ of calculated $\mathrm{K}$ values from field data. However, it was established that the $I$ ondimensional number, $K\left(\bar{t}_{d}-\bar{t}_{u}\right)$, is the single parameter to control the propag ation of error from concentration measurements to calculation of desorption coefficien s. In principle, therefore, the planning of a tracer study should be done so that an estimated nondimensional number is equal or larger than unity for the test reach. Division of the reach into several subreaches as was done in the present tests may be useful in obtaining an additional check on desorption data but a calculation based on subreach data may not be rellable If the nondimensional number for the subreach is much smaller than unity. 


\section{REFERENCES}

Ang, A. H-S., and Tang, W. H., 1975, Probability concepts in engineering planning and design: John Wiley and Sons, Inc., New York, 409 p.

Bencala, K. E., and Walters, R. A., 1983, Simulation of solute transport in a mountain pool-and-riffle stream: a transient storage model: Am. Geophys. Union, Water Resources Research, v. 19, no. 3, p. 718-724.

Elmore, H. L., and West, W. F., 1961, Effect of water temperature on stream reaeration: Am. Soc. Civil Engineers, Jour. of Sanitary Eng. Div., v. 87, no. SA6, p. 59-71.

Fischer, H. B., 1973, Longitudinal dispersion and turbulent mixing in open-channel flow: Annual Review of Fluid Mechanics, volume 5, Annual Review Inc., Palo Alto, Calif., p. 59-78.

Fischer, H. B., List, E. J., Koh, R. C. Y., Imberger, J., and Brooks, N. H., 1979, Mixing in inland and coastal waters: Academic Press., New York, 483 p.

Holley, E. R., 1973, Diffusion and boundary layer concepts in aeration through liquid surfaces: Water Research, volume 7, Pergamon Press, London, P. 559-573.

Holley, E. R., 1977, Dilution method of discharge measurement in pipes: Proceedings of the symposium on flow in open channels and closed conduits, National Bureau of Standards, Special Publication 484, p. 395-421.

O'Connor, D. J., and Lawler, J. P., 1965, Mathematical analysis of estuarine pollution: 55th National Meeting, Am. Inst. Chemical Engineers, Reprint no. 3la, Houston Texas.

Rainwater, K. A., and Holley, E. R., 1983, Laboratory studies on the hydrocarbon gas tracer technique for reaeration measurement: Center for Research in Water Resources, Report 189, University of Texas, Austin, Texas, 143 p.

Rathbun, R. E., Stephens, D. W., Shultz, D. J., and Tai, D. Y., 1978, Laboratory studies of gas tracers for reaeration: Am. Soc. Civil Engineers, Jour. of Environmental Eng. Div., v. 104, no. EE2, p. 215-229.

Rathbun, R. E., 1979, Estimating the gas and dye quantities for modified tracer technique measurement of stream reaeration coefficients: U. S. Geol. Survey Water Resources Investigations 79-27, 42 p.

Sayre, W. W., 1968, Dispersion of mass in open-channel flow: Hydraulics Paper No. 3, Colorado State University, Fort Collins, Colo., 73 p.

Smart, P. L., and Laidlaw, I. M. S., 1977, An evaluation of some fluorescent dyes for water tracing: Am. Geophys. Union, Water Resources Research, v. 13, no. 1, p. 15-33.

Taylor, G. I., 1959, The present position in the theory of turbulent diffusion: Advances in Geophysics, volume 6, Academic Press, New York, P. 101-112. 
Tsivoglou, E. C., O'Connell, R. L., Walter, C. M., Gadsil, P. J., and Logsdon, G. S., 1965, Tracer measurement of atmospheric reaeration - I. Laboratory studies: Jour. of Water Pollution Control Fed., v. 37, no. 10, p. 1343-1362.

U. S. Nuclear Regulatory Commission, 1977, Estimating aquatic dispersion of effluents from accidental routine reactor releases for the purpose of implementing Appendix 1: Regulatory Guide 1.113, Wash., D. C., 55 p.

Wylie, C. R., Jr., 1951, Advanced engineering mathematics: McGraw-Hill Book Co., Inc., New York, 640 p.

Yotsukura, N., and Cobb, E. D., 1972, Transverse diffusion of solute in natural streams: U. S. Geol. Survey Prof. Paper 582-C, 19 p.

Yotsukura, N., and Kilpatrick, F. A., 1973, Tracer simulation of soluble waste concentration: Am. Soc. Civil Engines, Jour. Environmental Eng. Div., v. 99, no. EE4, p. 499-515.

Yotsukura, N., and Sayre, W. W., 197 ;, Transverse mixing in natural channels: Am. Geophys. Union, Water Re. sources Research, v. 12, no. 4, p. 695-704.

88 